University of Louisville

ThinkIR: The University of Louisville's Institutional Repository

Electronic Theses and Dissertations

$12-2015$

\title{
The Ras effector NORE1A forms a tumor suppressor complex with BRCA1.
}

Nicholas C Nelson

University of Louisville

Follow this and additional works at: https://ir.library.louisville.edu/etd

Part of the Cancer Biology Commons

\section{Recommended Citation}

Nelson, Nicholas C, "The Ras effector NORE1A forms a tumor suppressor complex with BRCA1." (2015). Electronic Theses and Dissertations. Paper 2336.

https://doi.org/10.18297/etd/2336

This Doctoral Dissertation is brought to you for free and open access by ThinkIR: The University of Louisville's Institutional Repository. It has been accepted for inclusion in Electronic Theses and Dissertations by an authorized administrator of ThinkIR: The University of Louisville's Institutional Repository. This title appears here courtesy of the author, who has retained all other copyrights. For more information, please contact thinkir@louisville.edu. 
THE RAS EFFECTOR NORE1A FORMS A TUMOR SUPPRESSOR COMPLEX WITH BRCA1

By

Nicholas C. Nelson

B.S., Auburn University, 2010

M.S., University of Louisville, 2013

\begin{abstract}
A Dissertation
Submitted to the faculty of the

University of Louisville School of Medicine

In partial fulfillments of the requirements

For the degree of
\end{abstract}

\author{
Doctor of Philosophy \\ In \\ Biochemistry and Molecular Biology \\ Department of Biochemistry and Molecular Genetics \\ University of Louisville, School of Medicine \\ Louisville, KY
}

December 2015 
Copyright 2015 by Nicholas Carlton Nelson

All rights reserved 

THE RAS EFFECTOR NORE1A FORMS A TUMOR SUPPRESSOR COMPLEX WITH BRCA1

\section{By}

Nicholas C. Nelson

B.S., Auburn University, 2010

M.S., University of Louisville, 2013

A Dissertation Approved on

October 16, 2015

by the following Dissertation Committee

Dr. Geoffrey J. Clark (Mentor)

Dr. David Powell

Dr. Russell Prough

Dr. David Samuelson

Dr. Theodore Kalbfleisch 


\section{DEDICATION}

This dissertation is dedicated to my wife and my parents for their constant

encouragement, support, and motivation over the course of my life and my graduate studies. 


\section{ACKNOWLEDGEMENTS}

I am sincerely grateful to my mentor, Dr. Geoffrey Clark, for his encouragement, support, and patience that led to the successful completion of my $\mathrm{Ph} . \mathrm{D}$. His guidance and generosity were invaluable for my doctoral work. I would also like to thank the other committee members, Dr. David Samuelson, Dr. David Powell, Dr. Theodore Kalbfleisch, and Dr. Russell Prough for their comments and support concerning my project. Finally, I would like to thank the members of the Clark laboratory for their assistance and camaraderie over the years. 


\section{ABSTRACT \\ THE RAS EFFECTOR NORE1A FORMS A TUMOR SUPPRESSOR COMPLEX WITH BRCA1 \\ Nicholas C. Nelson}

October 9th, 2015

Ras proteins function as molecular signaling switches that can stimulate multiple mitogenic pathways in response to extracellular signaling. Oncogenic activation of Ras by structural mutation is a highly transforming event in $\sim 1 / 3$ of human cancers. However, aberrant Ras activation can also promote oncogene-induced senescence. This Rasinduced irreversible growth arrest is a physiological process that acts as a barrier to malignancy. The mechanisms by which Ras drives senescence and how this process is bypassed during Ras-driven transformation remains poorly understood.

Although mutations in the RAS gene are extremely rare in human breast cancer, the Ras signaling pathway is constitutively activated in roughly half of all primary breast tumors. This is largely due to aberrant activation of upstream regulators of Ras, like the EGFR family member Her2 and inactivation of negative Ras regulators, such as NF1.

NORE1A (RASSF5) is a direct Ras effector that acts as a tumor suppressor by promoting apoptosis and senescence. Expression of NORE1A is frequently lost in primary breast tumors and breast cancer cell lines, though its mechanism of action in breast cancer pathogenesis remains unclear. 
BRCA1 is a tumor suppressor that plays a key role in DNA DSB repair. Loss of BRCA1 is associated with hereditary breast and ovarian cancer, and is also thought to play a role in sporadic breast cancer. Recently, BRCA1 was shown to play a role in both Her2 and Ras senescence, but the mechanism underlying the communication between Her2/Ras and BRCA1 was not identified.

I have discovered that NORE1A forms an endogenous, Her2/Ras-regulated complex with BRCA1. I show that dual suppression of NORE1A and BRCA1 has a synergistic effect on transformation. Furthermore, I show that NORE1A loss suppresses the BRCA1-mediated senescence effect. Finally, I show that NORE1A and BRCA1 synergize to modulate DNA repair. Thus, I identify a novel tumor suppressor complex that connects Her2/Ras senescence signaling to BRCA1 in breast cancer. 


\section{TABLE OF CONTENTS}

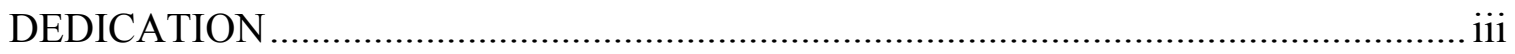

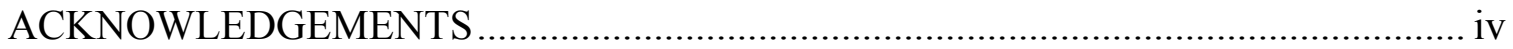

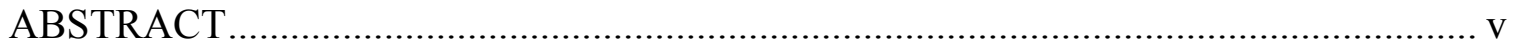

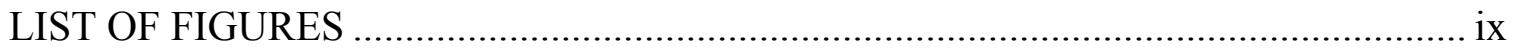

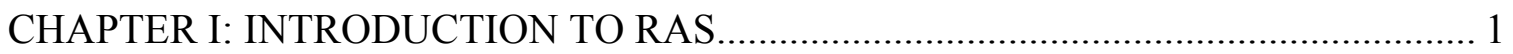

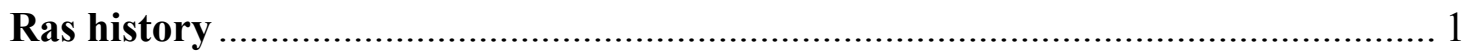

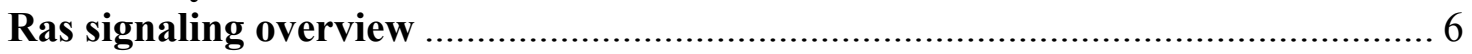

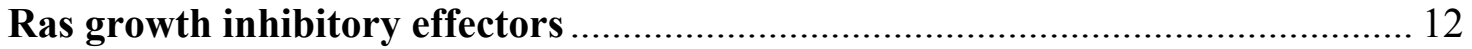

CHAPTER II: RAS SIGNALING IN BREAST CANCER …………........................... 13

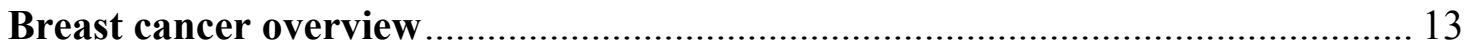

Ras activation in breast cancer ....................................................................... 13

Her2/Ras activation promotes incomplete senescence in immortalized cells ........ 15

NORE1A and BRCA1 link activated Ras signaling to breast cancer ................... 16

CHAPTER III: THE NORE1A TUMOR SUPPRESSOR ............................................ 17

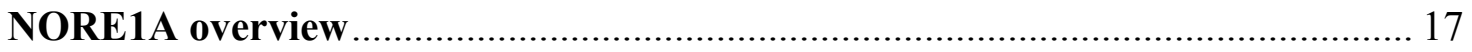

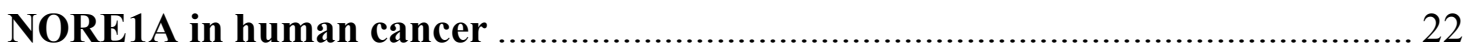

CHAPTER IV: THE BRCA1 TUMOR SUPPRESSOR ……………………….......... 23

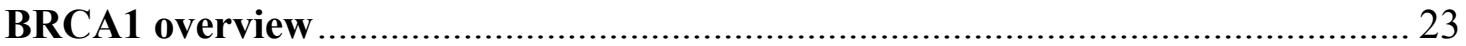

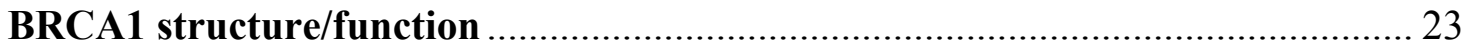

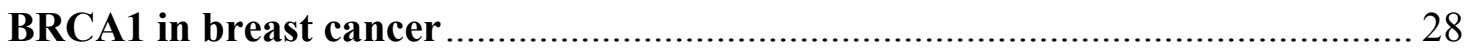

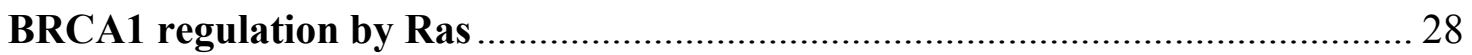

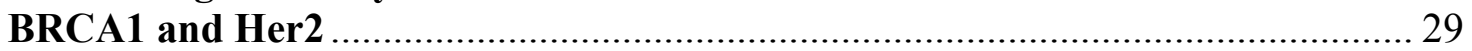

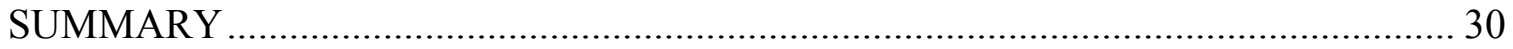

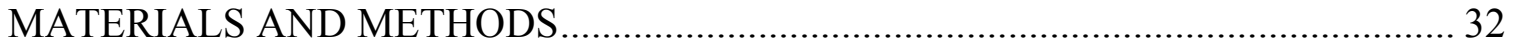

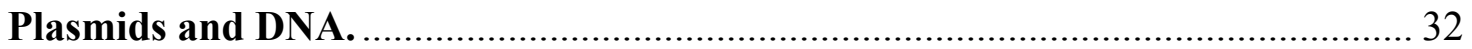

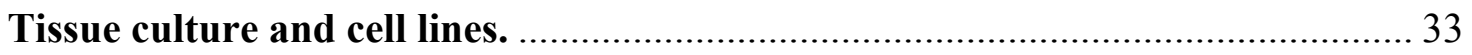

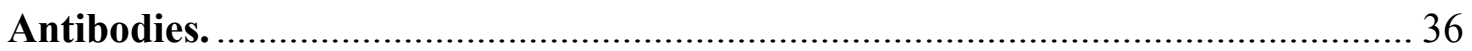

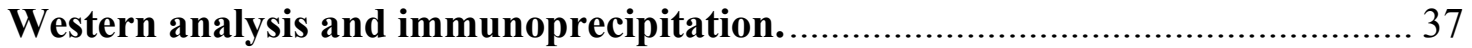

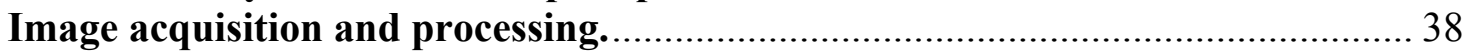

CHAPTER V: NORE1A AND BRCA1 FORM A HER2-REGULATED

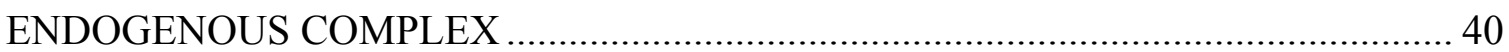

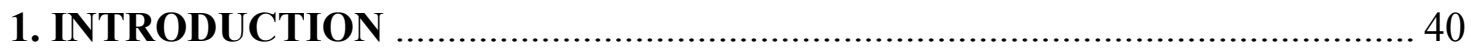

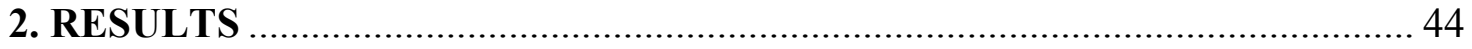

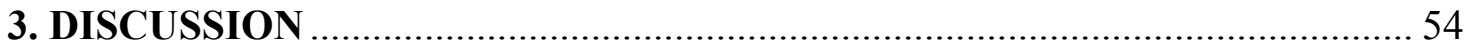


CHAPTER VI: NORE1A AND BRCA1 FORM A TUMOR SUPPRESSOR COMPLEX

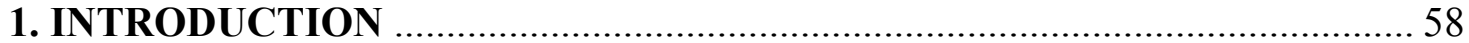

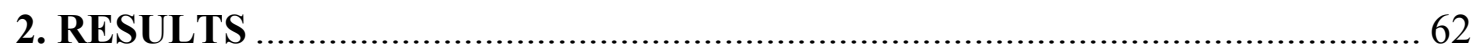

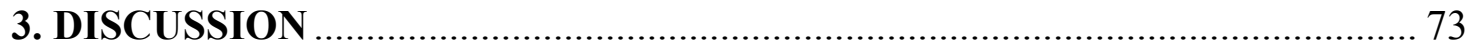

CHAPTER VII: NORE1A REGULATES BRCA1-MEDIATED DNA REPAIR............ 78

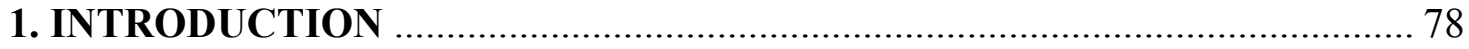

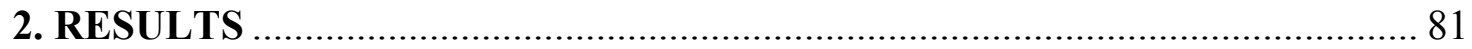

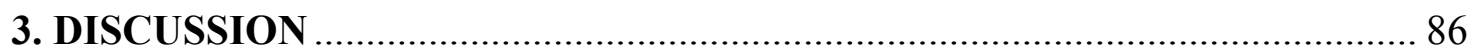

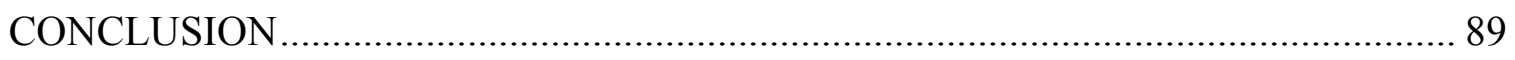

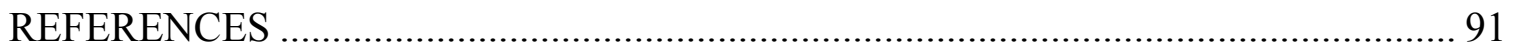

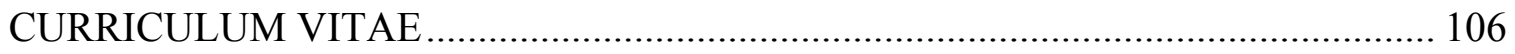




\section{LIST OF FIGURES}

Figure 1: The Ras activation/deactivation cycle is regulated by GEFs and GAPs ..... 4

Figure 2: Wild-type Ras is constitutively activated by mutations in its regulatory

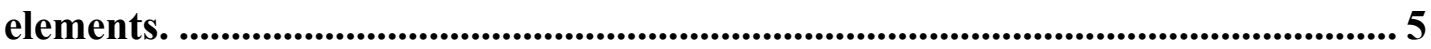

Figure 3: Ras activates mitogenic pathways...............................................................9

Figure 4: Activated Ras also stimulates growth inhibitory pathways. ...................... 11

Figure 5: NORE1A protein structure. ....................................................................... 20

Figure 6: NORE1A signaling pathways........................................................................... 21

Figure 7: BRCA1 protein structure. ................................................................................ 26

Figure 8: BRCA1-regulated pathways.............................................................................. 27

Figure 9: NORE1A and BRCA1 co-localize after replication stress......................... 46

Figure 10: NORE1A and BRCA1 form a Her2 and Ras-regulated complex............ 48

Figure 11: BRCA1 binds the INT-domain of NORE1A........................................... 52

Figure 12: Generation of MCF-10A knockdown cell lines......................................... 63

Figure 13: Depletion of NORE1A or BRCA1 enhances growth of MCF-10A cells.. 64

Figure 14: NORE1A depletion suppresses senescence in Her2+/BRCA1- cells........ 67

Figure 15: NORE1A and BRCA1 co-depletion enhances MCF-10A growth in soft

agar..................................................................................................................................... 70

Figure 16: NORE1A depletion confers anoikis resistance.......................................... 72

Figure 17: NORE1A monitors "Goldilocks" response to Her2/Ras/BRCA1 ............ 77 
Figure 18: Dual inactivation of NORE1A and BRCA1 synergizes to suppress DNA

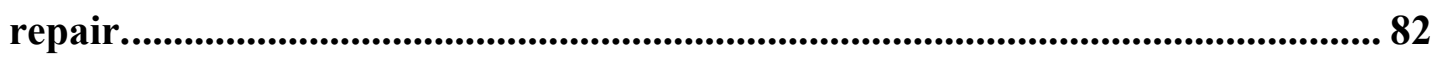

Figure 19: NORE1A scaffolds BRCA1 with BACH1 helicase................................ 85

Figure 20: NORE1A regulates the BRCA1 response to Ras-induced DNA damage 90 


\section{CHAPTER I: INTRODUCTION TO RAS}

\section{Ras history}

Nearly two decades of research on the Harvey and Kirsten murine sarcoma retroviruses led to the discovery in the late 1970s and early 1980 s that the sequences responsible for the transforming capabilities of these viral strains were actually derived from rat cellular genes, termed Ras (from rat sarcoma) [1]. The subsequent discovery of mutationally activated Ras genes in human cancer cells showed that Ras could play a role in human tumorigenesis [1], [2]. Intensive research into the structural, biochemical, and biological functions of Ras over the last thirty years has revealed much about how Ras communicates with both its upstream activators and downstream targets. However, the identification of multiple Ras regulators and effectors with unique expression patterns and intercellular functions has complicated the search for Ras-specific anti-cancer therapies [2], [3].

Structure and regulation of Ras

There are three human RAS genes (H-RAS, N-RAS, and K-RAS) that encode four homologous $21 \mathrm{kDa}$ proteins (K-RAS encodes two splice variants), all of which associate with cellular membranes. Ras is a guanosine nucleotide-binding protein (specifically, a small GTPase) that can bind and hydrolyze guanosine triphosphate (GTP) into guanosine diphosphate (GDP). When bound to GTP, Ras is "switched on" and can 
bind and activate multiple signaling pathways [4]. After GTP hydrolysis, Ras undergoes a conformational change that "turns off" Ras signaling. Ras is normally present in this inactive (GDP-bound) conformation (Figure 1) [3].

The process of exchanging bound GDP for GTP is facilitated by Ras GEFs (guanine nucleotide exchange factors). In response to external stimuli (e.g. mitogens, cytokines, and growth factors), Ras GEFs are recruited to Ras proteins where they catalyze a reaction that releases GDP from Ras [5]. Intracellular GTP is highly abundant compared to GDP, and preferentially enters the nucleotide binding region of Ras [6]. These GTP-bound Ras proteins undergo a conformational change that allows them to bind and activate effectors that carry information from the cell membrane to various intracellular signaling networks [4]. Ras has a weak intrinsic GTPase activity that can theoretically allow it to hydrolyze GTP and return to its inactive state in response to cellular feedback. This slow, inefficient process is greatly accelerated by Ras GAPs (GTPase activating proteins) that bind and stabilize the catalytic machinery of Ras and thereby enhance its hydrolytic activity [7]. It is therefore the balance between Ras GEF and GAP activity that regulates Ras signaling to its downstream effectors.

In a normal cell, Ras acts as a binary signaling switch that cycles between an inactive (GDP-bound) state and an active (GTP-bound) state [8]. The most common oncogenic mutations of Ras prevent stimulation of GTP hydrolysis by Ras GAPs, resulting in permanently GTP-bound (i.e. constitutively active) Ras proteins that continuously signal to downstream pathways [9]. These activating mutations in Ras are present in $\sim 1 / 3$ of all human cancers, making Ras the most common oncogene in human cancer [10]. 
In addition to mutations in the Ras gene itself, genetic alterations in Ras regulatory elements can also lead to constitutive Ras signaling (Figure 2). Mutation or amplification of the epidermal growth factor receptor Her2, which is upstream of Ras and signals through Ras, accounts for $\sim 25-30 \%$ of wild-type Ras activation in human breast cancer [11]-[13]. Genetic, epigenetic, or proteasomal inactivation of the Ras GAPs NF1, DAB2IP, and RASAL2 also account for significant wild-type Ras activation in human breast cancer [14]-[16]. Therefore, Ras is potentially constitutively activated in over 2/3 of all human cancers (and nearly half of all breast cancers), making Ras and its downstream pathways extremely important targets in cancer research. 
Figure 1: The Ras activation/deactivation cycle is regulated by GEFs and GAPs

Ras cycles between an active (GTP-bound) state and an inactive (GDP-bound state) due to regulation by its guanosine nucleotide exchange factors (GEFs) and GTPase-activating proteins (GAPs). GEFs release GDP from Ras, allowing Ras to preferentially bind to abundant intracellular GTP. Activated Ras is then able to stimulate its target effectors. GAPs stabilize the catalytic machinery of Ras, enhancing its intrinsic ability to hydrolyze GTP into GDP and returning Ras to its inactive conformation.

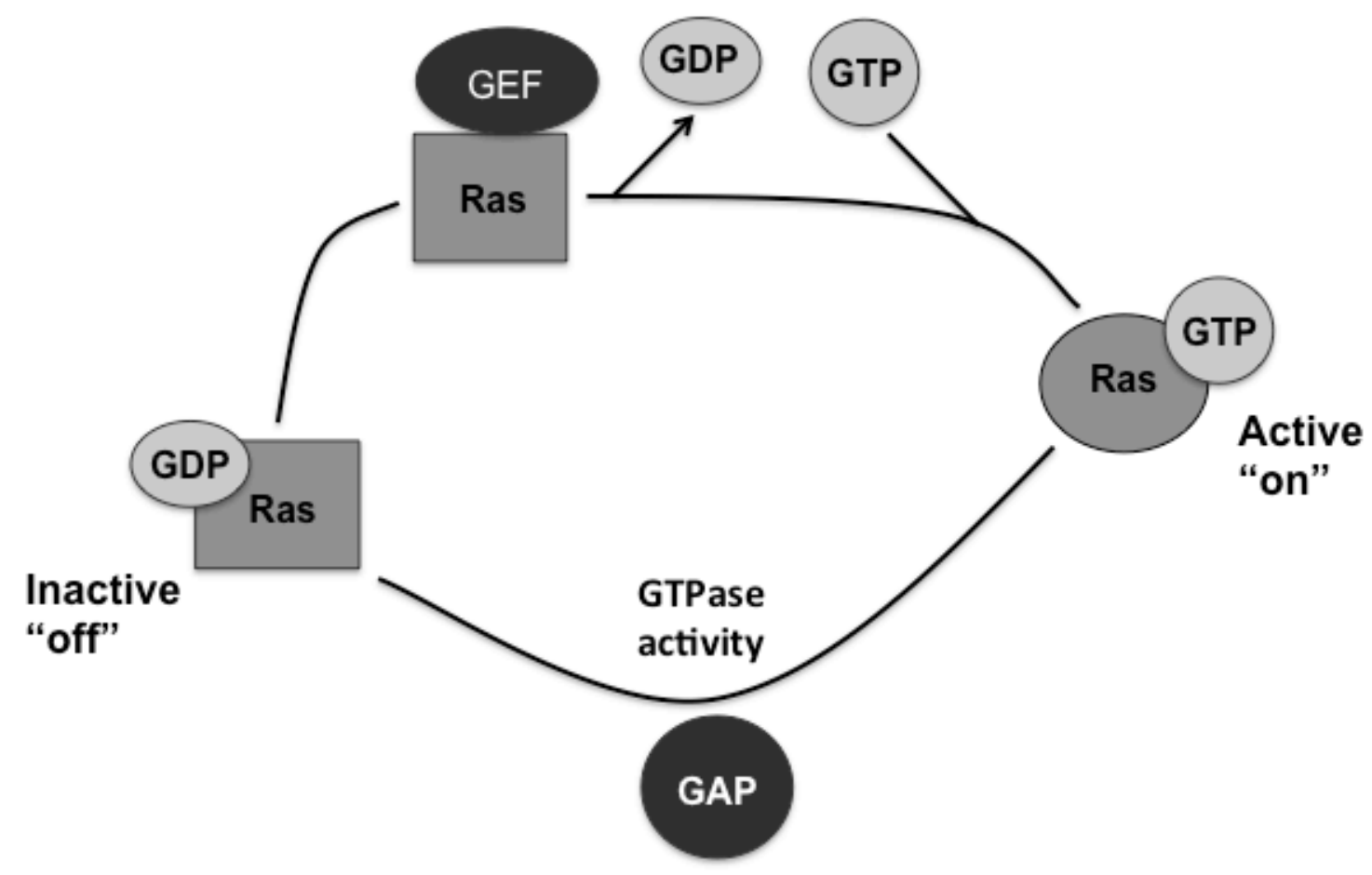


Figure 2: Wild-type Ras is constitutively activated by mutations in its regulatory elements.

Oncogenic Ras mutations occur in less than $2 \%$ of breast cancers, yet Ras is constitutively activated in over half of all primary breast tumors. This is a result of aberrant activation of upstream regulators of Ras that signal through Ras (such as Her2) or inactivation of negative regulators of Ras (such as the Ras GAPs NF1, DAB2IP, and RASAL2).

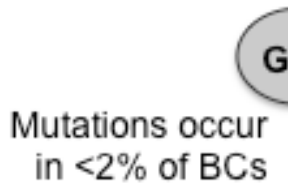

\section{GTP}

in $<2 \%$ of $\mathrm{BCs}$

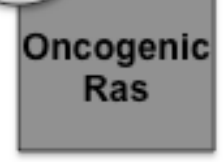

$\downarrow$

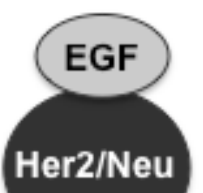

$\sim 25-30 \%$ of $\mathrm{BCs}$

Mutation/amplification occurs in 25-30\% of BCs

\section{Constitutive Ras}

signaling 


\section{Ras signaling overview}

Mitogenic signaling

Activated Ras proteins promote transformation by stimulating multiple mitogenic pathways (Figure 3) [17]. Constitutive activation of Ras simultaneously drives cellular proliferation and suppresses apoptosis via these signaling pathways by enhancing transcription of growth factors and anti-apoptotic molecules and down-regulating proapoptotic mediators [18], [19]. Two of the best-studied pathways that are activated by Ras are the RAF-MEK-MAPK pathway and the PI3K-AKT pathway [17].

In response to signaling from cell surface receptors (e.g. EGFR receptors), the Ras GEF Sos facilitates Ras activation, stimulating activated Ras to bind and promotes the phosphorylation and activation of RAF, which phosphorylates and activates MEK, which phosphorylates and activates ERK (MAPK). Activation of this signaling cascade ultimately activates the ETS family of transcription factors that induce expression of multiple genes that enhance cell cycle progression and migration [20]. The frequency of aberrant Ras-RAF pathway activation in human cancer has driven intense research into the development of RAF inhibitors for the treatment of these cancers [21], [22].

The P13K pathway is the second best characterized of the Ras effector pathways. Upon activation by Ras, PI3K stimulates the activation of AKT, which phosphorylates and activates numerous cellular proteins that lead to both the inhibition of multiple tumor suppressors (e.g. p53, p27, TSC1/2) and activation of multiple oncogenes [23]. Activation of the PI3K-AKT pathway ultimately results in cell growth and survival, cell cycle progression, migration, and cytoskeletal reorganization [24]. Similar to RAF, PI3K 
mutations are frequent in human cancers, and intense research has been focused on the development of specific inhibitors of this pathway [23], [25].

Ras can also bind and activate RalGDS, a guanine nucleotide exchange factor (GEF) for the small GTPase Ral. The interaction between Ras and RalGDS brings RalGDS into proximity with Ral. Activated Ral interacts with a variety of proteins, through which it regulates endocytosis, exocytosis, microtubule reorganization, and transcription [26]. Activation of these pathways ultimately enhances Ras-mediated transformation by promoting anchorage-independent cell growth [26].

\section{Apoptosis}

Activated Ras is highly transforming, yet in normal cells excessive Ras activation can induce a powerful pro-apoptotic response (Figure 4) [27], [28]. This is usually mediated through $\mathrm{p} 53$, and acts to protect cells from transformation in the presence of oncogenic stimuli [28]. Signaling through the Ras effector RASSF1A can lead to apoptosis via activation of caspase 3 and the pro-apoptotic proteins BAX and BAK1 or via phosphorylation of MST kinases and activation of the pro-apoptotic Hippo pathway [9]. In some cases, oncogenic Ras signaling through the RAF pathway can initiate a p53mediated apoptotic response [29]. The paradoxical mechanism by which Ras signaling can both induce and abrogate apoptosis by RAF activation remains to be fully understood, as the outcome varies greatly depending on cell/tissue type and cellular context, as well as signal intensity and duration [28].

\section{Senescence}


In addition to activating pro-apoptotic pathways, activated Ras can also promote oncogene-induced senescence [28], [30]. This physiological process has been observed in cell culture systems and in vivo mouse models as well as human rasopathies and premalignant human tumors [30]-[33], and has been hypothesized to protect cells that acquire Ras mutations from cancer development by stimulating them to undergo irreversible growth arrest [34]. While the mechanism behind Ras-driven senescence remains poorly understood, activation of the $\mathrm{p} 53-\mathrm{p} 21$ and $\mathrm{p} 16-\mathrm{Rb}$ pathways by Ras has been shown to play an important role [35]. Importantly, abrogation of p53-p21 or p16-Rb signaling allows cells to bypass Ras-induced senescence [30]. The RASSF family member NORE1A is known to play a key role in Ras senescence signaling via p53 [36] (Figure 4). 


\section{Figure 3: Ras activates mitogenic pathways.}

Oncogenic Ras mutations lock Ras in its GTP-bound (active) state, resulting in constitutive Ras signaling. Mutation or overexpression of Ras regulatory elements can also lead to constitutive activation of wild-type Ras. The Raf pathway ultimately activates the ETS family of transcription factors, which stimulate the transcription of genes that promote cell cycle progression. Activation of PI3K-AKT leads to the phosphorylation and inhibition of several tumor suppressors (p27, p53, TSC1/2, BAD) or activation of oncogenes. Ras can also activate the small GTPases RalA and RalB via RalGDS, which promote anchorage-independent growth. PLCE catalyzes the formation of IP3 and DAG, second messengers involved in intracellular calcium release and activation of protein kinase $\mathrm{C}$ (PKC). RIN1 facilitates Ras-regulated endocytosis by acting as a GEF for proteins involved in endosome maturation.

Figure copied with permission from [17] (Nature Publishing Group, license no. 3693130867077). 


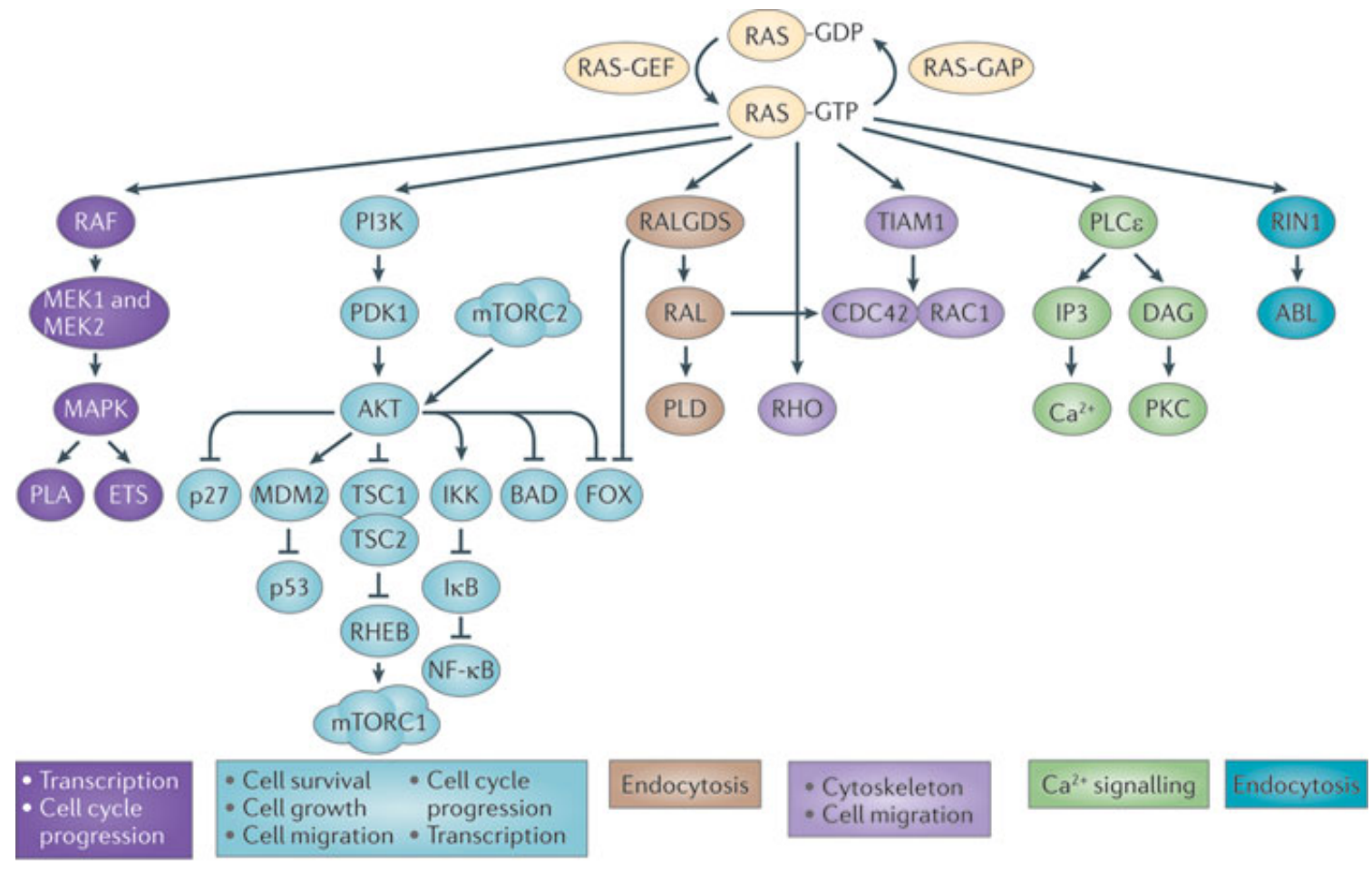

Nature Reviews | Cancer 
Figure 4: Activated Ras also stimulates growth inhibitory pathways.

In addition to mitogenic signaling, activated Ras can also drive apoptosis and senescence. Ras signaling through Raf can promote p53-mediated apoptosis, and has also been implicated in senescence induction via p21 and p16. Ras-mediated activation of RASSF1A leads to apoptosis via activation of pro-apoptotic BAX proteins, or by activation of the pro-apoptotic Hippo pathway via phosphorylation of the MST kinases. RASSF1A has also been reported to drive senescence via p53-independent regulation of $\mathrm{p} 21$. Ras-mediated activation of NORE1A can promote $\mathrm{p} 53$-dependent upregulation of p21 to drive cell cycle arrest or senescence.

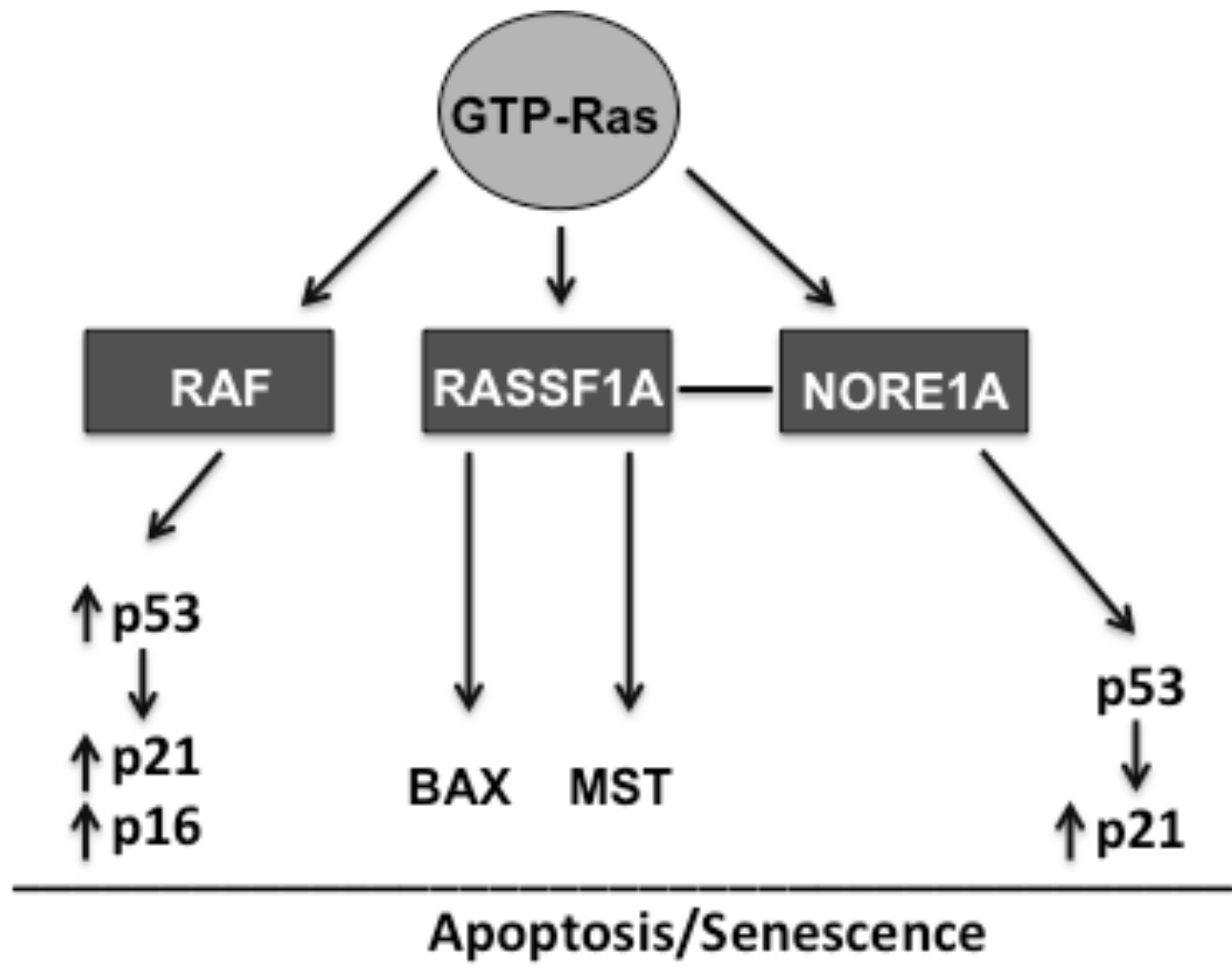




\section{Ras growth inhibitory effectors}

The RASSF family

There are ten RASSF family members (along with various isoforms), which are now split into two groups: the "classical" members (RASSF1-6), which contain an RA domain and a SARAH domain at their C-terminus, and the N-terminal members (RASSF7-10) that lack a SARAH domain and contain an RA domain at their N-terminus [37]. Most of these proteins act as tumor suppressors in the cell and have been implicated in a variety of cellular mechanisms, including apoptosis, senescence, cell cycle regulation, and microtubule stabilization [38]. The best studied of the RASSF proteins are RASSF1A and NORE1A [39].

NORE1A (RASSF5) can regulate Ras signaling to p53 [36], [40], and thus directly links Ras to this senescence pathway [41]. Epigenetic inactivation of NORE1A and other RASSF family members is a frequent occurrence in primary human tumors, as their loss allows cells to subvert Ras-mediated cell death and promotes transformation $[38]$. 


\section{CHAPTER II: RAS SIGNALING IN BREAST CANCER}

\section{Breast cancer overview}

Breast cancer is the most common invasive cancer in women worldwide [42], and can be classified as either hereditary or sporadic. Inherited mutations in certain high penetrance genes (such as BRCA1, BRCA2, or p53) promote breast cancer formation if the second allele of these genes becomes inactivated [43]. The majority of breast cancers are sporadic, and arise from the stepwise accumulation of acquired mutations [44]. The mutational activation of oncogenes (like Her2) and inactivation of tumor suppressors leads to genomic instability via this pathway, facilitating the accumulation of additional mutations that can promote tumor formation. Thus, both hereditary and sporadic breast cancers are genetic diseases, and are associated with the loss or mutation of multiple regulatory genes that control proliferation, apoptosis, and differentiation [44].

\section{Ras activation in breast cancer}

The high incidence of activating Ras mutations in various cancers (e.g. $90 \%$ of pancreatic cancers, $50 \%$ of colon cancers, $30 \%$ of lung cancers) supports the idea that aberrant Ras activation is a driving force in the development and advancement of these malignancies [10]. The use of in vitro knockdown studies [45] and transgenic mouse models [46], [47] further confirmed this idea that mutant Ras is highly transforming. 
However, less than $2 \%$ of all primary breast tumors contain activating Ras mutations [48]-[50]. This observation has led to the widely held belief that Ras is unimportant for breast cancer. Yet despite the low frequency of mutations, considerable experimental evidence exists to support an important role for aberrant Ras activation and signaling in human breast tumorigenesis [11], [51], [52]. Rather than direct mutational activation, Ras appears to be oncogenically activated in breast cancer by mutation or altered expression of its upstream activators (transmembrane growth factor receptors such as EGFRs) or negative regulators (GAPs) (Figure 2).

\section{Ras GAPS}

As mentioned in Chapter I, Ras cycles between an activated state (regulated by GEFs) and an inactivated state (regulated by GAPs). Ras GAPs are negative regulators of Ras that enhance its intrinsic GTPase activity. Loss or mutation of these GAPs renders Ras unable to return to its inactive state, resulting in constitutive Ras signaling. Several loss of function mutations have been discovered in the Ras GAP RASAL2, and RASAL2 is suppressed or lost in $\sim 20 \%$ of primary breast tumors and $\sim 33 \%$ of breast cancer cell lines [14]. Additionally, the Ras GAP DAB2IP was found to be reduced by promoter hypermethylation in $\sim 49 \%$ of primary breast tumors and $\sim 48 \%$ of breast cancer cell lines [15]. Spontaneous loss of the Ras GAP NF1 has been shown to occur in $\sim 28 \%$ of all human breast cancers [16], and is also associated with an autosomal dominant disorder that predisposes patients to breast cancer [53].

$\mathrm{Her} 2 / \mathrm{Neu}$ 
Human epidermal growth factor receptor 2 (Her2/Neu) is a member of the epidermal growth factor receptor (EGFR) family that lies upstream of Ras and signals through Ras [54]. In normal cells, Her2 becomes activated by ligand binding and transiently activates Ras, causing Ras to activate multiple downstream effectors that promote proliferation and survival [52]. Her2 mutation or amplification occurs in $\sim 25$ $30 \%$ of all breast cancers [11][12][13], resulting in hyper-activation of Her2 and thus constitutive activation of wild-type Ras. This sustained Her2/Ras activation has been linked to the development and progression of invasive breast carcinomas [51].

Her2 activation is an early event in human breast tumorigenesis, and Her2positive cancers usually have a worse prognosis and an increased propensity for brain metastasis compared to non-Her2 cancers [55][56][57]. Paradoxically, activation of Her2 can also promote oncogene-induced senescence [58], [59]. The molecular mechanisms underlying Her2-induced senescence and how it is bypassed during transformation are complex and remain poorly understood. One factor that clearly plays a key role is activation of the Ras pathway [60].

\section{Her2/Ras activation promotes incomplete senescence in immortalized cells}

Both Her2 and Ras overexpression have been reported to drive senescence in primary human mammary epithelial cells (HMECs) [58][61]. However, although oncogenic Her2 or Ras expression in MCF-10A immortalized, non-transformed human mammary epithelial cells results in the phenotype of senescence (senescence-associated morphological changes, enhanced $\beta$-galactosidase activity, upregulation of $\mathrm{p} 21)$ it fails to trigger irreversible growth arrest [62]. These cells are able to stably persist in state of 
incomplete senescence, and can be driven toward full senescence (growth arrest) or transformation by enhanced genotoxic stress or loss of critical cell cycle regulators [62].

\section{NORE1A and BRCA1 link activated Ras signaling to breast cancer}

Two tumor suppressor proteins that have been shown to play roles in both cell cycle regulation via p53-p21 [40], [63] and senescence via activated Ras [36], [64] are the RASSF family member NORE1A and the breast cancer susceptibility protein BRCA1. NORE1A is a direct Ras effector, and is inactivated in $\sim 40 \%$ of breast cancer cell lines and primary tumors by promoter hypermethylation [65]. BRCA1 expression is

frequently lost in sporadic breast cancers by promoter hypermethylation [66]-[69], and mutational inactivation of BRCA1 is linked to a hereditary breast and ovarian cancer (HBOC) syndrome [43]. The frequency of co-inactivation of these tumor suppressors in breast cancer is not known. The similar roles of these proteins in activation of the CDK inhibitor p21, a marker of senescence induction, coupled with their recently identified roles in Ras senescence suggests that these proteins may be acting to protect cells from breast tumor formation by regulating senescence induction after Ras activation. 


\section{CHAPTER III: THE NORE1A TUMOR SUPPRESSOR}

\section{NORE1A overview}

\section{NORE1A structure}

Nore1/RASSF5 was the first member of the RASSF family to be characterized [70]. There are three known isoforms of NORE1 as a result of alternative splicing, RASSF5A (NORE1A), RASSF5B, and RASSF5C (NORE1B) [38]. NORE1A is the fulllength $(418 \mathrm{aa} ; 47 \mathrm{kDa})$ protein, and the most widely expressed. It consists of an Nterminal proline-rich region that contains a nuclear localization sequence, followed by a cysteine-rich domain (CRD) that serves as a putative diacylglycerol/phorbol ester (DAG/PE)-binding site, a Ras association (RA) domain for binding Ras, and a C-terminal SARAH domain where it binds the pro-apoptotic MST kinases (Figure 5). The intermediate domain (INT) between the CRD and RA domains contains a second nuclear localization sequence, and the RA domain contains a nuclear export sequence [71].

\section{Subcellular localization}

NORE1A is a nucleocytoplasmic shuttling protein, and contains two identified nuclear localization signals and one identified nuclear export signal (Figure 5). NORE1A has been reported on microtubules and in the centrosome [72], but can most readily be detected in the nucleus. Phosphorylation of NORE1A by the tyrosine kinase Lck 
regulates its nuclear translocation via an importin-mediated pathway [73]. This nuclear translocation of NORE1A is critical for its role in cell cycle regulation [73]. Nuclear export of NORE1A was shown to be required for NORE1A-mediated apoptosis induction [74], and likely occurs via a CRM1-mediated pathway [73], [74]. Thus, the subcellular localization of NORE1A plays an important role in its tumor suppressor function.

Regulation and inactivation in human cancer

NORE1A is reported to be regulated by phosphorylation by Lck [73] and Aurora kinase [75], and can also be poly-ubiquitinated by the E3 ubiquitin ligase Itch in a manner dependent on the level of NORE1A acetylation [76]. This ubiquitination results in NORE1A degradation by the $26 \mathrm{~S}$ proteasome; thus, Itch acts a negative regulator of NORE1A [76]. The precise mechanism by which NORE1A is acetylated and marked for degradation remains unknown [76].

Another way in which NORE1A expression is regulated is by hypermethylation of its promoter region [77]. NORE1A is expressed in a wide variety of normal tissues, and is frequently downregulated by promoter hypermethylation in several cancer cell lines and primary tumors, including liver, lung, breast, and kidney cancers [65], [78].

\section{Hippo signaling/apoptosis}

NORE1A lacks enzymatic activity, and therefore likely functions as a scaffolding protein. The best-studied functions of NORE1A are its ability to bind specifically and with high specificity to Ras and the proapoptotic kinase MST1, a component of the Hippo pathway (Figure 6). The Hippo pathway controls organ size in mammals by 
regulating the balance between cell proliferation and apoptosis [79]. Earlier studies implicated Ras/NORE1A in the regulation of apoptosis via MST1 [80]. However, more recent research shows that while NORE1A and MST1 can form an endogenous complex in human cells, the kinase activity of MST1 is strongly suppressed in these complexes [81]. Additionally, deletion studies show that the ability of NORE1A to bind MST is not critical for its growth suppressive function [81]. Thus, canonical Hippo signaling via MST1 does not appear to be a major tumor suppressor function of NORE1A.

\section{Cell cycle regulation and senescence}

Although earlier studies identified a pro-apoptotic role for NORE1A [80], [82], recent research suggests that a more physiological role for NORE1A may be in the regulation of cell cycle arrest by p53 [40]. In support of this, NORE1A was shown to be a critical component of Ras-driven senescence signaling to p53 [36] (Figure 6). Senescence induced by Ras acts as a barrier to transformation in cells that have acquired constitutive activation of Ras [34]. In the absence of NORE1A, Ras becomes uncoupled from p53 and is able to drive transformation without the barrier of senescence [36]. Thus, the communication link between Ras, p53, and NORE1A is critical for the tumor suppressor function of NORE1A. 
Figure 5: NORE1A protein structure.

Full-length NORE1A contains a proline-rich region at its N-terminus that contains a nuclear localization signal (aa 51-100), followed by a cysteine-rich domain (CRD; also referred to as a zinc-finger) that functions as a DAG/PE binding domain. The C-terminal end of NORE1A contains a Ras association (RA) domain where it binds to activated Ras, and a coiled-coil SARAH domain required for binding the MST kinases. I refer to the $\sim 100$ aa region between the CRD and RA domains as the intermediate (INT) domain. This INT domain is reported to contain a second nuclear localization sequence (aa 200-260). Finally, a nuclear export sequence has been reported between aa 260-300.

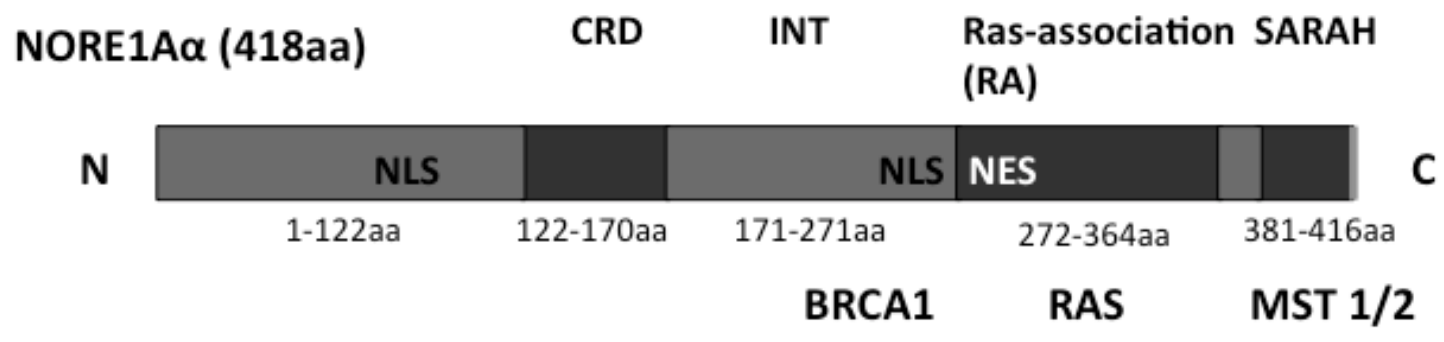




\section{Figure 6: NORE1A signaling pathways}

NORE1A can bind directly to activated Ras and the proapoptotic MST kinases, which form the start of the Hippo signaling pathway. MST activation leads to phosphorylation of LATS kinases via the Salvador (SAV) adaptor protein, and ultimately the phosphorylation and inactivation of transcriptional co-activators YAP and TAZ. The role of NORE1A in Hippo signaling is controversial and remains poorly understood. NORE1A can also communicate with p53 to induce senescence in the presence of activated Ras. Recently, NORE1A was shown to scaffold the ubiquitin ligase $\beta$-TrCP with its target substrate $\beta$-catenin in a Ras-dependent manner, which marks $\beta$-catenin for degradation by the $26 \mathrm{~S}$ proteasome [83].

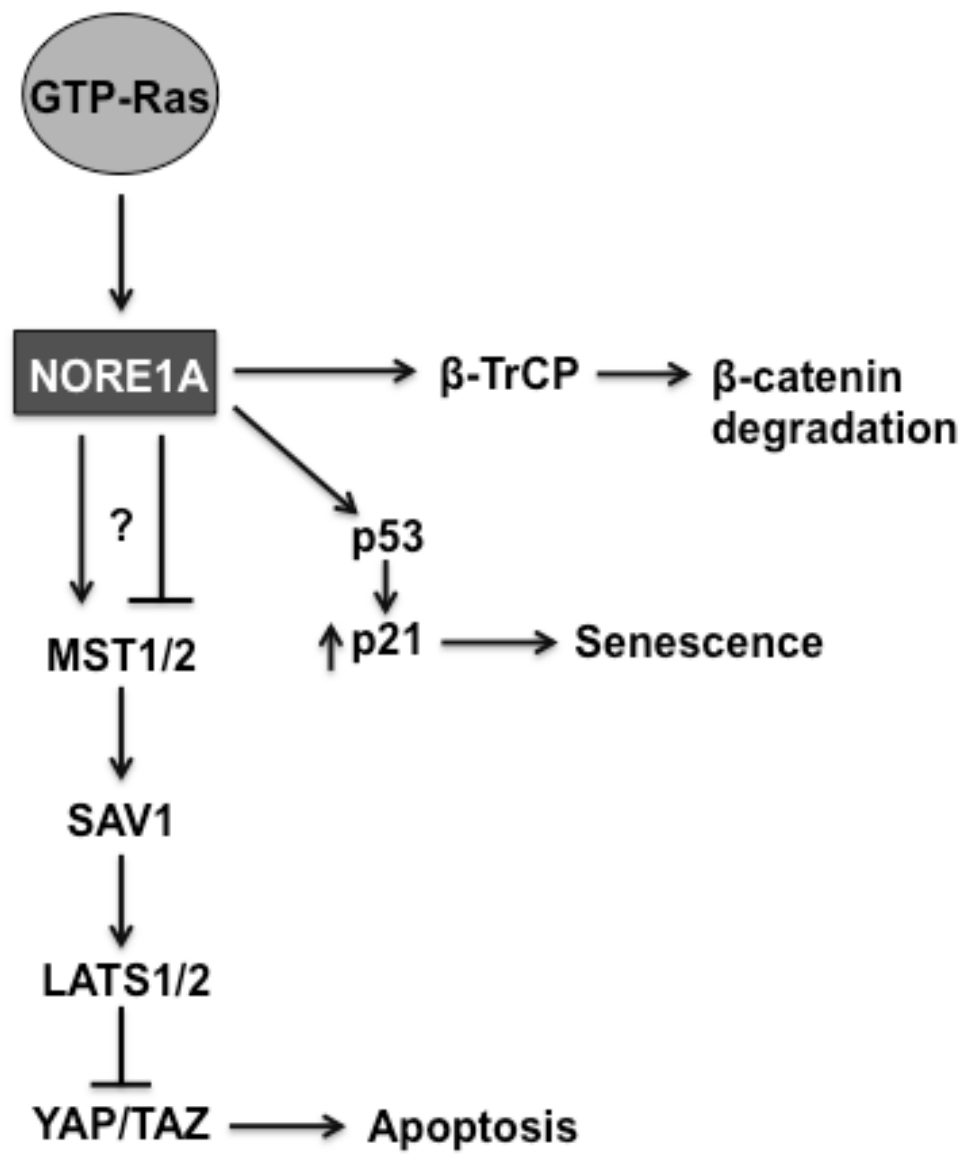




\section{NORE1A in human cancer}

NORE1A is frequently downregulated in human tumors and tumor cell lines by promoter hypermethylation [65], and loss of heterozygosity (LOH) at the NORE1A locus has been observed in primary tumors [84]. Furthermore, a translocation involving NORE1A is associated with a hereditary human cancer syndrome [85]. Overexpression of NORE1A can promote apoptosis [80], [82], cell cycle arrest [81], or senescence [36], and restoration of endogenous NORE1A levels to a human tumor cell line that is negative for NORE1A suppresses the tumorigenic phenotype [82]. Additionally, mouse embryonic fibroblasts (MEFs) from NORE1A ${ }^{-/-}$mice can be transformed by activated Ras without the presence of additional oncogenes, where wild-type MEFs are not susceptible to this one-step transformation [86]. Subcutaneous injection of activated Ras-expressing MEFs or NORE1A ${ }^{-/-}$MEFs into nude mice did not promote significant tumor formation after 35 weeks. However, $\operatorname{Ras}^{+} / \mathrm{NORE} 1 \mathrm{~A}^{-/-}$MEFs formed tumors in these mice in 3 weeks [86]. Thus, the evidence supports a role for NORE1A as a tumor suppressor and Ras effector that acts as a barrier to protect cells from Ras-driven transformation. 


\section{CHAPTER IV: THE BRCA1 TUMOR SUPPRESSOR}

\section{BRCA1 overview}

The breast cancer type $\underline{1}$ susceptibility gene (BRCA1) is a tumor suppressor that functions to maintain genomic integrity, largely by participating in DNA repair. Hereditary mutations in BRCA1 strongly predispose carriers to developing breast and ovarian cancers [87]. BRCA1 inactivation by promoter hypermethylation has also been observed in a considerable proportion of sporadic breast cancers [88]. Thus, loss or dysregulation of BRCA1 function is a frequent occurrence in all types of breast cancers.

\section{BRCA1 structure/function}

BRCA1 encodes a 1,863 AA $(\sim 220 \mathrm{kDa})$ protein (Figure 7$)$ that plays an important role in maintaining genomic stability by forming protein complexes with DNA repair proteins and other tumor suppressors in order to carry out its diverse roles in DNA repair, cell cycle control, transcriptional regulation, apoptosis, and centrosome duplication (Figure 8) [89]. BRCA1 is able to simultaneously participate in several different protein complexes, as each complex contains only a small fraction of the total cellular BRCA1 [90].

Three domains of BRCA1 are responsible for the majority of its biological functions and protein interactions: an N-terminal RING (ㅌeally Interesting New $\underline{\text { Gene) }}$ 
domain, a central domain encoded by exons 11-13, and two tandem BRCT (BRCA1 Cterminal) domains (Figure 7) [91]. Several cancer-associated mutations occur in these domains that render BRCA1 unable to interact with its target effectors [91].

The sole defined enzymatic activity associated with BRCA1 occurs within its RING domain, which functions as an E3 ubiquitin ligase [92]. Ubiquitination of target substrates by BRCA1 requires interaction with an E2 ubiquitin-conjugating enzyme, and is significantly enhanced by formation of a heterodimer between BRCA1 and the $\underline{B R C A 1-a s s o c i a t e d}$ RING domain protein (BARD1) [91]. Several targets of BRCA1/BARD1-mediated ubiquitination have been identified, including CtIP, Claspin, and Estrogen receptor alpha (ER- $\alpha)$ [93]-[95]. How these putative substrates are recruited to the BRCA1/BARD1 E3 ligase complex and the biological relevance of their ubiquitination in breast cancer remains unclear [90]. Recent in vivo studies have shown that the ubiquitin ligase function of BRCA1 is dispensable for tumor suppression [96]. Thus, the biological consequences of BRCA1-mediated ubiquitination remain to be fully understood.

The central region of BRCA1 encoded by exons 11-13 of the BRCA1 gene is critical for the tumor suppressor function of BRCA1 [89]. It is within this domain that BRCA1 becomes phosphorylated by ATM/ATR kinases in response to DNA damage, which enables several proteins involved in DNA repair (Rad51, BRCA2), cell cycle regulation $(\mathrm{Rb})$ and transcriptional control (cMyc) to bind to this site [91], [97]-[100]. Additionally, the nuclear localization sequences of BRCA1 are contained within this region [101]. Mutations within this central region of BRCA1 frequently involve loss of 
large portions of sequence, resulting in formation of a truncated protein that is unable to form DNA repair complexes or bind transcriptional regulators [89].

The BRCT domains of BRCA1 mediate DNA binding capability and phosphoprotein interactions involved in DNA damage repair (e.g. CtIP, Abraxas, BACH1, p53) [102]. Several cancer-associated mutations occur in this domain, most notably those that interfere with the binding of BRCA1 to $\mathrm{p} 53$, which is important for p53-dependent transcription of p21 [63]. Additionally, it is within this domain that BRCA1 interacts with the BRCA1-associated $\underline{\mathrm{C}}$-terminal helicase BACH1 [102]. BACH1 acts as a critical mediator of the BRCA1 DNA damage response by localizing BRCA1 to sites of DNA damage and using its helicase activity to provide chromatin access to BRCA1 and other members of the HR-mediated DNA repair complex [103]. Mutation or loss of BACH1 has been shown to disrupt BRCA1-mediated localization and DNA repair function [104]. 


\section{Figure 7: BRCA1 protein structure.}

BRCA1 contains an N-terminal RING domain that contains its nuclear export sequence (NES) as well as the binding site for the BRCA1-associated Ring domain containing protein BARD1, which shuttles BRCA1 to the nucleus and enhances its ubiquitin ligase activity. The central region of the protein is encoded by exons 11-13 and contains the two nuclear localization sequences (NLS) and target phosphorylation sites for ATM/ATR kinases (SCD). Binding sites for the DNA repair proteins Rad50/51, BRCA2, PALB2, the tumor suppressor $\mathrm{Rb}$ and the oncoprotein Myc are found within this central domain. The two tandem C-terminal BRCT domains of BRCA1 contain binding sites for several phosphoproteins, including the CtBP interacting protein (CtIP), Abraxas, BACH1/BRIP1 helicase, and the tumor suppressor p53.

\section{BRCA1 (1863aa)}

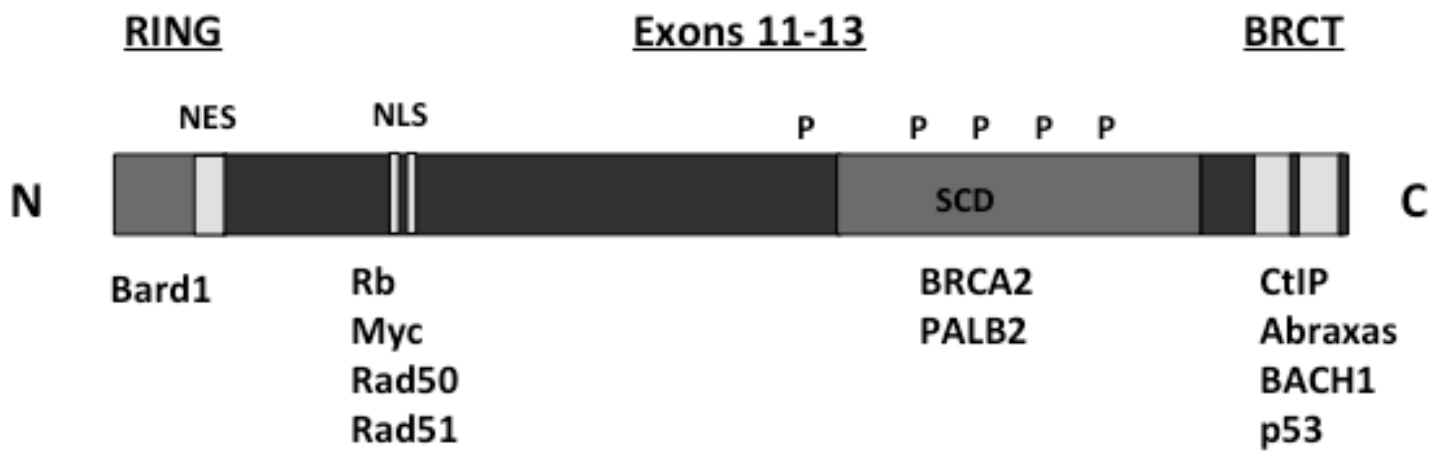




\section{Figure 8: BRCA1-regulated pathways.}

BRCA1 maintains genome integrity by forming a series of complexes that regulate DNA repair, cell cycle progression, transcription, and ubiquitination. BRCA1 becomes activated by ATM/ATR kinases in response to DNA damage and is able to interact with its downstream targets. Some downstream targets of BRCA1 include: p53, Rb, CHK1, and PLK1 (involved in cell cycle regulation; apoptosis), FANCD2 (cell cycle arrest; homologous recombination), BARD1 (ubiquitination), XIST (X-chromosome silencing; non-homologous end joining), and BACH1 (chromatin remodeling, homologous recombination).

Figure copied with permission from [105] (Nature Publishing Group, license no. 3693130867077).

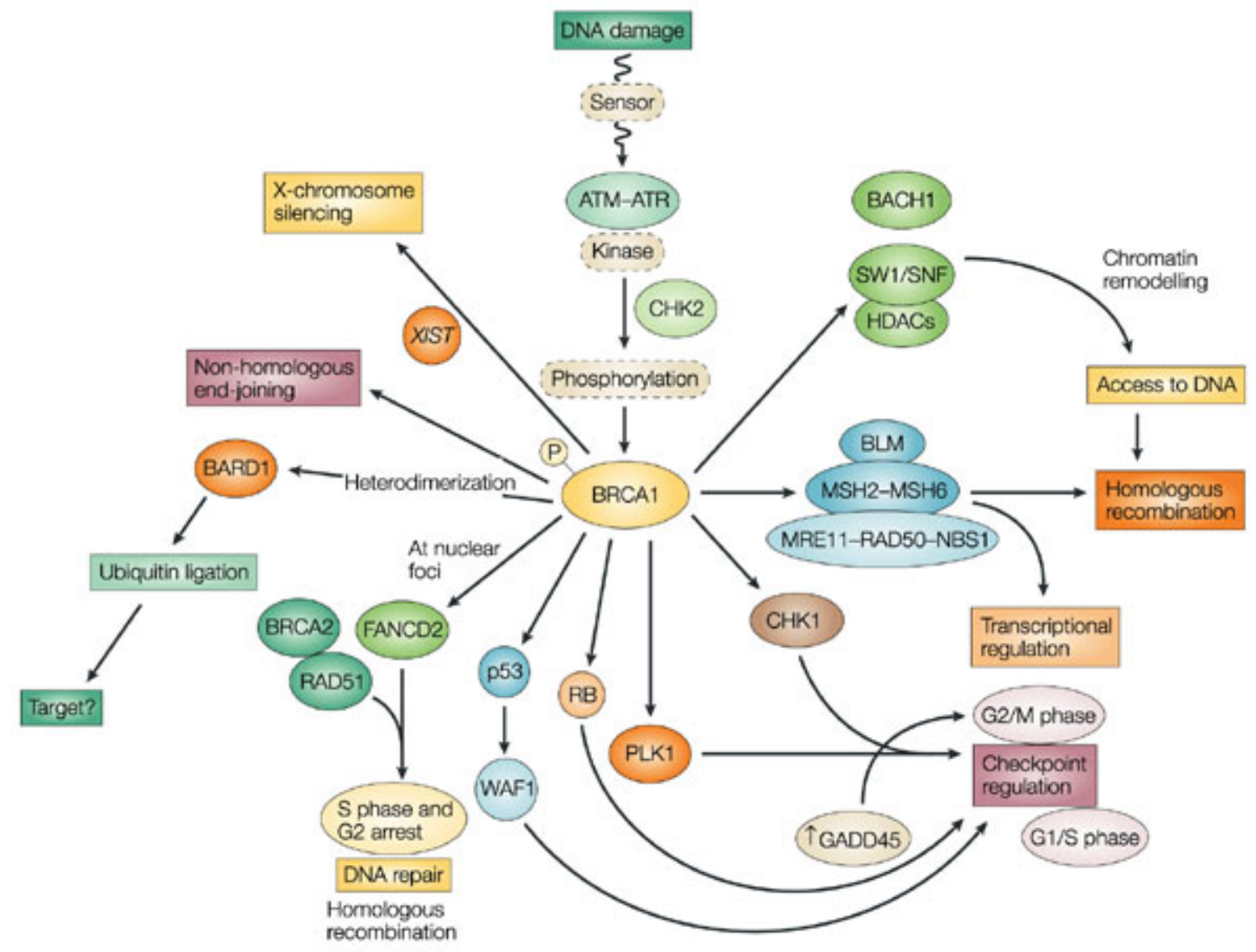

Nature Reviews | Cancer 


\section{BRCA1 in breast cancer}

The role of BRCA1 in hereditary human cancer has been well studied [106]. Loss of heterozygosity in carriers of a germline BRCA1 mutation results in complete loss of BRCA1 function, leading to genomic instability [107]. Accumulation of DNA damage in the absence of BRCA1-mediated DNA repair can either activate p53-dependent pathways (leading to cell cycle checkpoint, growth arrest, and apoptosis or senescence) or facilitate further mutations that inactivate tumor suppressors or activate oncogenes (leading to carcinogenesis) [107].

The majority ( $90 \%)$ of breast cancers are sporadic, and BRCA1 mutations are rare in these cancers [87]. However, BRCA1 expression is suppressed in $\sim 50 \%$ of sporadic breast tumors, especially those that are highly malignant [67]-[69]. Allelic loss and promoter hypermethylation of BRCA1 have both been demonstrated in sporadic breast cancers and thus may account for the observed decrease in BRCA1 expression [66], [108].

\section{BRCA1 regulation by $\operatorname{Ras}$}

Recently, a role for BRCA1 was identified in Ras-induced senescence [64]. Activated Ras was shown to downregulate expression of BRCA1-binding partner BACH1 helicase, leading to the dissociation of BRCA1 from chromatin [64]. Rasinduced hyperproliferation in the absence of BRCA1 DNA repair leads to genomic instability, triggering a DNA damage response that promotes cellular senescence [109]. The genomic instability caused by Ras activation and subsequent BRCA1 inactivation can also facilitate the acquisition of secondary oncogenic hits that allow certain cells to 
bypass senescence and become transformed [110]. Thus, BRCA1 dysregulation contributes to Ras-induced senescence yet renders cells susceptible to senescence bypass and transformation. Currently, no direct means of communication between BRCA1 and Ras has been established.

\section{BRCA1 and Her2}

Her2 overexpression contributes to $\sim 25-30 \%$ of Ras activation in human breast cancer [12]. Similar to Ras, activated Her2 expression has been shown to suppress the BRCA1-mediated DNA repair pathway and drive senescence [111]. These oncogeneinduced senescence pathways do not necessarily ensure complete growth arrest [62], and can be subverted in favor of malignancy by accumulation of additional oncogenic hits $[64][110]$.

Her2 overexpression is not common in hereditary BRCA1 tumors, and the majority of findings suggest either no association or an inverse correlation between Her2 overexpression and BRCA1 mutation in primary breast tumors [112]-[114]. However, two reports have shown that BRCA1 loss in Her2-positive sporadic breast tumors is associated with worse prognostic features (e.g. higher histological grade, increased proliferation) and a poor survival rate [115], [116]. Moreover, one of these studies found that $90 \%$ of the Her2-positive tumors in their experiments were in fact negative for BRCA1 [116]. While further studies are clearly required to determine the frequency and pathobiological characteristics of $\mathrm{Her}^{+} / \mathrm{BRCA}^{-}$tumors in sporadic breast cancer, the existing data supports a plausible role for BRCA1 loss in the development of Her2mediated tumor formation. 


\section{SUMMARY}

Despite the paucity of Ras mutations, constitutive Ras activation is a frequent occurrence in human breast cancer, largely as a result of overexpression of its upstream activators (e.g. Her2) or inactivation of its negative regulators (e.g. Ras GAPs). Activated Ras proteins are powerfully transforming, but can also promote apoptosis and senescence. The paradoxical mechanism by which Ras can have both growth-promoting and growth-inhibitory functions remains poorly understood, but is known to involve activation of the tumor suppressors p53 and $\mathrm{Rb}$ [30] and requires expression of the RASSF family member NORE1A.

NORE1A is a pro-apoptotic and pro-senescent effector of the Ras oncoprotein. NORE1A localizes primarily to the nucleus where it acts as a scaffold for various Rasregulated interactions. The growth inhibitory properties of NORE1A and its frequent loss in human cancers suggest that NORE1A is a tumor suppressor, though its mechanism of action in tumor suppression is poorly defined.

BRCA1 is a tumor suppressor that plays a key role in DNA repair. Loss of BRCA1 is associated with hereditary breast and ovarian cancer, and is also thought to play a role in sporadic breast tumorigenesis.

Recently, BRCA1 was shown to play a role in Her2/Ras signaling by regulating senescence induction by these oncogenes [64], [111]. However, loss of BRCA1 function can also contribute to Ras-driven transformation [64]. The mechanism linking Ras and 
BRCA1 is not understood. The frequent inactivation of BRCA1 in Her2-positive sporadic breast tumors suggests that loss of BRCA1 may also contribute to transformation in these cancers.

I observed nuclear co-localization between the Ras-regulated tumor suppressors NORE1A and BRCA1 in human tumor cells. Both of these proteins are frequently inactivated in breast cancer. I designed a series of experiments to determine whether NORE1A and BRCA1 could form a complex, whether they could cooperate to regulate Her2/Ras senescence, and if their dual inactivation synergized to enhance Her2/Ras transformation. Furthermore, I examined the role of NORE1A on a key tumor suppressor function of BRCA1, its ability to mediate DNA DSB repair. 


\section{MATERIALS AND METHODS}

\section{Plasmids and DNA.}

NORE1A: Human NORE1A cDNA was obtained from Origene and confirmed by sequencing. HA- and KATE-NORE1A expression plasmids were generated (courtesy of Dr. Lee Schmidt) by cloning the full-length NORE1A cDNA as a BglII-EcoRI fragment into a pcDNA vector with an HA epitope tag, pmKATE2 (Evrogen) and pEGFP-C1 (Takara Bio). NORE1A-INT domain was generated (courtesy of Dr. Lee Schmidt) by cloning AA 170-272 of the full-length NORE1A cDNA as a BglII-EcoRI fragment into a pCDNA vector with an HA epitope tag. All fusion proteins were under the control of a CMV promoter. shRNAs for human NORE1A (described in [36]) were obtained from Open Biosystems, and stable transfected cell lines were obtained after selection with blasticidine-S-hydrochloride ( $5 \mu \mathrm{g} / \mathrm{ml}$; Sigma-Aldrich).

BRCA1: YFP-BRCA1 was a gift from Dr. Ray White (Huntsman Cancer Institute, Utah). shRNAs for human BRCA1 were obtained from Origene (SKU: TG314440), and stable transfected cell lines were obtained after selection with puromycin dihydrochloride (1 $\mu \mathrm{g} / \mathrm{mL}$; Sigma-Aldrich).

Her2: HER2 CA (V659E) was a gift from Mien-Chie Hung (Addgene [117]), and stable transfected cell lines were obtained after selection with G418 Sulfate $(300 \mu \mathrm{g} / \mathrm{mL}$; Cellgro)

BACH1: pcDNA3-myc-his-BACH1 was a gift from Ronny Drapkin (Addgene [118]). 


\section{Tissue culture and cell lines.}

Cell lines: HEK-293T and MCF-10A cells were obtained from the ATCC (Manassas, VA). HEK-293T cells were grown in DMEM (Corning) with 10\% FBS (Valley Biomedical) and 1\% penicillin/streptomycin (Corning). MCF-10A cells were grown in DMEM/F12 medium (Corning) supplemented with 5\% horse serum (Gibco), 1\% penicillin/streptomycin (Corning), $0.5 \mathrm{mg} / \mathrm{mL}$ hydrocortisone (Sigma-Aldrich), 20ng/mL human epidermal growth factor (EGF) (Sigma-Aldrich), and 10 $\mu \mathrm{g} / \mathrm{mL}$ human insulin solution (Sigma-Aldrich).

Transfections: Stable transfectants were generated by transfecting cells each with $2 \mu \mathrm{g}$ of plasmid DNA using jetPRIME (PolyPlus) transfection reagent. Plasmid DNA was combined in a microcentrifuge tube with $200 \mu \mathrm{L}$ jetPRIME buffer and $4 \mu \mathrm{L}$ of jetPRIME reagent, mixed thoroughly and allowed to incubate for $10 \mathrm{~min}$ at room temperature. Transient transfections were performed by transfecting cells each with $1 \mu \mathrm{g}$ of plasmid DNA using jetPRIME as above. Medium was changed 24 hours after transfection, and cells were allowed to grow for an additional 24 hours.

Generation of stable MCF10A cell lines: Matched sets of MCF-10A NORE1A/BRCA1 cells were generated using stable sequential transduction. First, MCF10A cells were seeded to confluency in $100 \mathrm{~mm}$ dishes, transfected with either $2 \mu \mathrm{g}$ of shRNA against BRCA1 or a scrambled pRS-vector control, and then allowed to grow at $37 \mathrm{C}$ for 2 days. Fresh growth medium $(10 \mathrm{~mL}+1 \mu \mathrm{g} / \mathrm{mL}$ puromycin dihydrochloride) was applied every day for $\sim 2$ weeks until only puromycin resistant cells remained. These cells were then 
trypsinized and plated on a new $100 \mathrm{~mm}$ dish and allowed to recover for 2 passages. Next, $\mathrm{BRCA1}^{-}$and scr control cells were plated in $100 \mathrm{~mm}$ dishes and transfected with either a bRS-vector scrambled control or shRNA against NORE1A, then allowed to grow for 2 days at $37 \mathrm{C}$. These cells were then selected with $10 \mathrm{~mL}$ media $+5 \mu \mathrm{g} / \mathrm{ml}$ blasticidine-Shydrochloride (in the same manner as before) for $\sim 2$ weeks until only blasticidineresistant cells remained. These cells were allowed to recover for 2 passages. This resulted in a matched set of $4 \mathrm{MCF}-10 \mathrm{~A}$ cell lines: scr/scr (vector control), vec/shBRCA1 (BRCA1 ${ }^{-}$), vec/shNORE1A (NORE1A ${ }^{-}$), shBRCA1/shNORE1A (BRCA1/NORE1A ${ }^{-}$). In addition, a constitutively activated mutant of Her2 (V659E) was stably transfected into a set of each of these 4 cell lines. Her2 ${ }^{+}$cells were selected using $300 \mu \mathrm{g} / \mathrm{mL} \mathrm{G418}$ Sulfate in $10 \mathrm{~mL}$ growth media in the same manner as above for $\sim 2$ weeks. All cells were allowed to recover for 2 passages. The end result was two matched sets of MCF-10A NORE1A/BRCA1 ${ }^{-}$cell lines, one Her2 ${ }^{+}$and one without Her2.

Growth curves: MCF-10A standard growth curves were performed by plating $2 \times 10^{4}$ cells per $60 \mathrm{~mm}$ dish (Cellstar), and cells from each set were trypsinized $(0.25 \%$ Trypsin; Corning) and counted manually at the same time each day for four days.

Soft agar assays: Soft agar assays were performed by resuspending $10^{4} \mathrm{MCF}-10 \mathrm{~A}$ cells in standard soft agar mix $(0.5 \mathrm{~mL}$ penicillin/streptomycin (Corning), $1.8 \mathrm{~mL} 10 \mathrm{X}$ PBS, 1.6mL serum (Gibco), 30mL DMEM/F12 medium (Corning), 16mL melted agar (Difco)) and plating them on a pre-hardened $0.7 \%$ agar base in 12 -well plates (Cellstar). Anchorage-independent growth was determined by manually counting the number of colonies formed in agar 2 weeks after plating the cells. 
Senescence assays: $\beta$-galactosidase assays were performed using a BioVison kit (BioVision). $10^{4}$ MCF-10A cells were plated in 12 -well plates, fixed with $0.5 \mathrm{~mL}$ of fixing solution for $15 \mathrm{~min}$ at room temp, washed twice with $1 \mathrm{X}$ PBS, and stained overnight at $37 \mathrm{C}$ with $0.5 \mathrm{~mL}$ staining solution $(470 \mu \mathrm{L}$ staining reagent, $5 \mu \mathrm{L}$ staining supplement, $25 \mu \mathrm{L}$ of $20 \mathrm{mg} / \mathrm{mL}$ X-Gal in DMF). Senescent cells were observed and imaged using an IX50 inverted system microscope (Olympus) with a UPlanFl $4 \times / 0.13$ $\mathrm{PhL}$ or LCPlanF1 20×/0.40 Ph1 objective (Olympus).

Anoikis assays: Anoikis assays were performed as described in [119] [120]. Tissue culture wells of a 12-well plate (Cellstar) were coated with $12 \mathrm{mg} / \mathrm{ml}$ Poly-HEMA (Sigma-Aldrich) in $95 \%$ ethanol (BDH) and allowed to dry overnight. $2 \times 10^{5} \mathrm{MCF}-10 \mathrm{~A}$ cells/well in $1 \mathrm{~mL}$ growth medium were added to each well and plates were incubated at 37C for 48 hours. Apoptosis induction through loss of cell attachment was measured by mixing $0.5 \mathrm{~mL}$ of cell suspension with $0.1 \mathrm{~mL}$ of $0.4 \%$ Trypan Blue solution (Life Technologies), filling a hemocytometer, and manually counting the number of viable and non-viable cells. These results were compared to viability counts for control cells grown simultaneously in 12 -well plates without Poly-HEMA coating.

Replication stress: To induce replication stress, HEK-293T cells were treated with $2 \mathrm{mM}$ hydroxyurea (Sigma-Aldrich) in cell culture media for 6 hours as described in [121].

Comet assays: Sub-confluent MCF-10A cells were treated with doxorubicin hydrochloride (0.3 $\mu \mathrm{g} / \mathrm{mL}$; Sigma-Aldrich) for 24 hours to induce DNA damage. DNA damage was then assayed using a CometAssay Kit (Trevigen). Cells were harvested and resuspended at $1 \times 10^{5}$ in sterile PBS, and combined at a ratio of 1:10 with molten 
LMAgarose. $50 \mu \mathrm{L}$ of the cell/agarose mixture was plated on a CometSlide and allowed to cool for $30 \mathrm{~min}$ at $4 \mathrm{C}$. Slides were then immersed in $4 \mathrm{C}$ lysis solution for 1 hour, and then immersed in Alkaline Unwinding solution $(0.4 \mathrm{~g} \mathrm{NaOH}, 250 \mu \mathrm{L} 200 \mathrm{mM}$ EDTA, $49.75 \mathrm{~mL} \mathrm{dH}_{2} \mathrm{O}$ ) for 1 hour at room temperature in a sealed plastic Coplin staining jar. Slides were then placed immersed in $\sim 800 \mathrm{~mL}$ Alkaline Electrophoresis solution $(8 \mathrm{~g}$ $\mathrm{NAOH}, 2 \mathrm{~mL} 500 \mathrm{mM}$ EDTA, $1 \mathrm{~L} \mathrm{dH}_{2} \mathrm{O}$ ) in an electrophoresis tray and power supply was set to 21 volts for $\sim 30$ minutes. Electrophoresis solution was drained from slides, and they were gently immersed $2 \times 5$ min in $\mathrm{H}_{2} \mathrm{O}$ and then $1 \times 5 \mathrm{~min}$ in $70 \% \mathrm{EtOH}$. Slides were then dried for $\sim 45$ minutes at $37 \mathrm{C}$ and the dried agarose was stained with $100 \mu \mathrm{L}$ of SYBR green DNA stain (ThermoFisher Scientific) for $30 \mathrm{~min}$ at room temp in the dark. Slides were tapped gently to remove excess stain, rinsed briefly in $\mathrm{dH}_{2} \mathrm{O}$ and allowed to dry completely at $37 \mathrm{C}(\sim 30 \mathrm{~min})$. Slides were then visualized on an Olympus fluorescence inverted microscope or an Evos FL Cell Imaging System (ThermoFisher Scientific) at 100x magnification. Comet tails from 100 (randomly selected) cells were scored using OpenComet software for ImageJ based on their DNA content (intensity) [122]. DNA damage was quantified as comet tail moment, defined as the product of the tail length and the fraction of total DNA in the tail.

Fluorescent microscopy: GFP and RFP proteins were visualized at room temperature in live cells in growth medium using an IX50 inverted microscope (Olympus) with a UPlanF1 100×/1.3 oil immersion objective (Olympus) and a SPOT camera (Diagnostic Instruments Inc.)

\section{Antibodies.}


Monoclonal and polyclonal NORE1A antibodies have been described previously [36]. The PAS 17072 NORE1A antibody was used at 1:500 dilution in 5\% powdered milk + TBST. Mouse monoclonal HA antibodies (used at 1:5k dilution in 5\% milk + TBST) were obtained from Covance, and mouse monoclonal GFP and BRCA1 antibodies (1:200 dilution in 5\% milk + TBST) were from Santa Cruz Biotechnology, Inc. Mouse monoclonal $\beta$-actin antibodies (1:10k dilution in 5\% milk + TBST) were obtained from Sigma-Aldrich. Rabbit polyclonal p21 and Her2 (1:1k dilution in 5\% BSA + TBST) antibodies were obtained from Cell Signaling Technology. Mouse monoclonal c-Myc (1:5k dilution in $5 \%$ milk + TBST) antibodies were obtained from Thermo Scientific. Goat anti-mouse and anti-rabbit secondary antibodies conjugated to peroxidase (used at 1:10k-20k dilution in TBST) were obtained from Thermo Fisher Scientific.

\section{Western analysis and immunoprecipitation.}

Signaling assays: MCF-10A cells were seeded at confluence and grown in a $37 \mathrm{C}$ incubator overnight. Cells were lysed in $100 \mu \mathrm{L}$ RIPA buffer (Sigma-Aldrich) with sodium orthovanadate (Sigma-Aldrich) and protease inhibitor cocktail (Sigma-Aldrich cat \# P8340) added just prior to lysis, and the concentration of protein in the lysates was quantified using a Bio-Rad protein assay (Bio-Rad) using a spectrophotometer (abs: 595). Equal amounts of protein lysate were combined 1:1 with Laemmli Sample Buffer (BioRad) and 16-20 $\mu \mathrm{L}$ total was loaded onto a 4-15\% Tris-glycine gel (Bio-Rad) and run for $\sim 1 \mathrm{hr}$ at 120 volts using a Mini-PROTEAN electrophoresis system (Bio-Rad). Gels were then transferred at $4 \mathrm{C}$ for $\sim 4$ hours at 20 volts to a $0.2 \mu \mathrm{m}$ nitrocellulose membrane (BioRad). Membranes were blocked at room temperature for $1 \mathrm{hr}$ in $5 \%$ powdered milk + 
TBST solution and incubated in the appropriate primary antibody $(1: 200-1: 10,000)$ in $5 \%$ milk + TBST or $5 \%$ BSA + TBST solution overnight at $4 \mathrm{C}$, washed $5 \times 5$ min in TBST (Tris-buffered saline (Corning), 0.1\% Tween 20 (Sigma-Aldrich)), incubated with the appropriate secondary antibody $(1: 10,000-1: 20,000)$ in TBST for $1 \mathrm{hr}$, and washed again for $5 \times 5 \mathrm{~min}$ in TBST. Nitrocellulose membranes were then incubated in $4 \mathrm{~mL}$ of Pierce ECL solution $(2 \mathrm{~mL}$ of stable peroxide solution $+2 \mathrm{~mL}$ of luminol/enhancer solution; Thermo Scientific, Rockford, IL) for 2-5 minutes with constant rocking, placed inside a standard film cassette and developed using X-Ray film (MidSci, Valley Park, MO).

Co-immunoprecipitation: Cells were lysed in 100-200 $\mu \mathrm{L}$ modified RIPA buffer $(150 \mathrm{mM}$ $\mathrm{NaCl}, 50 \mathrm{mM}$ Tris (Cellgro), $\mathrm{pH} 7.5,1 \%$ Tergitol NP-40 (Sigma-Aldrich)) with protease inhibitors added prior to lysis as above. Precleared lysates were immunoprecipitated overnight with GFP-Trap agarose beads (Allele Biotech, San Diego CA) or primary antibody as appropriate and washed $3 \times 3$ min with lysis buffer, then Western blotted as above.

\section{Image acquisition and processing.}

All images were scanned and quantified using a Pharos FX plus Molecular Imager (BioRad) and Quantity One software (Bio-Rad) or ImageJ software. Linear range was determined for individual antibodies by plotting the quantitated densities of Western blotted bands against the initial amount of protein lysate loaded in each lane. To control for variability, the background-subtracted densities of each protein of interest and normalizing control (e.g. beta-actin) were quantified and protein of interest values were 
divided by relative normalized control values in their respective lanes. For quantitative experiments, each condition was performed in duplicate or triplicate as described. For statistical comparison, one-way analysis of variance (ANOVA) was used to determine if mean differences existed across groups (ctrl, shB, shN, shBN) following each experimental condition. The null hypothesis used was that all means were equal. If at least two means were identified as significantly different (critical value method $=F>F$ crit or $\mathrm{p}$-value method $=\mathrm{p}<0.05)$, post hoc Student's t-tests were applied. Averages, $\mathrm{p}$ values, and fold-changes were calculated and the results graphed using Excel (Microsoft). Images were compiled using PowerPoint (Microsoft) or Photoshop (Adobe). 


\section{CHAPTER V: NORE1A AND BRCA1 FORM A HER2-REGULATED ENDOGENOUS COMPLEX}

\section{INTRODUCTION}

Ras is constitutively activated in breast cancer.

Mutational activation of the Ras oncogene is found in $\sim 1 / 3$ of all human cancers, making Ras the most common oncogene in human cancer [123]. Ras mutations are infrequent in breast cancer [48]-[50]; however, persistent upstream signaling by the growth factor receptor Her2 results in constitutive activation of wild-type Ras in $\sim 25$ $30 \%$ of human breast cancers [11]-[13]. Mutations in Ras GAPs (e.g. NF1, RASAL2, and DAB2IP) lead to constitutive Ras activation in up to $50 \%$ of human breast cancers [14]-[16]. Thus, the Ras signaling pathway is hyperactivated in a large percentage of all human breast cancers.

Her2 and Ras activation can drive senescence or transformation.

Constitutive activation of Ras drives growth and transformation by binding and activating multiple effectors that stimulate various mitogenic pathways, the best characterized of which are the Raf and PI3K pathways [17]. Accordingly, activation of Her2 can also promote transformation via Ras signaling pathways [11], [52], [124], [125]. Paradoxically, activation of Her2 and Ras can also promote cellular senescence, an irreversible cell growth arrest [30], [59]. This oncogene-induced senescence represents an 
early barrier to Her2/Ras transformation, and is thus an important tumor suppressor mechanism in vivo [126]. In order to become cancerous, cells must acquire mutations or epigenetic changes that allow them to subvert the senescence program. The mechanism by which activated Her2/Ras drives senescence and how this is bypassed during transformation remains poorly understood [127].

NORE1A is a critical Ras senescence effector.

NORE1A (RASSF5) is a member of the Ras-association domain family (RASSF) of tumor suppressors that binds activated Ras and mediates its growth inhibitory properties [36][81][86]. NORE1A is frequently downregulated in primary human tumors and breast cancer cell lines by promoter hypermethylation [65], and a translocation involving NORE1A is associated with a hereditary human cancer syndrome [85]. Thus, NORE1A acts as a tumor suppressor, though its mode of action in tumor suppression and Ras-mediated growth inhibition remains poorly understood.

NORE1A lacks enzymatic activity and has been shown to act as a scaffolding molecule [36]. Similar to other RASSF proteins, NORE1A can bind the proapoptotic MST kinases which begin the canonical Hippo pathway [80]. However, the interaction with MST is not required for NORE1A tumor suppressor activity [81], suggesting that other interactions are key to this function. Although NORE1A overexpression can induce apoptosis, when expressed at more physiological levels NORE1A induces cell cycle arrest by promoting the p53-mediated activation of p21 [40].

In the presence of activated Ras, NORE1A acts as a critical component in Rasmediated senescence signaling to p53 [36]. NORE1A facilitates Ras senescence by 
scaffolding p53 in a nuclear complex with the kinase HIPK2 that mediates the prosenescent acetylation of p53 [36]. Loss of NORE1A (at least, partially) uncouples Ras from p53 and abrogates its ability to induce senescence [36], [40]. Consequently, loss of NORE1A expression can facilitate senescence bypass and transformation in response to activated Ras signaling.

\section{BRCA1 plays a role in Her2/Ras senescence}

Oncogene-induced senescence is often characterized by the accumulation of DNA double strand breaks (DSBs) [109], [126]. This is largely due to replication fork stalling and collapse caused by aberrant DNA replication in response to hyperactive Ras signaling [126]. Under normal conditions, DNA DSB accumulation would lead to initiation of checkpoint activation, cell cycle arrest, and formation of DNA repair complexes at stalled replication forks mediated by the breast cancer susceptibility protein BRCA1 [128]. However, activation of Her2/Ras suppresses BRCA1-mediated DNA repair [64][111]. Oncogene-induced hyperproliferation in the absence of BRCA1 DNA repair mechanisms produces sufficient replication stress and accumulation of DNA DSBs to initiate a senescence response [64][111]. The role of BRCA1 in Her2/Ras-mediated senescence remains ill defined [129], as currently no direct mechanism of communication between Ras and BRCA1 has been identified.

\section{Summary}

Both NORE1A and BRCA1 mediate Ras senescence, modulate p21 expression, and are downregulated in breast cancer. The connection between Her2/Ras and BRCA1 
is not known. I decided to examine the possibility that NORE1A might connect Ras (and therefore, Her2) to BRCA1. Using activated Her2 as a model of constitutive Ras signaling, I now show that NORE1A and BRCA1 form a physiological, Her2-regulated complex in human cells. In response to aberrant Her2/Ras signaling, NORE1A appears to localize BRCA1 to stalled replication forks. Thus, the cellular levels of NORE1A may dictate how Ras mediates the localization and function of BRCA1. Moreover, the interaction with BRCA1 may regulate the tumor suppressor activity of NORE1A in breast cancer. 


\section{RESULTS}

\section{NORE1A and BRCA1 co-localize in the nucleus.}

NORE1A functions as a scaffolding molecule, and has been shown to promote the nuclear localization and activation of the tumor suppressor p53 [40]. BRCA1 contains two nuclear localization sequences (NLS) that mediate its transport from the cytosol to the nucleus (Figure 7). The nuclear localization of BRCA1 is important for its tumor suppressor ability [130], as loss of this localization renders BRCA1 unable to participate in DNA repair and subsequently leads to an increase in unrepaired mutations and chromosomal abnormalities [91]. Accordingly, in nearly all primary breast tumors and breast cancer cell lines that express BRCA1, it is largely localized in the cytoplasm [131]. To determine if NORE1A expression could alter the subcellular localization BRCA1, I overexpressed RFP-tagged NORE1A and YFP-tagged BRCA1 in HEK-293T cells. Figure 9 shows that BRCA1 and NORE1A co-expression shifted a fraction of total cellular BRCA1 into nuclear foci with NORE1A, suggesting that NORE1A is recruiting BRCA1 to these nuclear foci.

Although breast cancer seldom exhibits Ras mutations, mutation or overexpression of the upstream Ras activator Her2 occurs in $25-30 \%$ of all breast cancers [12]. NORE1A is a direct effector of Ras, and BRCA1 has also been shown to play a role in Ras signaling [64]. To determine whether Her2 (and thus Ras) signaling could regulate NORE1A/BRCA1 co-localization, I overexpressed a constitutively activated Her2 mutant (V659E) in HEK-293T cells with my fluorescently tagged NORE1A and BRCA1. Figure 9 shows that addition of Her2 (V659E) enhanced the size of the observed nuclear foci 
formed by NORE1A/BRCA1 co-localization, suggesting that Her2/Ras signaling enhances the ability of NORE1A to recruit BRCA1 to the nucleus.

Activation of oncogenes like Her2 or Ras promotes hyperproliferation, which can lead to replication stress induced by deoxyribonucleotide pool depletion [132][133]. BRCA1 responds to this replication stress by forming protein complexes at stalled replication forks to protect and repair damaged DNA [134]. Since NORE1A can promote the nuclear localization of BRCA1 in the presence of activated Her2 signaling, I wondered if these proteins were co-localizing at stalled replication forks in response to oncogene-induced replication stress. To determine if this was the case, I treated cells coexpressing YFP-BRCA1 and RFP-NORE1A with 2mM hydroxyurea (HU) for 6 hours, as described in [135]. HU depletes cells of dNTP pools, which slows/stalls replication machinery, generating a replication stress response [135]. Thus, HU treatment promotes replication stress via a similar mechanism as activated Her2/Ras. Figure 9 shows that hydroxyurea-induced replication stress enhanced NORE1A/BRCA1 co-localization at nuclear foci. 
Figure 9: NORE1A and BRCA1 co-localize after replication stress.

HEK-293T cells were transfected with GFP-vector or YFP-tagged BRCA1 and RFPNORE1A, in the presence or absence of Her2 (V659E), and images were captured 24 hours later using a fluorescence microscope (magnification $=1000 \mathrm{x}$ ). A group of cells were also treated with $2 \mathrm{mM}$ hydroxyurea (HU) for 6 hours.

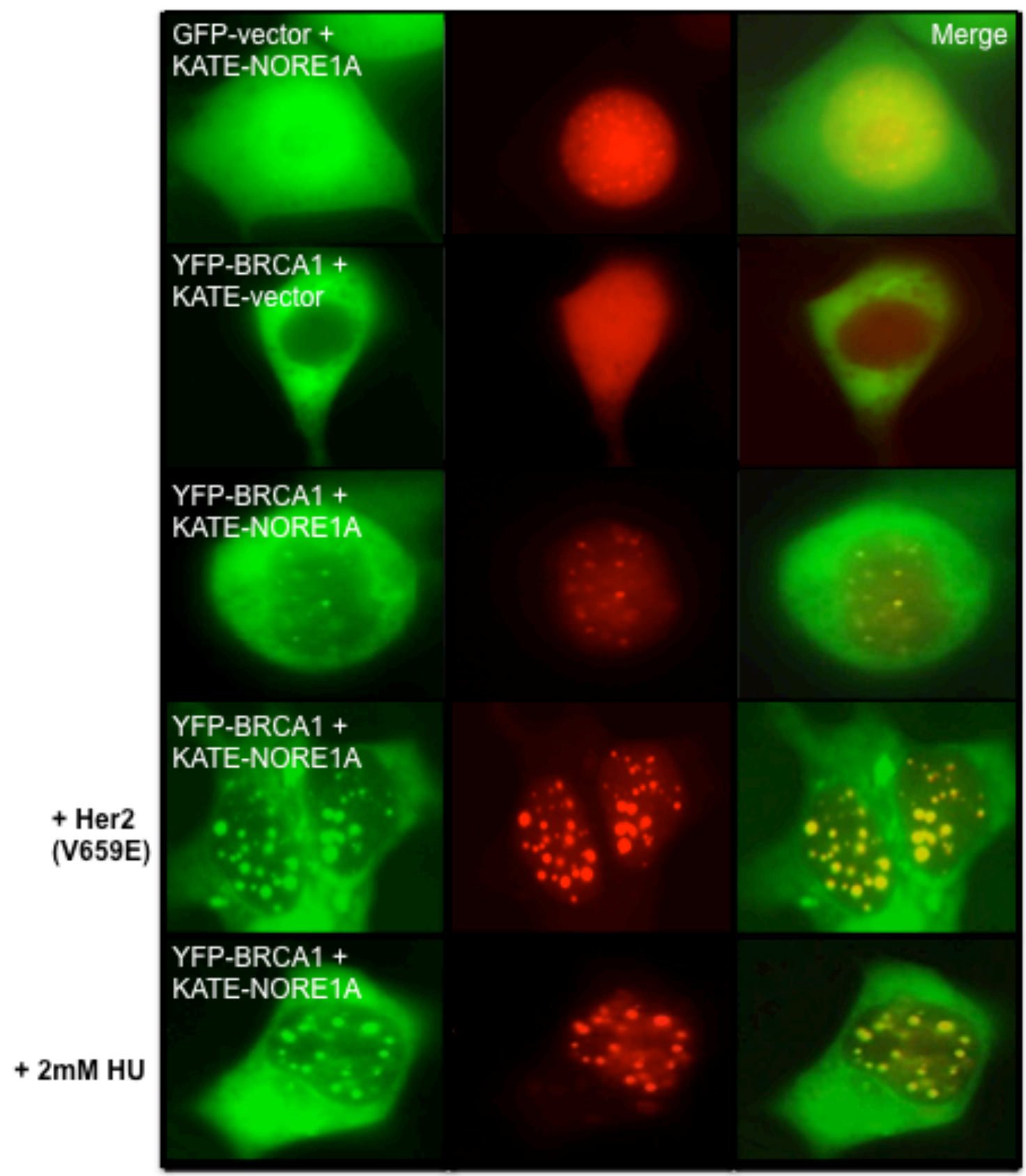




\section{NORE1A and BRCA1 form an endogenous Her2 and Ras-regulated complex.}

NORE1A is a direct Ras effector that mediates the growth inhibitory properties of Ras. BRCA1 functions as a tumor suppressor by forming protein complexes in the cell important for maintaining genome integrity [91], and can also play a role in Her2/Ras signaling [64][111]. Currently, no direct mechanism of communication between Ras and BRCA1 has been discovered. Since I observed NORE1A recruiting BRCA1 to nuclear foci in response to activated Her2 (and thus Ras) signaling, I wondered whether Her2 could regulate their complex formation. This would suggest the existence of a Her2/Ras/BRCA1 signaling pathway.

To determine if NORE1A and BRCA1 could form a physiological complex in human mammary cells, I stably transfected MCF-10A cells with Her2 (V659E) or a vector control, immunoprecipitated cell lysates with NORE1A, and immunoblotted for BRCA1. In the absence of activated Her2 I was able to detect a modest association between endogenous NORE1A and BRCA1 proteins. However, when cells were stably transfected with activated Her2, the association of endogenous NORE1A with endogenous BRCA1 was greatly enhanced (Figure 10A). As further confirmation, exogenous expression of NORE1A and BRCA1 in HEK-293T cells challenged with activated Ras (K12V) or Her2 (V659E) gave similar results (Figure 10B). 


\section{Figure 10: NORE1A and BRCA1 form a Her2 and Ras-regulated complex.}

(A) Equal amounts of protein lysate from MCF-10A human breast epithelial cells stably transfected with Her2 (V659E) or a vector control were immunoprecipitated (IP) with anti-NORE1A antibody, fractionated on an SDS-polyacrylamide gel, and then immunoblotted (IB) for the presence of BRCA1 in the complex. Cell lysate immunoprecipitated with IgG alone and lysis buffer immunoprecipitated with NORE1A antibody were used as negative controls. (B) HEK-293T cells were transiently transfected with either YFP-tagged BRCA1 or HA-tagged NORE1A in the presence or absence of KRas12V or Her2 (V659E) expression constructs. Cells were lysed 24 hours after transfection and equal amounts of protein were immunoprecipitated for GFP. The immunoprecipitate was fractionated on an SDS-polyacrylamide gel and then immunoblotted with anti-HA and anti-GFP antibodies. Fold change was calculated after normalizing to total HA-NORE1A expression levels in addition to total BRCA1 expression levels. Figure is representative of 2 independent experiments. 
A

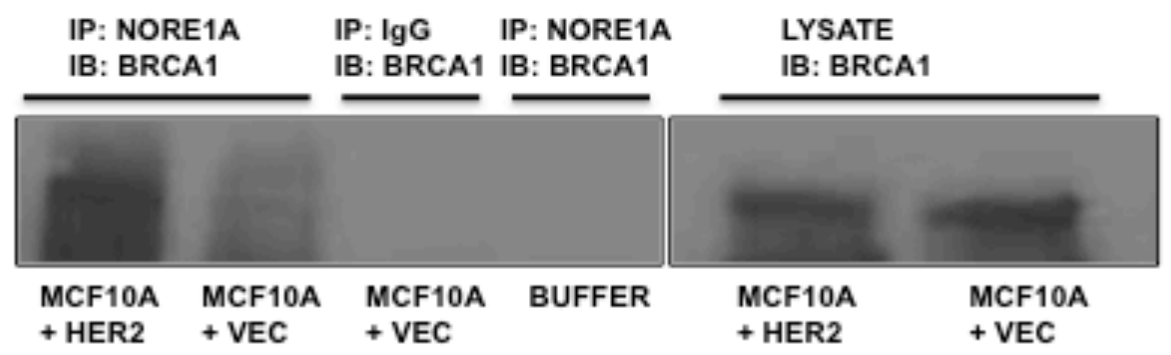

B

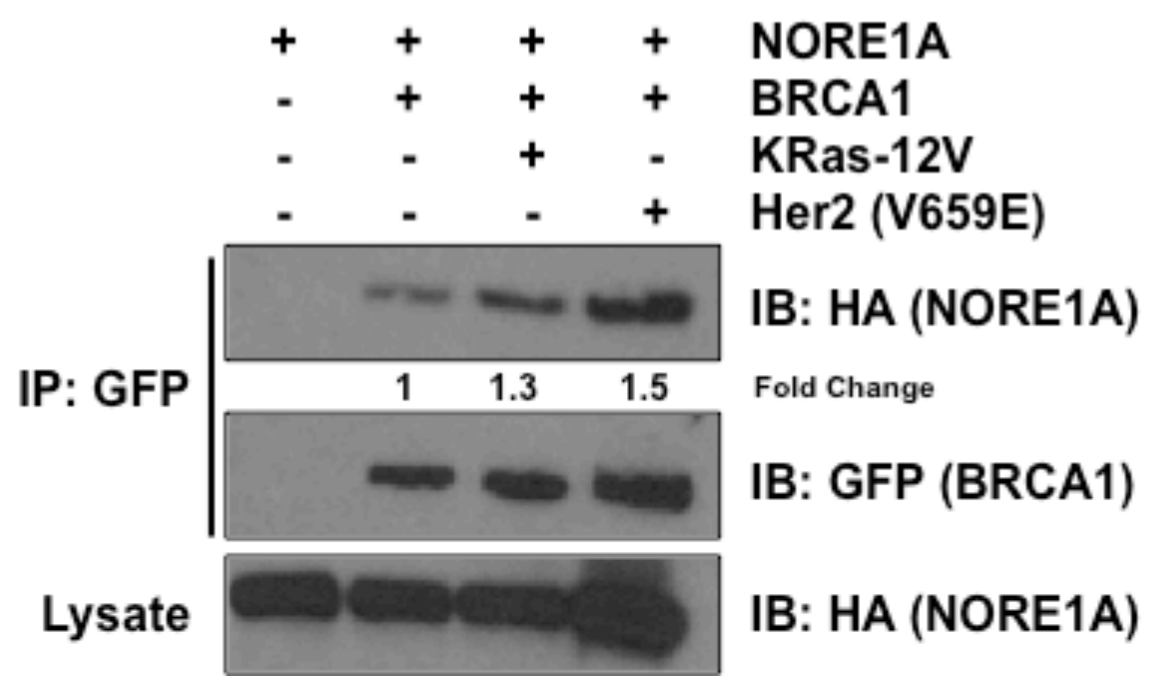




\section{BRCA1 binds the INT-domain of NORE1A.}

NORE1A has several protein binding domains that have been identified, including a Ras-binding domain and C-terminal SARAH domain that binds the MST kinases (Figure 5). In addition, NORE1A contains a stretch of $\sim 100$ aa that lies between the DAG/PE binding domain and Ras-association (RA) domain which my laboratory has termed the intermediate (INT) domain (Figure 11A). This domain is relatively uncharacterized, but does contain several putative phosphorylation sites, as predicted by the Netphos tool (sensitivity 69-96\%) [136]. These include S177 (score $=87 \%$ ), S182 (99\%), T186 (87\%), T202 (98\%), and S260 (99\%).

To further characterize the interaction between NORE1A and BRCA1, I cooverexpressed serial deletions of NORE1A with full-length BRCA1 in HEK-293T cells. I determined that BRCA1 could interact with the INT domain of NORE1A (Figure 11B). Since the INT domain is a fragment of the full-length NORE1A protein that can bind BRCA1, I hypothesized that it could be used as a dominant-negative for the NORE1A/BRCA1 interaction. Specifically, that overexpression of the INT domain might block the binding of full-length NORE1A to BRCA1. Since NORE1A and BRCA1 act as tumor suppressors in the cell, I hypothesized that blocking their interaction could have a transforming effect on cells.

To determine whether overexpression of the INT-domain had an effect on the morphology or growth of non-transformed cells, I stably overexpressed the INT-domain into MCF-10A human mammary epithelial cells, which are non-transformed. I observed that overexpression of the INT-domain in these cells caused them to exhibit a transformed phenotype, as indicated by their enhanced ability to grow under anchorage- 
independent conditions in soft agar compared to control MCF-10A cells (Figure 11C). Thus, overexpression of a fragment of the tumor suppressor NORE1A-that I have shown can bind BRCA1 — had a transforming effect. This is, to my knowledge, the first identification of a transforming capacity in a RASSF tumor suppressor. This result also implies that blocking the NORE1A/BRCA1 interaction could be transforming. Further experiments are required to determine if this is the case. 


\section{Figure 11: BRCA1 binds the INT-domain of NORE1A.}

(A) Location of the NORE1A-INT domain within the full-length NORE1A protein and its $\sim 100$ AA sequence. Asterisks indicate potential S/T phosphorylation sites (score $>97 \%$ [136]). (B) HEK-293T cells were transiently transfected with either GFP-tagged BRCA1 or NORE1A-INT expression constructs. Cells were lysed 24 hours after transfection and equal amounts of protein were immunoprecipitated (IP) for GFP. The immunoprecipitate was fractionated on an SDS-polyacrylamide gel and then immunoblotted (IB) with anti-HA and anti-GFP antibodies. (C) MCF-10A cells stably transfected with HA-vector or HA-tagged NORE1A-INT domain were plated in soft agar and grown for 2 weeks at 37C. Representative images are from 2 independent experiments performed in duplicate. 
A NORE1Aa (418aa)

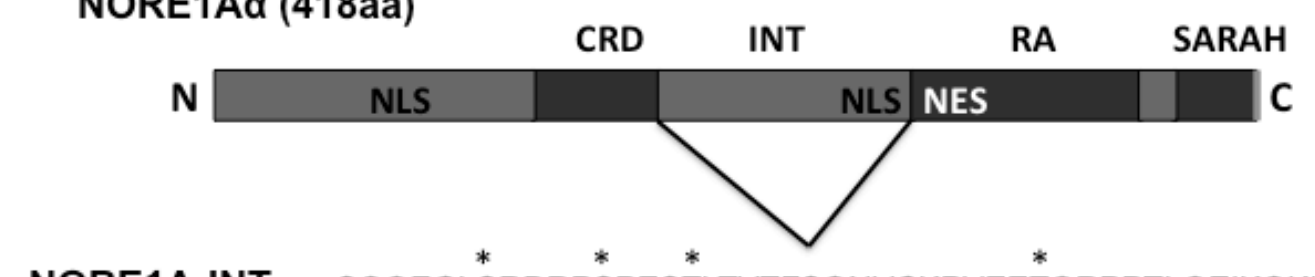

NORE1A-INT SQQEGLSRDRPPSPESTLTVTFSQNVCKPVEETQRPPTLQEIKQKIDSYNT domain (100 AA) REKNCLGMKLSEDGTYTGFIKVHLKLRRPVTVPAGIRPQSIYDAIKEVNLA

B

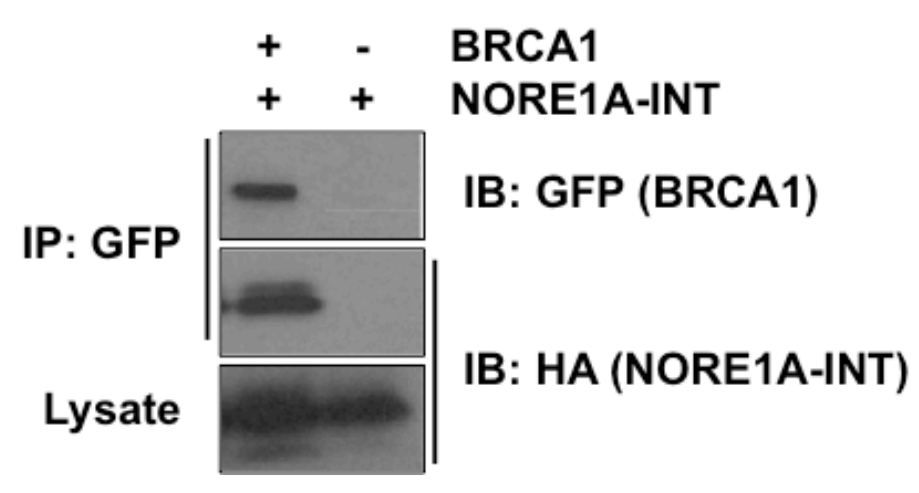

C

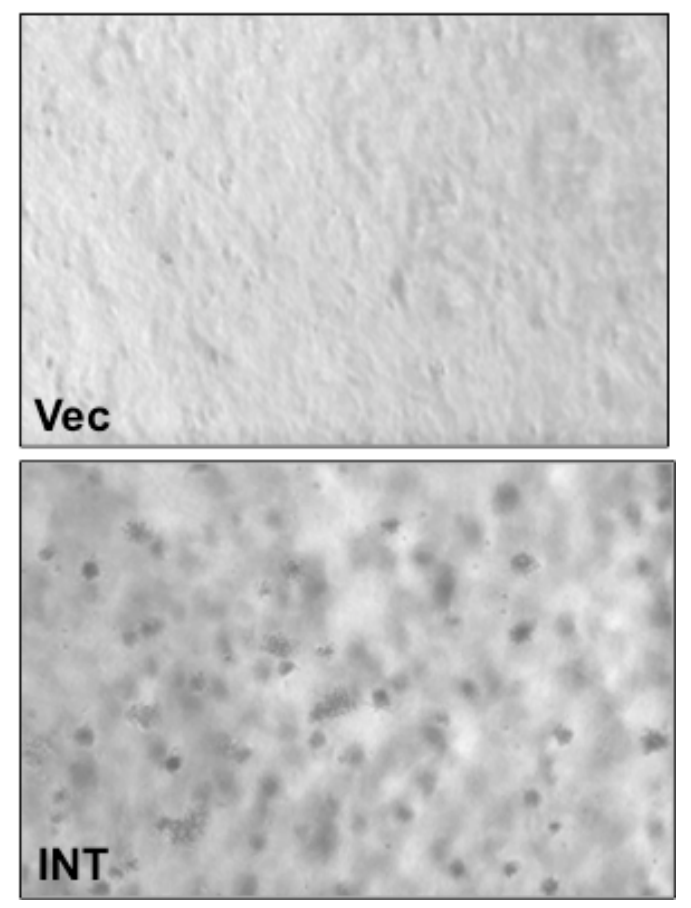




\section{DISCUSSION}

Ras is the most frequently mutated oncogene in human cancer. The low percentage of breast cancers with Ras mutations led to the theory that Ras does not play an important role in breast tumorigenesis [11]. However, the Ras signaling pathway is constitutively activated in over half of all breast tumors due to persistent upstream signaling by the EGFR family member Her2 [11], [124], [125] or certain Ras GAPs [14]$[16]$.

Her2 overexpression is an early-occurring and highly transforming event in breast cancer [52]. Her $2^{+}$breast cancers usually have much worse prognosis and propensity for metastasis than non-Her2 breast cancers [55]-[57]. The majority of $\mathrm{Her} 2^{+}$primary breast tumors have lost expression of the tumor suppressor BRCA1 [115], [116]. This is paradoxical, as Her2 or Ras-mediated inactivation of BRCA1 in non-transformed cells promotes senescence [64], [111]. Therefore, additional oncogenic mutations must be occurring that are allowing these $\mathrm{Her} 2^{+} / \mathrm{BRCA}^{-}$cells to bypass senescence and undergo transformation.

The most important tumor suppressor function of BRCA1 is its ability to localize to the nucleus in response to replication stress and participate in DNA repair [137]. In nearly all primary breast tumors and breast cancer cell lines that retain BRCA1 expression, it is predominantly localized to the cytoplasm [131]. I have shown that Her2 overexpression can promote the nuclear localization of BRCA1 in human tumor cells. In addition, Her2 promoted the co-localization of BRCA1 with the Ras effector NORE1A. NORE1A has been shown to act as a nuclear localization factor for the tumor suppressor 
p53 [40]; thus, I hypothesized that NORE1A was recruiting BRCA1 to the nucleus in response to aberrant Her2/Ras activation.

NORE1A appears to be acting as a direct communication link between BRCA1 and Ras signaling. I showed that NORE1A forms an endogenous, Her2/Ras-regulated complex with BRCA1 that mediates its subcellular localization. Thus, the interaction between these two proteins is physiological, though whether it is occurring directly or as part of a larger DNA repair complex remains to be determined.

I mapped the BRCA1 binding domain down to a $\sim 100$ amino acid region of the full-length NORE1A protein that my laboratory termed the NORE1A-INT domain. This domain was previously shown to be indispensible for NORE1A-mediated growth inhibition [81]. However, the mechanism of action of the INT domain remains to be fully investigated. Using an artificial neural network that predicts phosphorylation sites [136], I found several putative consensus phosphorylation sites for $\mathrm{S} / \mathrm{T}$ kinases within the INT domain, suggesting that it may serve as a potential interaction site of NORE1A with numerous kinases. Two of these consensus phosphorylation sites (T202 and S260) are particularly interesting, as NORE1A contains a nuclear localization sequence in this region of the INT domain (aa 200-260). Phosphorylation of NORE1A has been shown to regulate its subcellular localization, and subsequently its function within the cell [73][75]. Thus, kinase interactions within the INT domain could regulate the subcellular localization of NORE1A. This could explain previous reports that the INT domain was indispensible for growth inhibition [81].

My observation that overexpressing the INT domain in MCF-10A nontransformed human breast epithelial cells caused these cell to exhibit a transformed 
phenotype is, to my knowledge, the first identification of a transforming capacity in a RASSF tumor suppressor. One possibility is that the INT domain is competing with fulllength NORE1A for binding to BRCA1, and overexpressing the INT domain is effectively blocking the NORE1A/BRCA1 interaction. Whether blocking the NORE1A/BRCA1 interaction is transforming is not known; however, this could be determined by knocking down expression of NORE1A and BRCA1 in a non-transformed cell line.

BRCA1 and NORE1A are both frequently inactivated in human tumors by promoter hypermethylation [65], [66]. The rate of their co-inactivation in breast cancer is not known. I hypothesize that co-inactivation of NORE1A and BRCA1 would result in decreased senescence induction by activated Her2/Ras, likely contributing to the worse prognosis seen in Her $2^{+}$breast tumors. The expression status of NORE1A/BRCA1 in these tumors may be difficult to determine by methylation analysis alone, as NORE1A can also be regulated at the mRNA [138] and protein levels [139]. Protein array analysis from breast tissue tumor samples would be necessary to determine more accurate NORE1A/BRCA1 expression levels.

Thus, I identify a novel Her2-Ras-NORE1A-BRCA1 pathway that links activated Her2 and Ras signaling to BRCA1. This pathway has the potential to be constitutively activated in over half of all breast cancers due to the high frequency of aberrant Her2/Ras activation in these cancers.

I propose a scenario in which NORE1A and BRCA1 form a complex to repair or maintain integrity of stalled replication forks in response to the increase in proliferation stimulated by physiological Her2/Ras activation. The role of NORE1A/BRCA1 complex 
formation in Her2/Ras-mediated human breast tumorigenesis remains to be determined. Since NORE1A and BRCA1 act as barriers to Ras transformation, loss of complex formation between these tumor suppressors could shift the balance of Her2/Ras signaling from pro-senescent to pro-tumorigenic during breast cancer formation. 
CHAPTER VI: NORE1A AND BRCA1 FORM A TUMOR SUPPRESSOR COMPLEX

\section{INTRODUCTION}

Constitutive Her2/Ras activation can drive senescence or transformation.

Constitutive activation of Ras signaling pathways occurs in over half of all breast cancers, for the most part due to mutation or amplification of its upstream activator Her2 [11]-[16]. Up to $90 \%$ of Her $2^{+}$sporadic breast tumors are negative for BRCA1 expression, and these tumors have a worse prognosis and poorer survival rate than nonHer2 ${ }^{+}$tumors [115], [116]. The underlying paradox is that Her2/Ras activation or BRCA1 inactivation in normal cells promotes senescence [59], [64]. Thus, loss of additional senescence regulators must be occurring that are driving these cells toward malignancy.

Aberrant activation of Her2/Ras induces hyperproliferation, which triggers a DNA damage response that drives premature senescence in cells as a precaution against malignant transformation [109], [140]. This oncogene-induced senescence induction is characterized by an upregulation of certain tumor suppressor pathways, like the p53-p21 and $\mathrm{p} 16-\mathrm{Rb}$ pathways.

Once cells have become immortalized, their response to activated Ras signaling changes. For example, activation of Her2 and Ras in MCF-10A human mammary epithelial cells (which have reactivated telomerase [141]) promotes the biomarkers of 
senescence (e.g. enhanced SA- $\beta$-gal activity and upregulation of $\mathrm{p} 21)$ yet fails to trigger irreversible growth arrest [62]. This state of incomplete senescence (referred to as the SWING state by Sherman et al.) is stable, and is suggested to be an intermediary step between activation of oncogenes and cellular senescence or transformation [62]. Accordingly, cells residing in the SWING state can be manipulated to senesce or transform via enhanced genotoxic stress or loss of p53-p21 signaling [62].

\section{Her2/Ras senescence requires activation of 211.}

Her2/Ras-driven senescence is dependent on the upregulation of $\mathrm{p} 21$, and does not occur in p21- or p53-knockdown cells [142]. Similarly, formation of the intermediary SWING state in MCF-10A cells is dependent on Her2/Ras-induced upregulation of p21 [62][111]. Thus, in order for immortalized MCF-10A cells (which lack p16) to bypass senescence, they must lose the ability to activate $\mathrm{p} 21$.

Expression of p21 is tightly controlled by the tumor suppressor p53, through which p21 mediates $\mathrm{G}_{1}$ cell cycle arrest in response to various cellular stressors [143]. In response to oncogene activation, $\mathrm{p} 53$ becomes activated and transactivates p 21 to drive senescence [144], [145]. Nuclear localization of p53 is critical for its transactivation function, and its sequestration in the cytoplasm has been observed in human tumors [146].

The tumor suppressor and Ras senescence effector NORE1A plays a key role in regulation of the cell cycle by p53-p21 signaling. In response to Ras activation, NORE1A binds p53 and promotes its nuclear localization, leading to the upregulation of $\mathrm{p} 21$ and induction of senescence [36], [40]. NORE1A loss in primary human tumors has been 
shown to tightly correlate with loss of p21 expression [40]. Thus, NORE1A is critical regulator of Ras senescence that connects Ras to p53-p21 signaling.

Overexpression of the DNA repair protein BRCA1 can also regulate $\mathrm{p} 53 / \mathrm{p} 21$ signaling. BRCA1 interacts directly with p53 [63] and can act as a coactivator of p21 transcription in response to DNA damage [147]. Interestingly, loss of expression of BRCA1 can also activate p53-p21 signaling by triggering a DNA damage response that promotes senescence [64]. This appears to be part of a controlled suicide response to oncogene activation, as both aberrant Her2 and Ras signaling can promote BRCA1 inactivation [64], [111]. Thus, under physiological conditions BRCA1 can activate p53p21 signaling to temporarily stall the cell cycle, and under aberrant conditions BRCA1 loss activates p53-p21 signaling to shut down the cell cycle.

The "Goldilocks" response and senescence

Both activation of Her2/Ras and inactivation of BRCA1 can drive senescence [62], [64], [111], [148]. In other words, cells are programmed to commit suicide in response to genomic stressors like "too much" oncogene (Her2/Ras) activation or "too little" tumor suppressor (BRCA1) expression in order to avoid malignancy. This effect where senescence is initiated in response to elevated Her2/Ras or inactivated BRCA1 is hereafter referred to as the "Goldilocks" response.

I provided evidence in Chapter $\mathrm{V}$ that suggested the existence of a Her2/Ras/NORE1A/BRCA1 signaling pathway. NORE1A is required for senescence after Ras activation [41]. Since Her2 lies upstream of Ras and signals through Ras pathways [11], [12], I was curious to determine if NORE1A could monitor the senescent response to Her2 activation via the same pathway. Since I showed that NORE1A could 
link BRCA1 to Ras signaling, I also wondered whether NORE1A was required for BRCA1 to drive senescence after oncogene activation. Thus, I hypothesized that NORE1A was monitoring the "Goldilocks" response that drives oncogene-induced senescence.

\section{Summary}

In the preceding chapter I introduced a physiological, Her2/Ras regulated interaction between NORE1A and the breast cancer associated protein BRCA1. Her2/Ras-mediated inactivation of BRCA1 was shown to enhance p21 expression and promotes senescence [64], [111]. I hypothesized that inactivation of NORE1A would impair this Her2/Ras/BRCA1 senescence pathway.

I show here that NORE1A inactivation suppresses Her2 ${ }^{+}$senescence, and that dual inactivation of NORE1A and BRCA1 has a synergistic effect on Her2/Ras transformation. Furthermore, I show that dual inactivation of NORE1A and BRCA1 is sufficient to transform MCF-10A cells in the absence of additional stimuli. This is due in part to anoikis resistance in these cells. This data suggests that NORE1A monitors the "Goldilocks" response to Her2/Ras activation and BRCA1 inactivation; NORE1A expression must be "just right", or cells cannot activate apoptosis or senescence in response to these stressors and instead will become transformed. 


\section{RESULTS}

\section{Generation of NORE1A/BRCA1 stable double knockdown cells.}

I showed previously that NORE1A and BRCA1 form a Her2/Ras-regulated complex in MCF-10A cells. To examine the role of NORE1A and BRCA1 complex formation in neoplastic transformation of these cells, I generated a matched set of stable NORE1A/BRCA1 double knockdown clones by sequential shRNA vector transduction, which resulted in $80 \%$ BRCA1 depletion in BRCA1 knockdown cells, 60\% NORE1A depletion in NORE1A knockdown cells, and 91\% NORE1A and 96\% BRCA1 depletion in the double knockdown cells (Fig. 12A). Standard growth analysis revealed that individual depletion of NORE1A or BRCA1 enhanced the proliferation of MCF-10A cells $\sim 1.5$-fold and $\sim 2.5$ fold, respectively, compared to vector control cells, and dual depletion of NORE1A and BRCA1 had an additive effect (Fig. 13). This suggests that dual inactivation of these proteins is having an effect on cell cycle regulation. 
Figure 12: Generation of MCF-10A knockdown cell lines.

(A) Western blot analysis of NORE1A and BRCA1 expression in MCF-10A immortalized human mammary epithelial cells. Expression levels of NORE1A and BRCA1 were quantified after sequential stable transduction of shRNA against NORE1A or BRCA1 or a scrambled control into these cells. The density of the bands was quantified using ImageJ software and relative BRCA1 or NORE1A expression was calculated after normalizing to $\beta$-actin expression. (B) Western blot analysis of Her2 expression in shBRCA1/shNORE1A MCF-10A cells. Her2 (V659E) was stably overexpressed in the matched set of MCF-10A knockdown cells from (A) and its expression was validated by Western blot.

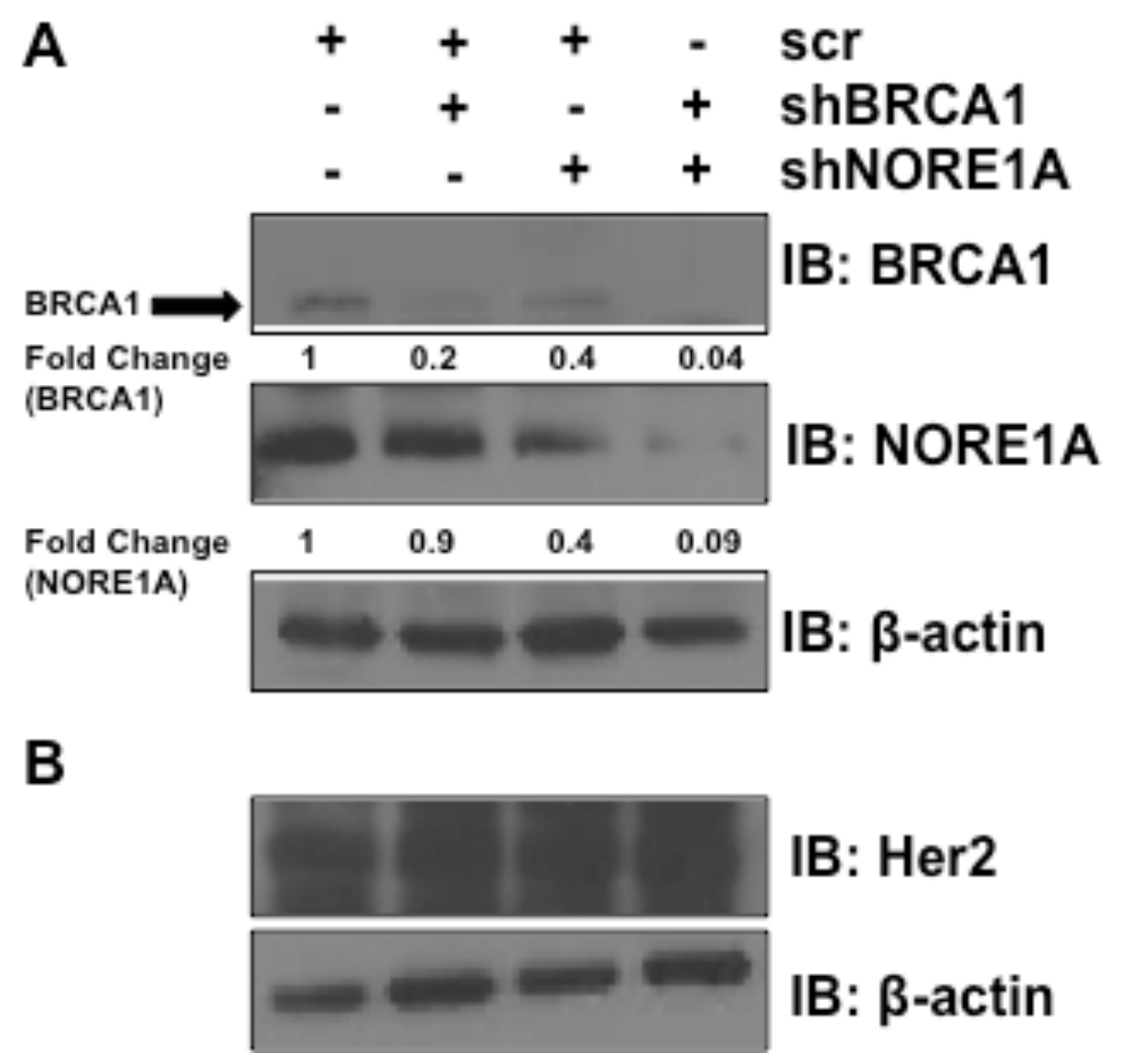


Figure 13: Depletion of NORE1A or BRCA1 enhances growth of MCF-10A cells.

Matched sets of knockdown MCF-10A cells were plated at $2 \times 10^{4}$ and grown in $2 \mathrm{D}$ culture for 4 days. Cells were trypsinized and counted each day. (bottom) Relative changes in growth between each set at Day 4 expressed as a bar graph. Data represent the mean \pm SD of duplicate experiments. Data that are significantly different are indicated by asterisks as follows: ${ }^{*}, P<0.05$ compared to vector control; **, $P<0.05$ compared to shNORE1A (One-way ANOVA followed by Student's t-test).
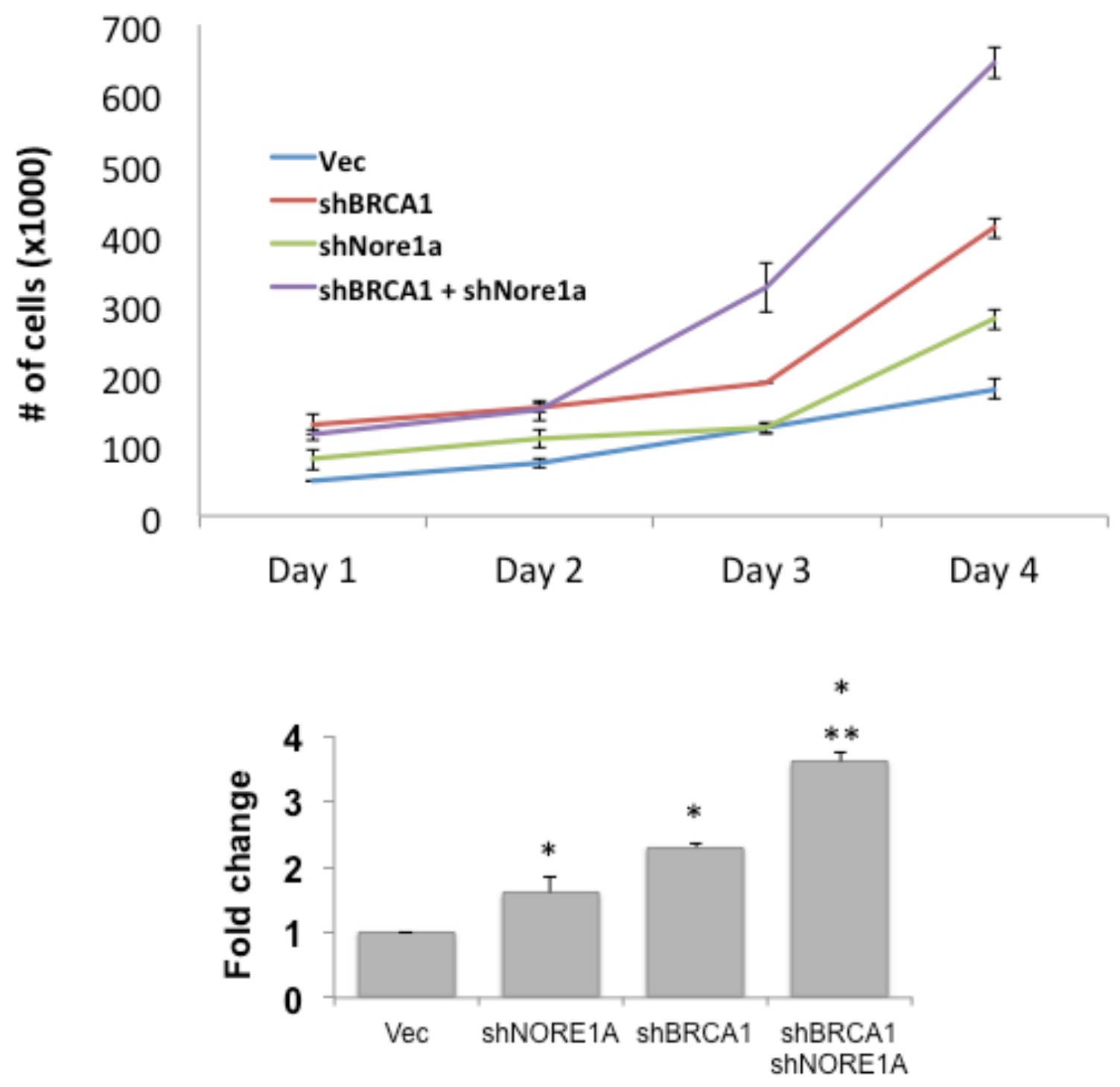


\section{NORE1A depletion suppresses Her2 ${ }^{+}$senescence.}

Activated Her2/Ras signaling has been shown to promote the phenotype of senescence (as measured by enhanced SA- $\beta$-gal activity and p21 expression) in MCF10A cells [62]. NORE1A is required for Ras to induce senescence [36]. Her2/Ras signaling to BRCA1 was also shown to promote senescence via upregulation of p21 [64], [111].

I showed in Chapter V that NORE1A acts as a communication link between Ras and BRCA1. I was therefore curious to determine whether inactivation of NORE1A would disrupt senescence signaling between Her2/Ras and BRCA1.

To determine whether NORE1A depletion blocks the ability of Her2 to communicate with BRCA1 and induce senescence, I stably overexpressed a constitutively active Her2 mutant (V659E) in my matched set of NORE1A/BRCA1 ${ }^{-}$ MCF-10A cells (Figure 12B). These Her2 ${ }^{+}$cells were then grown for 48 hours and assayed for senescence induction as measured by $\beta$-galactosidase activity and p21 expression.

NORE1A inactivation suppressed the ability of Her2 to induce senescence, as indicated by a reduction in SA- $\beta$-gal activity in $\mathrm{Her}^{+} / \mathrm{NORE}^{-} \mathrm{A}^{-}$cells. $\mathrm{Her}^{+} / \mathrm{BRCA}^{-}$ cells showed a $\sim 65 \%$ increase in SA- $\beta$-gal activity compared to Her $2^{+}$control cells, and co-depletion of NORE1A completely suppressed the BRCA1 effect (Figure 14A). $\mathrm{Her}^{+} / \mathrm{NORE}^{-} \mathrm{A}^{-} / \mathrm{BRCA}^{-}$cells also showed a synergistic reduction in $\mathrm{p} 21$ expression (Figure 14B). Interestingly, NORE1A inactivation did not show a significant reduction in p21 expression compared to control cells. This could be explained by differences in NORE1A knockdown levels in our NORE1A` cells compared to NORE1A/BRCA1 ${ }^{-}$cells 
(60\% knockdown and 91\% knockdown, respectively). Additionally, BRCA1 inactivation did not enhance expression of p21 compared to control cells. This was surprising, as BRCA1 knockdown has been shown to drive senescence via upregulation of both p21 and p16 [149]. This suggests that BRCA1 inactivation is driving senescence independent of p53-p21 signaling in our system; possibly via upregulation of p16 or Rb. Further experiments are required to determine if this is the case. 
Figure 14: NORE1A depletion suppresses senescence in Her2+/BRCA1- cells.

(A) shBRCA1 (shB) and shNORE1A (shN) MCF-10A Her2 ${ }^{+}$cells were grown in 12-well plates and $\beta$-galactosidase activity was quantified after 24 hours. The percent increase over Her $2^{+}$control cells was measured. Data represent the mean $\pm \mathrm{SD}$ of triplicate experiments. *, $\mathrm{P}<0.05$ compared to scrambled control; **, $\mathrm{P}<0.05$ compared to shBRCA1 (one-way ANOVA followed by Student's t-test). (Bottom) A representative image of senescence induction in each set of cells. (B) Double knockdown of NORE1A/BRCA1 synergistically suppresses p21. (Bottom) Western blot analysis of p21 expression from shBRCA1/shNORE1A MCF-10A Her2 ${ }^{+}$cells. The density of the bands was quantified using ImageJ software and relative p21 expression was quantified after normalizing to $\beta$-actin. (Top) Relative p21 levels expressed as a bar graph. Data represent the mean $\pm \mathrm{SD}$ of three independent experiments. ${ }^{*}, \mathrm{P}<0.05$ compared to scrambled control; **, $\mathrm{P}<0.05$ compared to shBRCA1 (one-way ANOVA followed by students ttest). 
A
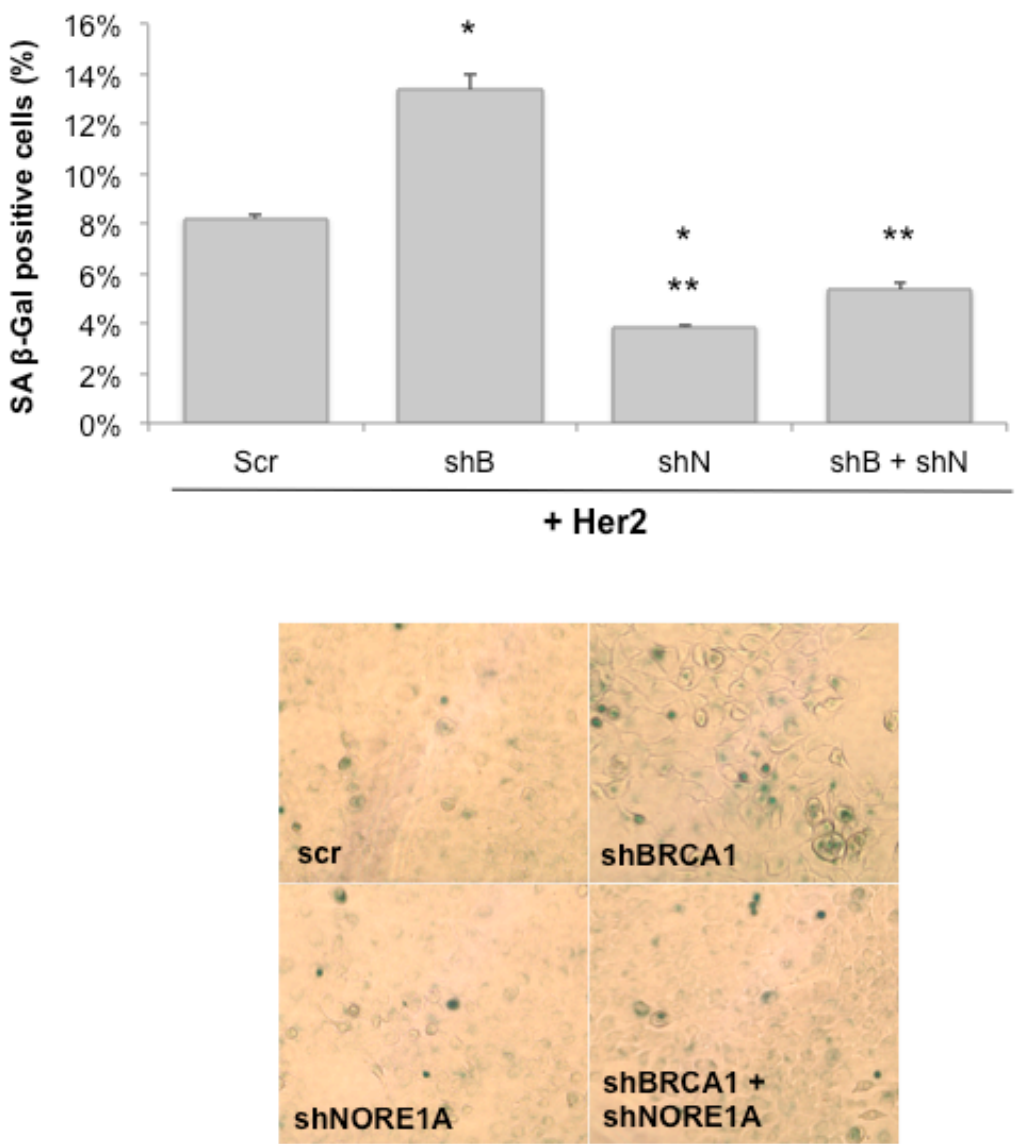

B
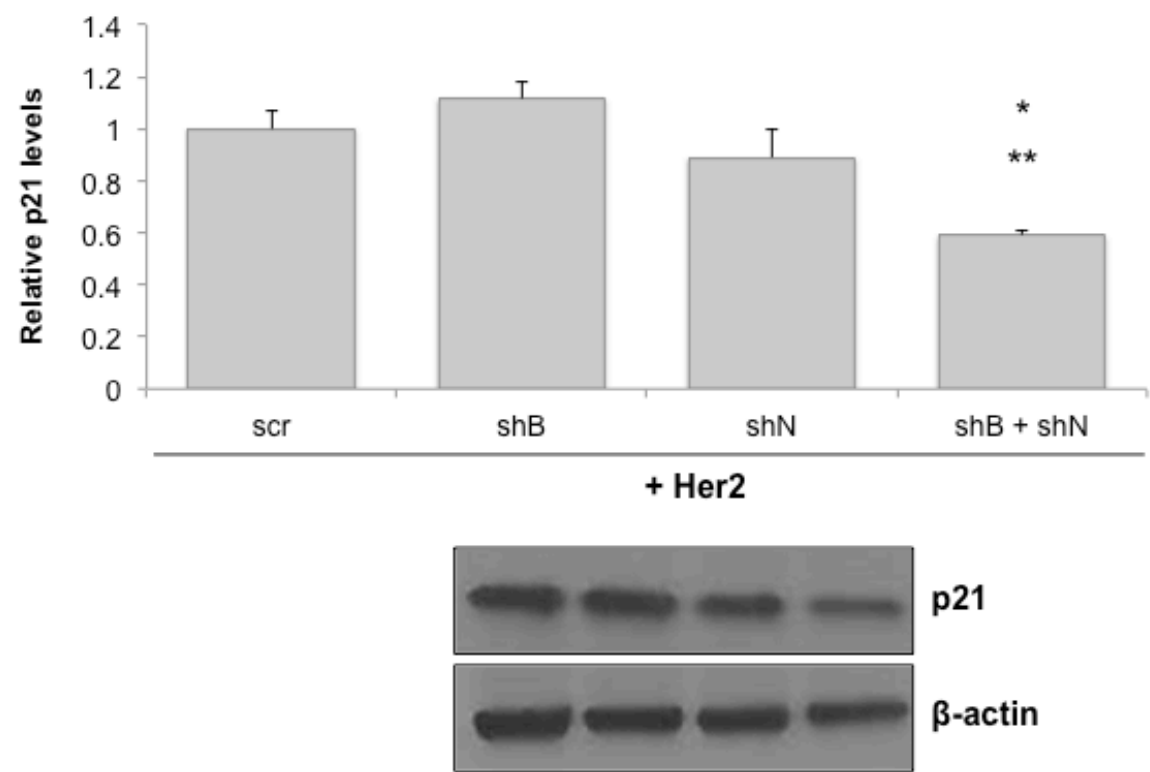

$\beta$-actin

$\begin{array}{llll}1 & 1.1 & 0.9 & 0.6\end{array}$ 


\section{NORE1A and BRCA1 co-depletion enhances Her2/Ras transformation.}

Activation of Her2/Ras in immortalized cells promotes the phenotype of senescence, yet these cells can still proliferate and undergo anchorage-independent growth [61], classic indicators of malignant transformation. I showed earlier that codepletion of NORE1A and BRCA1 in MCF-10A cells had an additive effect on their proliferation rate. I was curious to determine if this increase in proliferation corresponded with an enhanced ability to grow in soft agar. Individual knockdown of NORE1A or BRCA1 did not permit the anchorage-independent growth of MCF-10A cells $(<7$ colonies/well). However, double knockdown of NORE1A and BRCA1 was sufficient to transform MCF-10A cells (> 40 colonies/well) (Figure 15). This is reminiscent of the transforming effect that the NORE1A-INT domain had on these cells (Figure 11C).

Her2 overexpression alone was sufficient to promote anchorage-independent growth of my control MCF-10A cells (> 40 colonies/well). Furthermore, co-depletion of NORE1A and BRCA1 synergistically enhanced colony formation in my Her2 ${ }^{+}$cells $(\sim 6-$ fold increase over Her2 ${ }^{+}$control cells) (Figure 15). 
Figure 15: NORE1A and BRCA1 co-depletion enhances MCF-10A growth in soft

agar.

shBRCA1 (shB) and shNORE1A (shN) MCF-10A cells with and without Her2overexpression $\left(\mathrm{Her}^{+}\right)$were plated in soft agar and grown for 2 weeks at 37C. Data represent the mean $\pm \mathrm{SD}$ of 3 independent experiments.

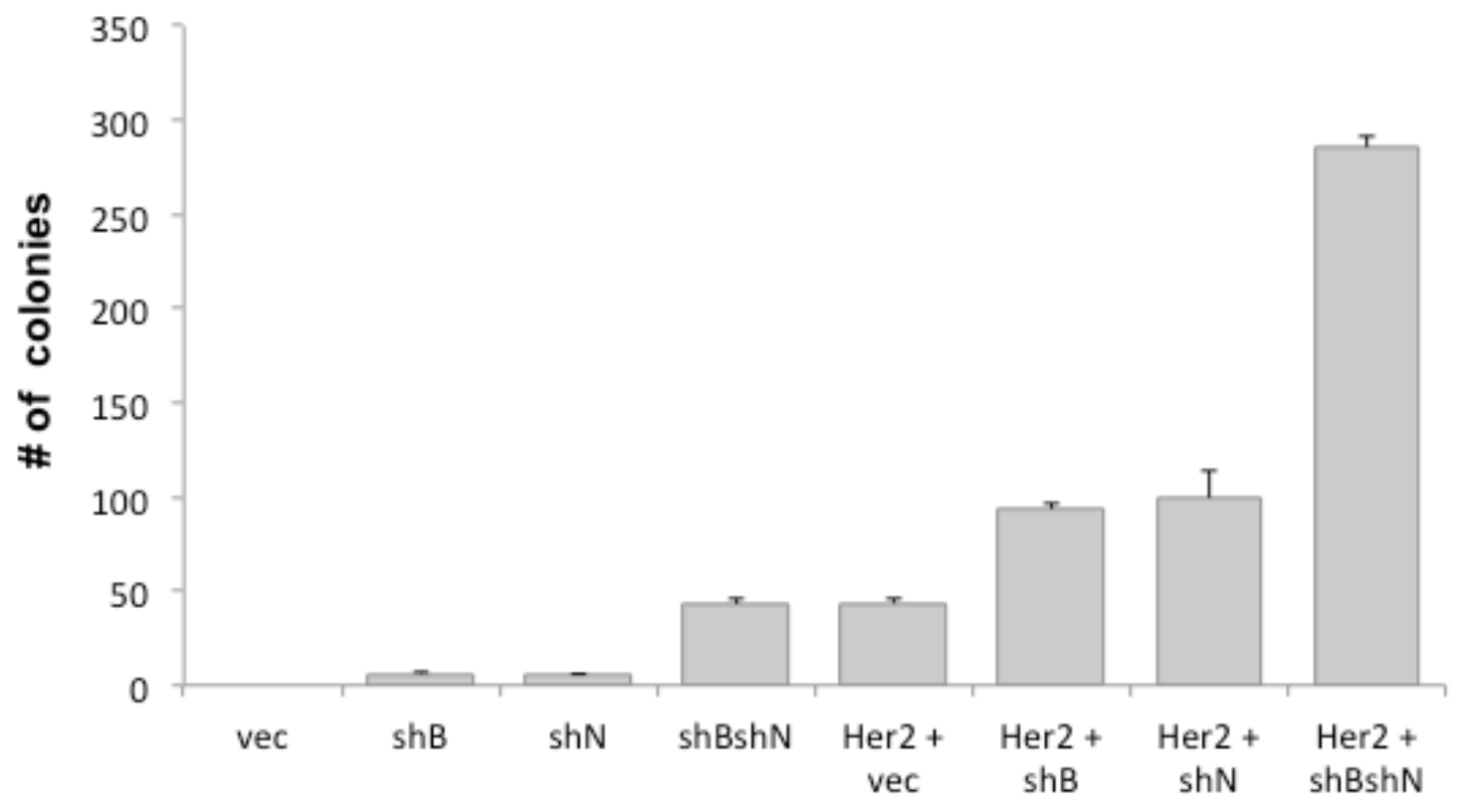




\section{NORE1A depletion suppresses anoikis.}

In order for cells to become transformed they must be able to continue proliferating and also avoid cell death. I showed earlier in this chapter that NORE1A and BRCA1 loss enhances the proliferation of MCF-10A cells, and that dual inactivation of NORE1A and BRCA1 was sufficient to promote the growth of these cells in soft agar, a marker of malignant transformation. NORE1A has a well-studied role in apoptosis [34], [38]. Thus, I hypothesized that NORE1A loss could be conferring apoptosis resistance to these cells.

Epithelial cells require contact with the surrounding extracellular matrix (ECM) in order to send and receive signals essential for their growth and survival [120]. Loss of ECM attachment can cause cells to undergo a matrix deprivation-induced apoptosis termed anoikis [151]. The acquisition of anoikis resistance allows cells to grow under anchorage-independent conditions [152], and is a crucial step in Ras-mediated breast tumorigenesis [52].

To determine whether NORE1A ${ }^{-} \mathrm{MCF}-10 \mathrm{~A}$ cells were resistant to anoikis, I grew the NORE1A'/BRCA1 ${ }^{-}$MCF-10A matched set of cells in suspension culture for 48 hours and assayed for total survival, or resistance to anoikis. Cell survival was enhanced by $\sim 200 \%$ in NORE1A knockdown cells and $\sim 285 \%$ in NORE1A/BRCA1 double knockdown cells (Figure 16). Cell survival was not significantly altered by BRCA1 knockdown. Thus, the effect of NORE1A on anoikis appears to be BRCA1-independent. 
Figure 16: NORE1A depletion confers anoikis resistance.

shBRCA1 (shB) and shNORE1A (shN) MCF-10A cells were grown in suspension for 48 hours and cell viability was determined by Trypan blue exclusion assay. Percentage of cell survival is represented as mean $\pm \mathrm{SD}$ from 3 independent experiments. ${ }^{*}, P<0.05$ compared to scrambled control (One-way ANOVA followed by Student's t-test).

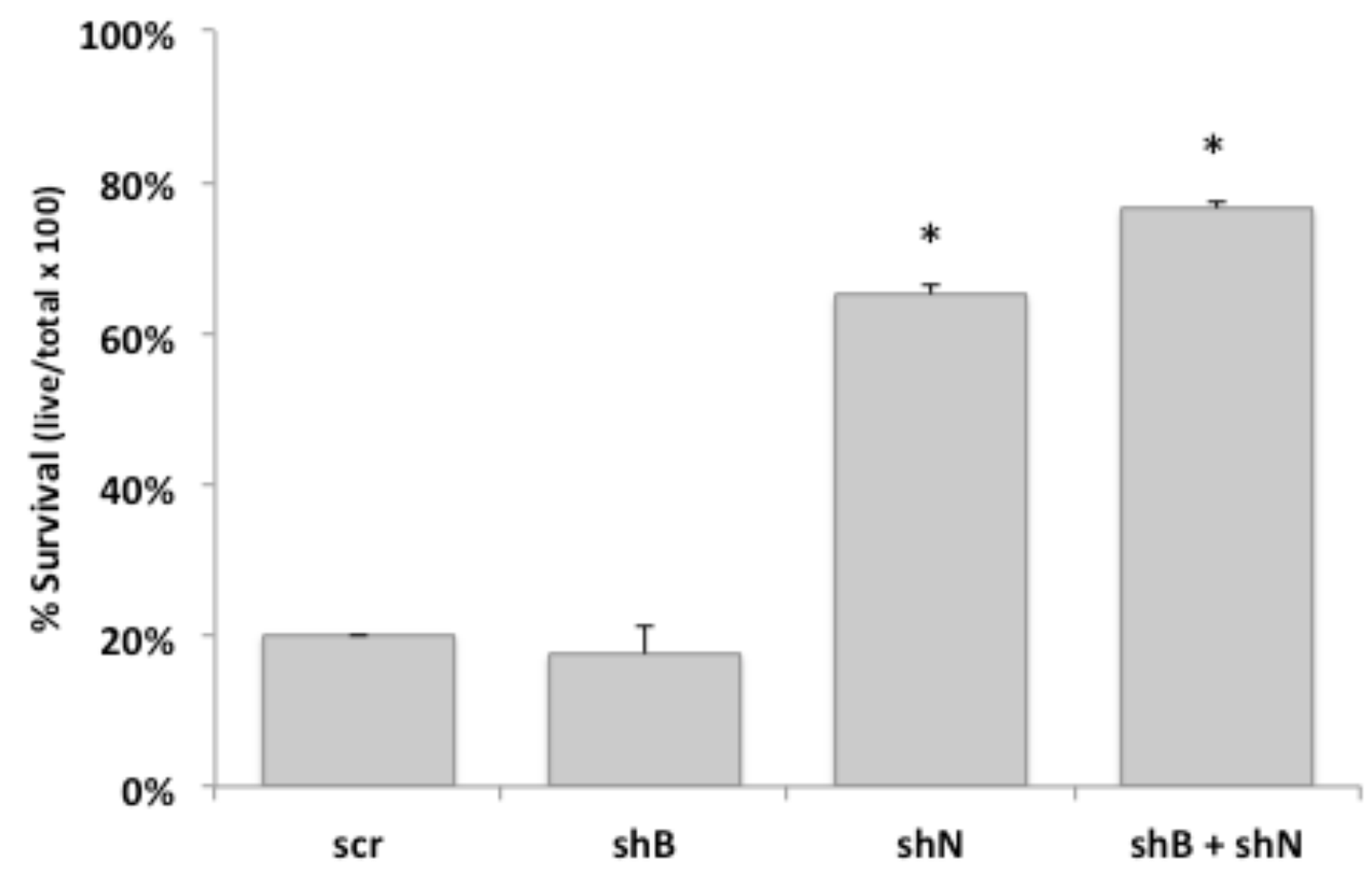




\section{DISCUSSION}

Oncogene-induced senescence occurs as a result of cells permanently disabling their cell cycle machinery via activation of multiple tumor suppressor signaling pathways, such as the p53-p21 and p16-Rb pathways [140]. Both NORE1A and BRCA1 play a role in Ras-induced senescence [36], [64], and can interact with p53 to promote p21 activation [40], [147]. Using immortalized, non-transformed MCF-10A human breast epithelial cells, I successfully established a viable model of constitutive Her2/Ras activation that allowed us to examine the effects of NORE1A and BRCA1 inactivation on senescence induction by these oncogenes.

Her2-overexpression has been reported to promote the senescent phenotype (enhanced SA- $\beta$-gal activity, upregulated p21 expression) in MCF-10A cells [62]. Upon oncogene activation, these cells have been shown to reside in a relatively stable intermediary state until increasing levels of stress drive them to fully senesce or transform [62]. For example, BRCA1 loss after Her2/Ras activation triggers a DNA damage response that promotes senescence [64], [111]. The fact that inactivation of a tumor suppressor can trigger growth arrest may seem counter-intuitive. However, this is actually part of a controlled suicide response initiated by cells that lose BRCA1 in order to avoid becoming malignant in the absence of adequate DNA repair mechanisms [148], and has been observed after loss of other tumor suppressors besides BRCA1, such as the Von Hippel-Lindau (VHL) protein [153]. Activation of Her2/Ras facilitates BRCA1 inactivation for this purpose: as a senescence fail-safe mechanism to protect cells with activated Her2/Ras from malignant transformation. 
I discovered that NORE1A depletion disrupted the ability of Her2 expression and BRCA1 loss to induce senescence. This verifies the existence of a Her2/Ras/NORE1A/BRCA1 senescence-signaling pathway, and demonstrates that NORE1A inactivation is essential for cell survival after BRCA1 expression is lost. Thus, NORE1A loss allows the tumorigenic effects of Her2/Ras and BRCA1 dysregulation (e.g. accumulation of mutations caused by enhanced proliferation in the absence of errorfree DNA repair) to manifest and provides cells with the ability to subvert apoptosis and senescence. In effect, NORE1A appears to be monitoring the "Goldilocks" response; "too little" BRCA1 or "too much" Her2/Ras causes death as long as NORE1A expression is "just right". Loss of NORE1A disables this response, facilitating transformation (Figure 17).

Tumorigenesis is a multi-stage process comprised of the accumulation of cellular, genetic, and epigenetic alterations over time [154]. These alterations allow normal cells to progress to malignancy by overcoming pro-senescent and pro-apoptotic signaling after Her2/Ras activation. Since NORE1A and BRCA1 are both tumor suppressors, I hypothesized that their complex formation could play a role in tumor suppression.

Consistent with Knudson's two-hit hypothesis [155], inactivation of NORE1A or BRCA1 alone was not sufficient to transform immortalized MCF-10A cells into cancer cells in vitro, suggesting that additional oncogenic hits must be required. Interestingly, dual inactivation of NORE1A and BRCA1 was sufficient to transform MCF-10A cells, as I hypothesized would occur based on the transforming effects of the NORE1A-INT domain in these cells. Her2 overexpression greatly enhanced the level of transformation 
observed in NORE1A/BRCA1 ${ }^{-}$cells. Thus, I conclude that NORE1A and BRCA1 form a tumor suppressor complex that can protect cells from Her2/Ras transformation.

An important marker of malignant transformation is the ability of cells to grow under anchorage-independent conditions. A crucial step in obtaining anchorageindependent growth is acquiring resistance to matrix deprivation-induced apoptosis, which is referred to as anoikis [152]. Non-transformed MCF-10A cells undergo anoikis when they lose matrix attachment, whereas Her2/Ras-transformed MCF-10A cells will continue to proliferate [156][157]. This Her2/Ras-induced anoikis resistance was reported to be due in part to activation of the Raf-ERK pathway [157], [158]. However, additional analysis on breast carcinoma cells suggests that neither ERK nor AKT activation are necessary for Ras inhibition of anoikis [52]. Thus, additional Ras signaling pathways are likely involved.

I hypothesized that the pro-apoptotic Ras effector NORE1A might play a role in Ras-mediated anoikis resistance. I discovered that depletion of NORE1A conferred anoikis resistance to MCF-10A cells. Thus, in addition to facilitating senescence bypass after Ras activation, NORE1A inactivation also provides cells a means to subvert apoptotic signaling.

Under normal conditions, constitutive Her2/Ras signaling drives senescence by triggering a DNA damage response [109], [126]; or, as a fail-safe mechanism, by inactivating BRCA1-mediated DNA repair [64], [111]. Any Her2/Ras-positive cells that survive the senescent response and continue to proliferate will undergo anoikis before they can metastasize. If NORE1A is inactivated, neither these pro-senescent nor proapoptotic pathways can be initiated in response to Her2/Ras activation. Consequently, 
Ras-induced hyperproliferation is allowed to continue in the absence of proper DNA repair mechanisms, contributing to the accumulation of cancer-causing mutations. Thus, NORE1A inactivation facilitates Her2/Ras-driven tumor formation by allowing cells to continually proliferate without the barriers of apoptosis or senescence. The frequency of NORE1A inactivation in breast cancers ( 40\%) [65] could therefore offer an explanation for the high incidence of Ras activation ( $\sim 50 \%)$ observed in sporadic breast cancers.

In conclusion, I propose that NORE1A is part of the surveillance machinery that monitors a "Goldilocks" response to Her2/Ras activation or BRCA1 inactivation: In the case of "too much" oncogene (Ras) or "too little" tumor suppressor (BRCA1) expression, NORE1A levels must be "just right" in order to prevent tumor formation (Figure 17). Since NORE1A and BRCA1 co-localize in response to replication stress, and loss of NORE1A appears to be altering the cellular response to BRCA1, it is possible that NORE1A plays a role in the BRCA1-mediated response to replication stress. Experiments examining the effect of NORE1A expression on BRCA1-mediated DNA repair could thus reveal a physiological role for their complex formation. 
Figure 17: NORE1A monitors "Goldilocks" response to Her2/Ras/BRCA1

Earlier, I described a "Goldilocks" model for senescence whereby NORE1A monitors senescence induction in response to constitutive activation of Her2/Ras (i.e. "too much" oncogene) or inactivation of BRCA1 (i.e. "too little" tumor suppressor). NORE1A expression must be "just right" to monitor senescence, as loss of NORE1A expression disables this effect and promotes tumorigenesis.

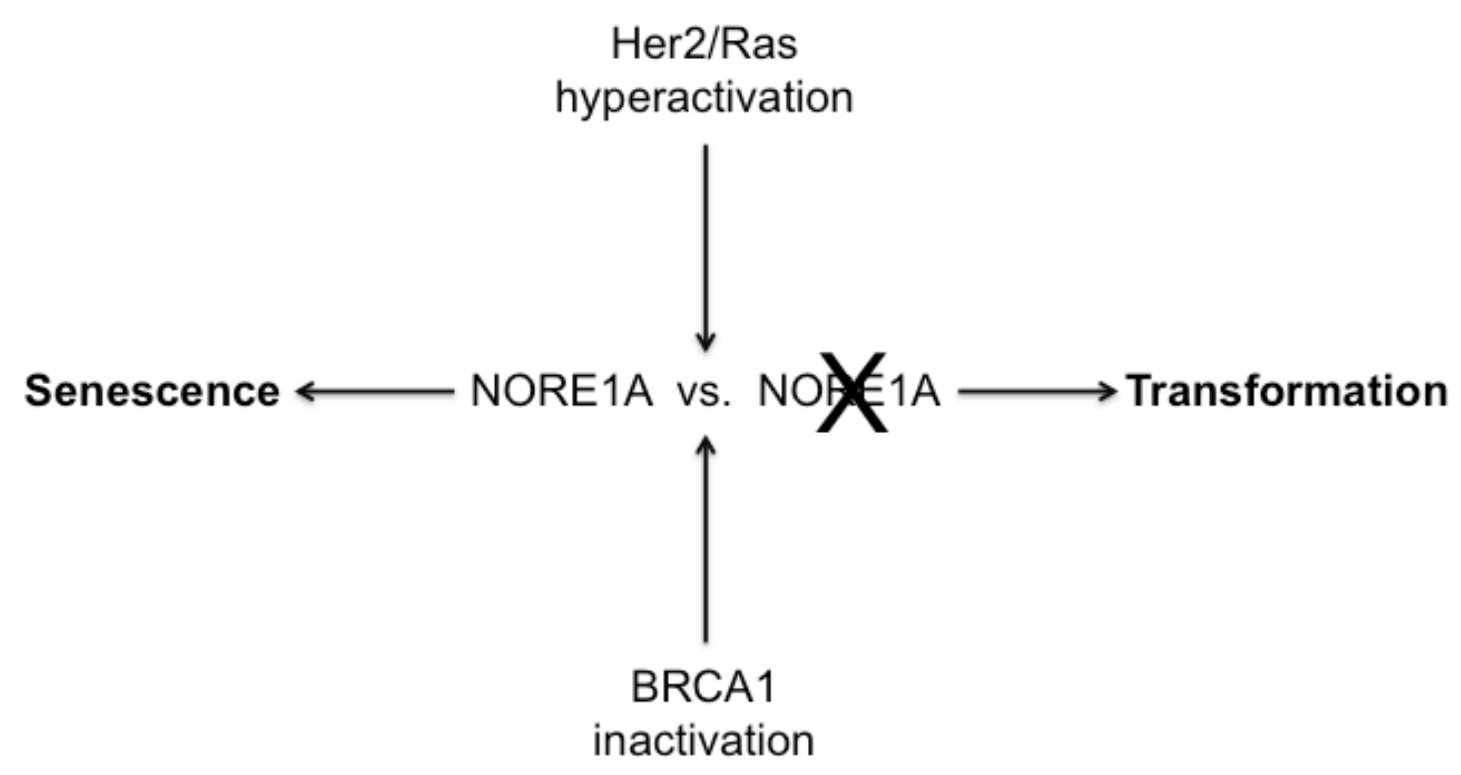




\section{CHAPTER VII: NORE1A REGULATES BRCA1-MEDIATED DNA REPAIR}

\section{INTRODUCTION}

BRCA1 maintains genomic stability via checkpoint activation and DNA repair.

Genomic instability is a hallmark of cancer development [159]. One of the main causes of genomic instability is the accumulation of DNA damage. This can occur in response to endogenous or exogenous stressors, or from errors in DNA replication [160], [161]. Normal cells respond to DNA damage by coordinating the activation of checkpoint and repair pathways [107]. If the damage persists, these cells undergo apoptosis or senescence. Failure to properly repair damaged DNA or activate growth inhibitory pathways can lead to tumor formation.

The tumor suppressor BRCA1 acts as a central mediator of the DNA damage response by coordinating the formation of protein complexes involved in checkpoint activation and DNA repair [89]. Only a fraction of total cellular BRCA1 is in each of these complexes, allowing BRCA1 to form multiple interactions simultaneously [90]. BRCA1 and binding partners abraxas and CtIP control entry into mitosis upon DNA damage detection by enhancing the phosphorylation of checkpoint kinase 1 (CHK1) and transiently arresting the cell cycle at $\mathrm{G}_{2}$ [162]-[164], allowing the BRCA1, BRCA2, PALB2 and Rad51 complex to participate in homologous recombination (HR)-mediated DNA repair [165], [166]. BRCA1, BACH1, and TopBP1 regulate entry into S-phase, and 
also help maintain and repair stalled replication forks during DNA replication [167], [168].

Genome instability is triggered by replication stress

The majority of genomic instability that occurs in cancer cells is a result of errors in normal DNA replication [169]. During replication, endogenous and exogenous agents challenge genome integrity by pausing and destabilizing the replication fork. In most cases, the replisome maintains association with the stalled fork, and replication can resume after the stress is removed [170]. Failure to protect or restart the replication fork in a timely manner can cause the replisome to dissociate and the fork to collapse, leading to the formation of DSBs [171].

In response to replication fork stalling, cells trigger a replication stress response that promotes complex formation between BRCA1 and BACH1 helicase [172]. BACH1 binds directly to the $\mathrm{C}$-terminal $\mathrm{BRCT}$ repeats of $\mathrm{BRCA} 1$, a region that is essential for its tumor suppressor function [168]. This BRCA1/BACH1 complex can transiently inhibit DNA synthesis and participate in error-free HR-mediated DNA repair in order to resume progression of the stalled fork [173]. Mutations in BRCA1 or BACH1 that inhibit their complex formation render cells unable to participate in HR-mediated repair and are associated with an increased risk for breast cancer [118], [174]-[177].

Her2/Ras activation can trigger replication stress.

Activation of oncogenes such as Her2/Ras promotes genomic instability by enhancing the rate of cellular proliferation [178]. This results in the depletion of 
nucleotide pools, which subsequently impedes the progression of DNA replication forks [133]. Persistently stalled forks can collapse, leading to the formation of DSBs [178]. The replication stress and DNA damage accumulation triggered by Her2/Ras activation drives senescence [109], and I have shown that Her2-driven senescence requires expression of NORE1A. Additionally, activated Her2/Ras downregulates expression of BACH1, which dissociates BRCA1 from chromatin and inactivates BRCA1-mediated DNA repair [64]. This BRCA1 inactivation drives senescence [64], but simultaneously predisposes cells to mutations as they become reliant on more error-prone pathways of DNA repair [179]. Thus, Her2/Ras can facilitate transformation by inactivating the BRCA1/BACH1 complex and selecting for cells that acquire secondary mutations in the absence of BRCA1-mediated HR repair [64], [111], [129].

I showed earlier that inactivation of the Ras effector NORE1A is one way that cells can subvert Her2/Ras-mediated growth inhibition. I observed NORE1A and BRCA1 co-localizing in nuclear foci in response to Her2/Ras induced replication stress. I hypothesized that these nuclear foci were sites of replication fork stalling, and decided to examine the possibility that NORE1A could be participating in the BRCA1 response to replication stress. Currently, no role for NORE1A in DNA repair has been reported.

Here, I show that NORE1A forms a complex with BACH1 and BRCA1. Furthermore, I discovered that co-inactivation of NORE1A and BRCA1 synergizes to suppress DNA repair. Thus, I identify a novel role for NORE1A in the control of DNA repair by BRCA1/BACH1. As NORE1A regulates both senescence and DNA repair, it may play a key role in the balance between growth arrest and repair after Her2/Ras activation. 


\section{RESULTS}

\section{NORE1A plays a role in BRCA1-mediated DNA repair.}

I observed earlier that NORE1A and BRCA1 co-localize in nuclear foci in response to replication stress. I also discovered that NORE1A forms a complex with BACH1 and BRCA1, two proteins that co-localize at stalled replication forks in order to maintain fork integrity and repair DNA DSBs [103], [168].

BRCA1 plays a key role in DNA DSB repair [89]. Consequently, BRCA1deficient cells are highly sensitive to drugs that induce DSBs. Doxorubicin hydrochloride (Dox) is an anthracycline that stabilizes the topoisomerase II complex during replication, causing DNA cleavage and DSB formation [180]. I subjected cells from my MCF-10A NORE1A ${ }^{-} / \mathrm{BRCA1}^{-}$matched set to Dox treatment for 24 hours and then measured their capacity for DNA repair using the comet assay.

I observed a large increase in DNA damage (i.e. enhanced DNA tail moment) in NORE1A ${ }^{-}$and BRCA1 ${ }^{-}$cells compared to control cells after treatment with Dox (Figure 18A). Additionally, I discovered that co-depletion of NORE1A and BRCA1 synergized to suppress DNA repair after Dox treatment. Figure 18B shows representative control and NORE1A ${ }^{-}$comet tails after Dox treatment. 
Figure 18: Dual inactivation of NORE1A and BRCA1 synergizes to suppress DNA repair.

(A) Matched sets of cells from my NORE1A ${ }^{-} / \mathrm{BRCA}^{-} \mathrm{MCF}-10 \mathrm{~A}$ system were treated with $0.3 \mu \mathrm{g} / \mathrm{mL}$ doxorubicin hydrochloride (Dox) for 24 hours to induce DNA damage. Cells were harvested and assayed for changes in DNA repair activity using a comet assay. Data was measured as comet tail moment, and represents 100 randomly chosen cells from two independent experiments. Results are displayed as box-and-whisker plots. The box includes $50 \%$ of the measured values for each condition, and the bottom and top of each box represent the $25^{\text {th }}$ and $75^{\text {th }}$ centiles, respectively. The inner line marks the median. Data from the upper and lower quartiles are indicated as whiskers that are capped at the minimum or maximum calculated values. Asterisks indicate mean values that are significantly different, as follows: ${ }^{*}, P<0.05$ compared to the value for Dox treated control cells. ${ }^{*}, P<0.05$ compared to the value for Dox treated shB cells. ${ }^{* * *}, P$ $<0.05$ compared to the value for Dox treated shN cells. (B) Representative comet tails after Dox treatment. 


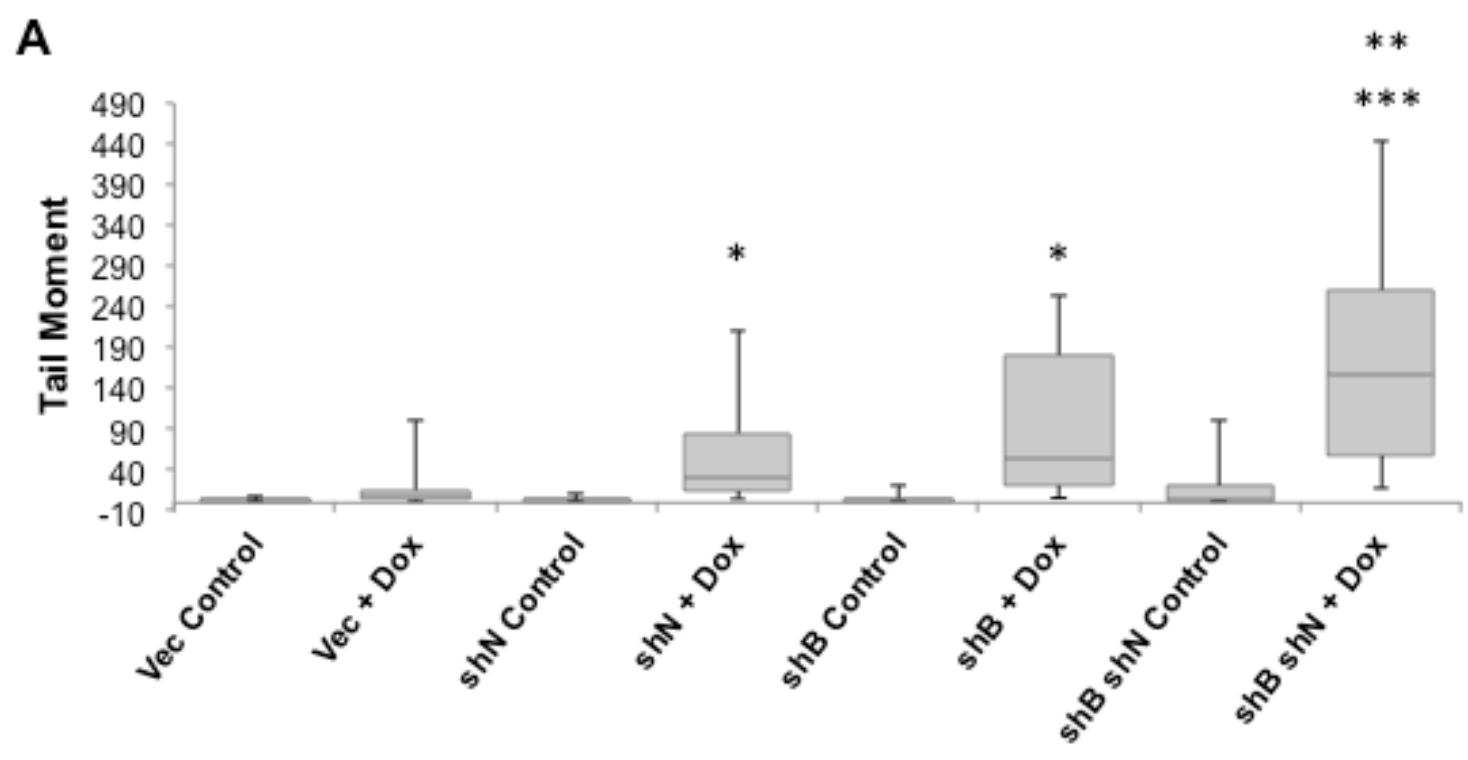

B

Vector

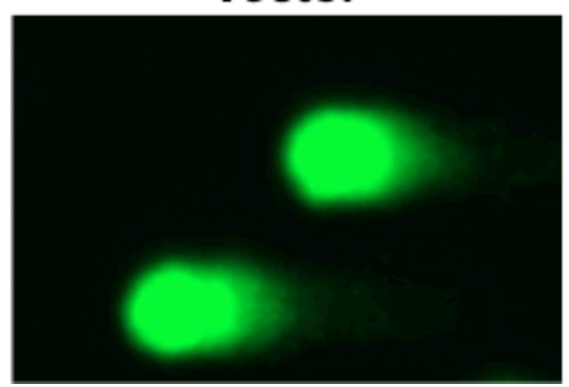

ShNORE1A

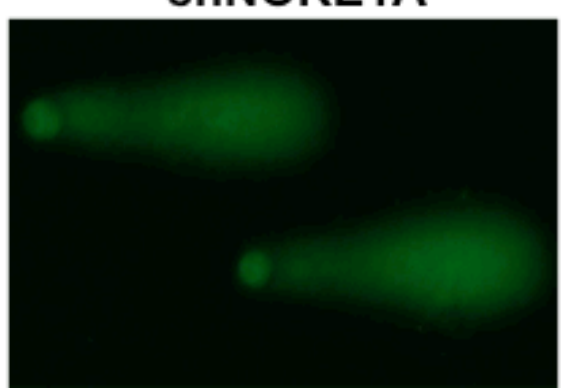




\section{NORE1A forms a complex with BACH1 and BRCA1.}

BACH1 is a well-studied, physiological binding partner of BRCA1 [168]. These two proteins form a tumor suppressor complex that plays a role in checkpoint control after replication stress and HR-mediated DNA repair after DNA damage [64], [103], [118]. I have observed NORE1A co-localizing with BRCA1 after replication stress. Since NORE1A can function as a nuclear scaffolding protein [36], I was curious to determine whether NORE1A could facilitate complex formation between BRCA1 and BACH1.

I was able to detect an interaction between NORE1A and BACH1 when these proteins were overexpressed in HEK-293T cells (Figure 19A). Furthermore, I determined that NORE1A expression enhances complex formation between BRCA1 and BACH1 1.7 fold (Figure 19B). 
Figure 19: NORE1A scaffolds BRCA1 with BACH1 helicase.

(A) HEK-293T cells were transiently transfected with either GFP-tagged NORE1A or Myc-tagged BACH1. Cells were lysed 24 hours after transfection and equal amounts of protein were immunoprecipitated for GFP. The immunoprecipitate was fractionated on an SDS-polyacrylamide gel and then immunoblotted with anti-GFP and anti-Myc antibodies. (B) HEK-293T cells were transiently transfected with either YFP-BRCA1 or Myc-BACH1 in the presence or absence of HA-tagged NORE1A, then lysed and Western blotted as above with anti-GFP, anti-HA, and anti-Myc antibodies. Fold change was calculated after normalizing to total Myc-BACH1 expression levels.

A

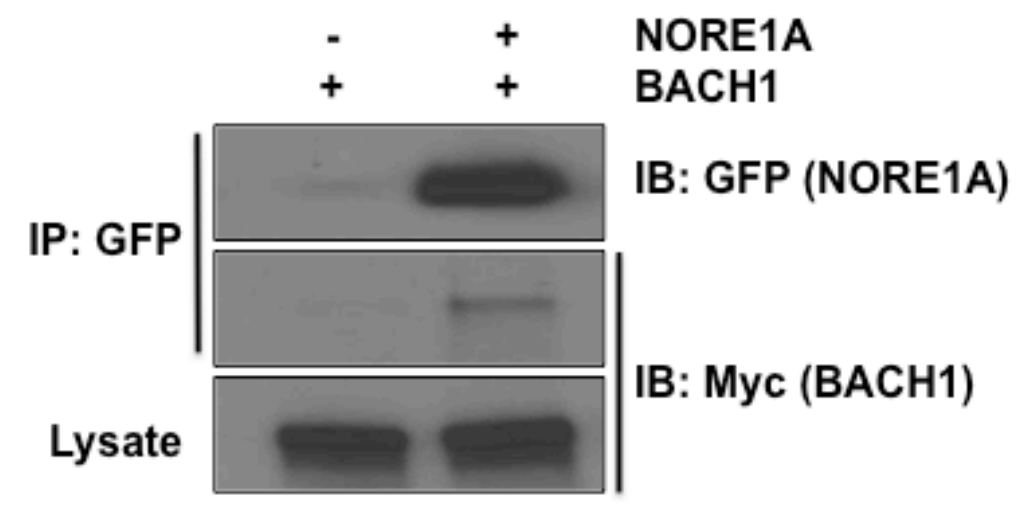

B

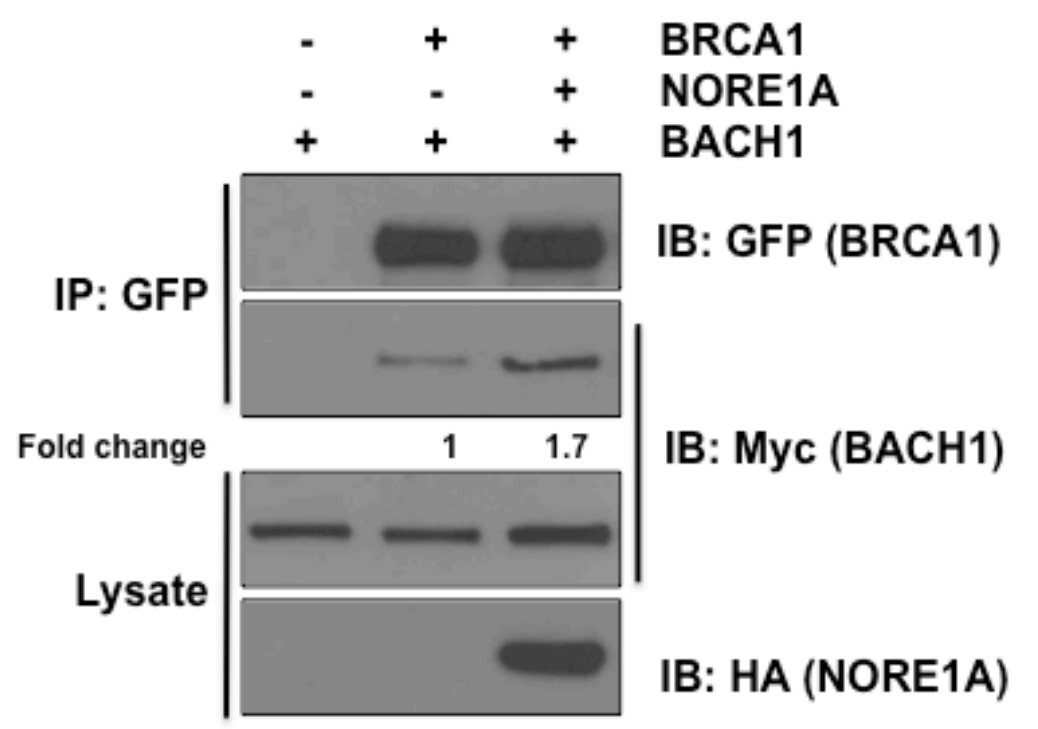




\section{DISCUSSION}

In this chapter, I examined the possibility that NORE1A could be regulating the DNA repair ability of BRCA1. I proposed this hypothesis based on my observation that these proteins co-localize in the nucleus (at what appear to be stalled replication forks) in response to replication stress, and that NORE1A loss can alter the cellular response to BRCA1. I provide evidence to support this hypothesis by demonstrating that NORE1A plays a role in DNA repair. Specifically, I show that NORE1A inactivation impairs the ability of non-transformed human mammary epithelial cells to repair DNA DSBs, and that dual inactivation of NORE1A and BRCA1 synergistically suppresses the DNA repair ability of these cells.

The ability of BRCA1 to participate in homologous recombination (HR)-mediated DNA repair in response to DSB formation is determined by its interaction with BACH1 helicase. Complex formation between BRCA1 and $\mathrm{BACH} 1$ is required for HR-mediated DNA repair, and depletion of either BACH1 or BRCA1 disables HR [181]. The BRCA1/BACH1 complex is readily detected during S-phase, specifically in response to replication stress caused by stalled or collapsed replication forks [104]. Interestingly, I was able to detect exogenous NORE1A in a complex with BACH1, and determined that NORE1A enhanced complex formation between BRCA1 and BACH1. Thus, it appears that NORE1A is scaffolding the BACH1/BRCA1 interaction. One explanation for the decreased DNA repair capability of the NORE1A ${ }^{-}$MCF-10A cells compared to control cells might therefore be impaired complex formation between BACH1/BRCA1.

One of the more promising therapies targeting tumor cells with BRCA1 deficiency involves inhibition of poly-ADP ribose polymerase (PARP), a key enzyme 
involved in SSB DNA repair. PARP inhibitors are reported to be particularly effective against BRCA1-null cancers, since these tumor cells are unable to use HR-mediated DSB repair pathways and rely solely on PARP for DNA repair [182], [183]. When PARP is also inhibited in these cells they cannot repair any DNA damage and are forced to undergo apoptosis [184]. Unfortunately, clinical trials with PARP inhibitors have been less than promising in treating patients with BRCA1-mutated breast cancers [185].

Interestingly, it has been shown preclinically that disruption of proteins that interact with BRCA1 can increase PARP inhibitor sensitivity [186], [187]. Since dual inactivation of BRCA1 and NORE1A synergize to suppress DNA repair, it is exciting to speculate that NORE1A loss might render cells more susceptible to PARP inhibitor treatment. Preliminary experiments in our lab showed no significant differences in survival between my MCF-10A knockdown set of cells after treatment with the PARP inhibitor Olaparib (data not shown). This could be due to the concentration of drug that I chose or its efficacy in general. More recently, the PARP inhibitor Veliparib showed promise in early clinical studies when used to treat $\mathrm{BRCA1}^{-}$sporadic breast cancers in combination with platinum agents [188]. Thus, further experiments are required to determine whether NORE1A ${ }^{-} / \mathrm{BRCA}^{-}$cells (and breast cancers) would be more sensitive to treatment with PARP inhibitors, alone or in tandem with other drugs like cisplatin.

In addition to its role in DNA repair, BRCA1 also has an important biological function as an E3 ubiquitin ligase. This sole identified enzymatic activity of BRCA1 occurs within its N-terminal RING domain, and is largely enhanced by formation of a

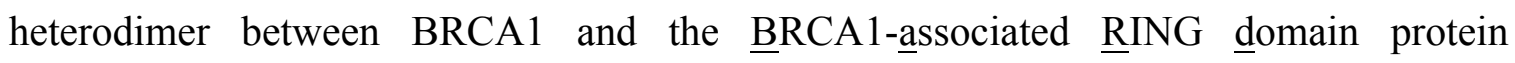
(BARD1) [189]. Putative targets of BRCA1-BARD1 ubiquitination include histones, $\gamma$ - 
tubulin, estrogen receptor alpha $(\mathrm{ER} \alpha), \mathrm{CtIP}$, and the checkpoint kinase 1 (CHK1) coactivator claspin [93]-[95], [190]. While the most common function of polyubiquitin chains are to serve as a signal for proteolysis by the proteasome, it appears that BRCA1 ubiquitination does not always signal degradation of its substrates [90]. In addition, this function of BRCA1 was shown to be disposable for its tumor suppressor function [96]. Thus, the biological consequences of BRCA1-mediated ubiquitination remain poorly understood. Recently, NORE1A was shown to scaffold the ubiquitin ligase $\beta$-TrCP in a Ras-regulated manner that enhances its enzymatic activity toward specific targets [83]. Given this information, it is interesting to speculate that NORE1A might also function as a Ras-regulated scaffold for BRCA1-mediated ubiquitination of its target substrates. Preliminary experiments in our lab have identified NORE1A as a regulator of both Claspin and ER $\alpha$ ubiquitination (unpublished data). Further experiments are required to determine whether this is a BRCA1-specific effect, as additional enzymes have been identified that ubiquitinate these targets in vivo [191]-[193]. 


\section{CONCLUSION}

Based on the results detailed in this dissertation, I propose that NORE1A and BRCA1 form a tumor suppressor complex that either participates in DNA repair or promotes senescence depending on the signal intensity and duration of Her2/Ras activation. Essentially, the NORE1A/BRCA1 complex functions to regulate the balance between growth arrest and repair after Her2/Ras activation (Figure 20).

If Her2/Ras signaling persists and excessive DNA damage accumulates, cells will initiate a controlled suicidal response that involves the inactivation of BRCA1 [64], [111]. NORE1A is required for this senescence induced by Her2 (shown here) and Ras [36]. When NORE1A is not present in cells, they cannot undergo this "suicidal" senescence triggered by constitutive Her2/Ras activation or BRCA1 inactivation and will instead continue to grow and transform. Thus, NORE1A appears to be a key part of the surveillance machinery that promotes a "Goldilocks" response. Too much oncogene activation or too little tumor suppressor expression can cause cell death. Loss of NORE1A disables this effect, allowing the tumorigenic effects of Her2 and BRCA1 dysregulation to manifest. 
Figure 20: NORE1A regulates the BRCA1 response to Ras-induced DNA damage

In response to Ras activation, NORE1A can form a complex with BRCA1 to repair damaged DNA. If the damage is too great, NORE1A and BRCA1 can promote the activation of p21 to drive senescence. NORE1A inactivation uncouples both Her2/Ras and BRCA1 from senescence and impairs BRCA1-mediated DNA repair, thereby facilitating senescence bypass and transformation.

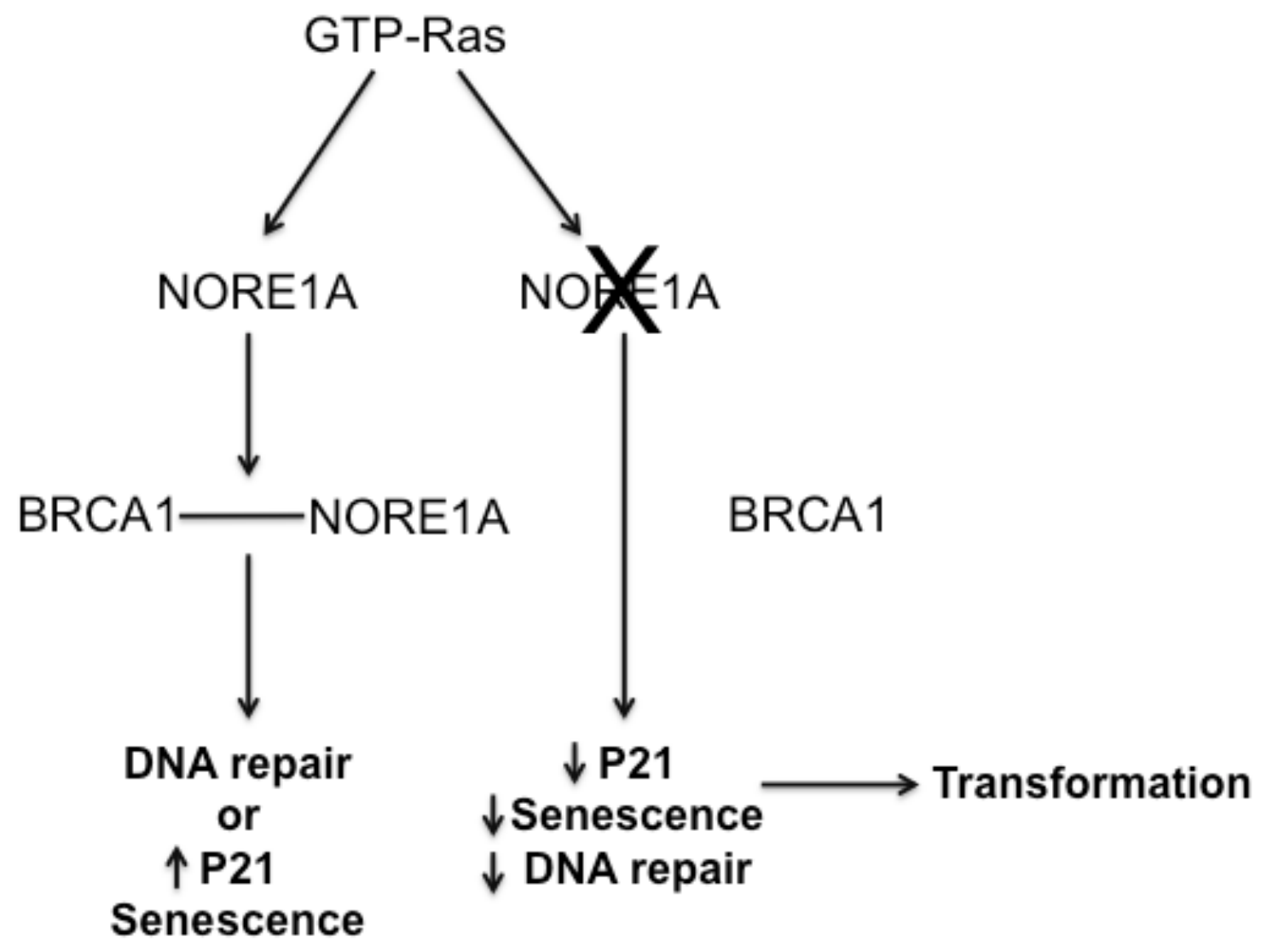




\section{REFERENCES}

[1] M. Malumbres and M. Barbacid, "RAS oncogenes: the first 30 years," Nat. Rev. Cancer, vol. 3, no. 6, pp. 459-465, Jun. 2003.

[2] A. E. Karnoub and R. A. Weinberg, "Ras oncogenes: split personalities," Nat. Rev. Mol. Cell Biol., vol. 9, no. 7, pp. 517-531, Jul. 2008.

[3] A. D. Cox and C. J. Der, "Ras history," Small GTPases, vol. 1, no. 1, pp. 2-27, 2010.

[4] M. O. Nandan and V. W. Yang, "An Update on the Biology of RAS/RAF Mutations in Colorectal Cancer," Curr. Colorectal Cancer Rep., vol. 7, no. 2, pp. 113-120, Jun. 2011.

[5] A. Schmidt and A. Hall, "Guanine nucleotide exchange factors for Rho GTPases: turning on the switch," Genes Dev., vol. 16, no. 13, pp. 1587-1609, Jul. 2002.

[6] I. G. Macara, K. M. Lounsbury, S. A. Richards, C. McKiernan, and D. Bar-Sagi, "The Ras superfamily of GTPases," FASEB J. Off. Publ. Fed. Am. Soc. Exp. Biol., vol. 10, no. 5, pp. 625-630, Apr. 1996.

[7] A. Bernards and J. Settleman, "GAP control: regulating the regulators of small GTPases," Trends Cell Biol., vol. 14, no. 7, pp. 377-385, Jul. 2004.

[8] I. R. Vetter and A. Wittinghofer, "The Guanine Nucleotide-Binding Switch in Three Dimensions," Science, vol. 294, no. 5545, pp. 1299-1304, Nov. 2001.

[9] Y. Pylayeva-Gupta, E. Grabocka, and D. Bar-Sagi, "RAS oncogenes: weaving a tumorigenic web," Nat. Rev. Cancer, vol. 11, no. 11, pp. 761-774, Nov. 2011.

[10] J. L. Bos, "ras Oncogenes in Human Cancer: A Review," Cancer Res., vol. 49, no. 17, pp. 4682-4689, Sep. 1989.

[11] F. C. von Lintig, A. D. Dreilinger, N. M. Varki, A. M. Wallace, D. E. Casteel, and G. R. Boss, "Ras activation in human breast cancer," Breast Cancer Res. Treat., vol. 62, no. 1, pp. 51-62, Jul. 2000.

[12] D. J. Slamon, W. Godolphin, L. A. Jones, J. A. Holt, S. G. Wong, D. E. Keith, W. J. Levin, S. G. Stuart, J. Udove, and A. Ullrich, "Studies of the HER-2/neu protooncogene in human breast and ovarian cancer," Science, vol. 244, no. 4905, pp. 707-712, May 1989.

[13] R. Bose, S. M. Kavuri, A. C. Searleman, W. Shen, D. Shen, D. C. Koboldt, J. Monsey, N. Goel, A. B. Aronson, S. Li, C. X. Ma, L. Ding, E. R. Mardis, and M. J. Ellis, "Activating HER2 mutations in HER2 gene amplification negative breast cancer," Cancer Discov., vol. 3, no. 2, pp. 224-237, Feb. 2013.

[14] S. K. McLaughlin, S. N. Olsen, B. Dake, T. De Raedt, E. Lim, R. T. Bronson, R. Beroukhim, K. Polyak, M. Brown, C. Kuperwasser, and K. Cichowski, "The RasGAP gene, RASAL2, is a tumor and metastasis suppressor," Cancer Cell, vol. 24, no. 3, pp. 365-378, Sep. 2013. 
[15] H. Dote, S. Toyooka, K. Tsukuda, M. Yano, M. Ouchida, H. Doihara, M. Suzuki, H. Chen, J.-T. Hsieh, A. F. Gazdar, and N. Shimizu, "Aberrant promoter methylation in human DAB2 interactive protein (hDAB2IP) gene in breast cancer," Clin. Cancer Res. Off. J. Am. Assoc. Cancer Res., vol. 10, no. 6, pp. 2082-2089, Mar. 2004.

[16] M. D. Wallace, A. D. Pfefferle, L. Shen, A. J. McNairn, E. G. Cerami, B. L. Fallon, V. D. Rinaldi, T. L. Southard, C. M. Perou, and J. C. Schimenti, "Comparative Oncogenomics Implicates the Neurofibromin 1 Gene (NF1) as a Breast Cancer Driver," Genetics, vol. 192, no. 2, pp. 385-396, Oct. 2012.

[17] N. Berndt, A. D. Hamilton, and S. M. Sebti, "Targeting protein prenylation for cancer therapy," Nat. Rev. Cancer, vol. 11, no. 11, pp. 775-791, Nov. 2011.

[18] M. Malumbres and A. Pellicer, "RAS pathways to cell cycle control and cell transformation," Front. Biosci. J. Virtual Libr., vol. 3, pp. d887-912, Aug. 1998.

[19] L. Wu, Y.-J. Nam, G. Kung, M. T. Crow, and R. N. Kitsis, "Induction of the apoptosis inhibitor ARC by Ras in human cancers," J. Biol. Chem., vol. 285, no. 25, pp. 19235-19245, Jun. 2010.

[20] F. Chang, L. S. Steelman, J. T. Lee, J. G. Shelton, P. M. Navolanic, W. L. Blalock, R. A. Franklin, and J. A. McCubrey, "Signal transduction mediated by the Ras/Raf/MEK/ERK pathway from cytokine receptors to transcription factors: potential targeting for therapeutic intervention," Leukemia, vol. 17, no. 7, pp. 12631293, 2003.

[21] K.-K. Wong, "Recent developments in anti-cancer agents targeting the Ras/Raf/ MEK/ERK pathway," Recent Patents Anticancer Drug Discov., vol. 4, no. 1, pp. 28-35, Jan. 2009.

[22] P. J. Roberts and C. J. Der, "Targeting the Raf-MEK-ERK mitogen-activated protein kinase cascade for the treatment of cancer," Oncogene, vol. 26, no. 22, pp. 3291-3310, May 2007.

[23] E. Castellano and J. Downward, "RAS Interaction with PI3K," Genes Cancer, vol. 2, no. 3, pp. 261-274, Mar. 2011.

[24] L. C. Cantley, "The phosphoinositide 3-kinase pathway," Science, vol. 296, no. 5573, pp. 1655-1657, May 2002.

[25] R. Marone, V. Cmiljanovic, B. Giese, and M. P. Wymann, "Targeting phosphoinositide 3-kinase: moving towards therapy," Biochim. Biophys. Acta, vol. 1784, no. 1, pp. 159-185, Jan. 2008.

[26] E. Ferro and L. Trabalzini, "RalGDS family members couple Ras to Ral signalling and that's not all," Cell. Signal., vol. 22, no. 12, pp. 1804-1810, Dec. 2010.

[27] L. A. Feig and R. J. Buchsbaum, "Cell signaling: life or death decisions of ras proteins," Curr. Biol. CB, vol. 12, no. 7, pp. R259-261, Apr. 2002.

[28] A. D. Cox and C. J. Der, "The dark side of Ras: regulation of apoptosis," Oncogene, vol. 22, no. 56, pp. 8999-9006, 2003.

[29] A. Kauffmann-Zeh, P. Rodriguez-Viciana, E. Ulrich, C. Gilbert, P. Coffer, J. Downward, and G. Evan, "Suppression of c-Myc-induced apoptosis by Ras signalling through PI(3)K and PKB," Nature, vol. 385, no. 6616, pp. 544-548, Feb. 1997.

[30] M. Serrano, A. W. Lin, M. E. McCurrach, D. Beach, and S. W. Lowe, "Oncogenic ras provokes premature cell senescence associated with accumulation of p53 and p16INK4a," Cell, vol. 88, no. 5, pp. 593-602, Mar. 1997. 
[31] S. Courtois-Cox, S. M. Genther Williams, E. E. Reczek, B. W. Johnson, L. T. McGillicuddy, C. M. Johannessen, P. E. Hollstein, M. MacCollin, and K. Cichowski, "A negative feedback signaling network underlies oncogene-induced senescence," Cancer Cell, vol. 10, no. 6, pp. 459-472, Dec. 2006.

[32] M. E. Caldwell, G. M. DeNicola, C. P. Martins, M. A. Jacobetz, A. Maitra, R. H. Hruban, and D. A. Tuveson, "Cellular features of senescence during the evolution of human and murine ductal pancreatic cancer," Oncogene, vol. 31, no. 12, pp. 15991608, Mar. 2012.

[33] A. L. Kennedy, J. P. Morton, I. Manoharan, D. M. Nelson, N. B. Jamieson, J. S. Pawlikowski, T. McBryan, B. Doyle, C. McKay, K. A. Oien, G. H. Enders, R. Zhang, O. J. Sansom, and P. D. Adams, "Activation of the PIK3CA/AKT pathway suppresses senescence induced by an activated RAS oncogene to promote tumorigenesis," Mol. Cell, vol. 42, no. 1, pp. 36-49, Apr. 2011.

[34] A. Prieur and D. S. Peeper, "Cellular senescence in vivo: a barrier to tumorigenesis," Curr. Opin. Cell Biol., vol. 20, no. 2, pp. 150-155, Apr. 2008.

[35] T. Kuilman, C. Michaloglou, W. J. Mooi, and D. S. Peeper, "The essence of senescence," Genes Dev., vol. 24, no. 22, pp. 2463-2479, Nov. 2010.

[36] H. Donninger, D. F. Calvisi, T. Barnoud, J. Clark, M. L. Schmidt, M. D. Vos, and G. J. Clark, "NORE1A is a Ras senescence effector that controls the apoptotic/senescent balance of p53 via HIPK2," J. Cell Biol., vol. 208, no. 6, pp. 777-789, Mar. 2015.

[37] V. Sherwood, R. Manbodh, C. Sheppard, and A. D. Chalmers, "RASSF7 is a member of a new family of RAS association domain-containing proteins and is required for completing mitosis," Mol. Biol. Cell, vol. 19, no. 4, pp. 1772-1782, Apr. 2008.

[38] A. M. Richter, G. P. Pfeifer, and R. H. Dammann, "The RASSF proteins in cancer; from epigenetic silencing to functional characterization," Biochim. Biophys. Acta BBA - Rev. Cancer, vol. 1796, no. 2, pp. 114-128, Dec. 2009.

[39] "RASSF3 and NORE1: identification and cloning of two human homologues of the putative tumor suppressor gene RASSF1," Publ. Online 17 April 2002 Doil01038sjonc1205365, vol. 21, no. 17, Apr. 2002.

[40] D. F. Calvisi, H. Donninger, M. D. Vos, M. J. Birrer, L. Gordon, V. Leaner, and G. J. Clark, "NORE1A tumor suppressor candidate modulates p21CIP1 via p53," Cancer Res., vol. 69, no. 11, pp. 4629-4637, Jun. 2009.

[41] H. Donninger, D. Calvisi, T. Barnoud, M. L. Schmidt, and G. J. Clark, “Abstract A06: NORE1A is a double-barreled Ras senescence effector linking Ras to p53 and Rb," Mol. Cancer Res., vol. 12, no. 12 Supplement, pp. A06-A06, Dec. 2014.

[42] F. Kamangar, G. M. Dores, and W. F. Anderson, "Patterns of cancer incidence, mortality, and prevalence across five continents: defining priorities to reduce cancer disparities in different geographic regions of the world," J. Clin. Oncol. Off. J. Am. Soc. Clin. Oncol., vol. 24, no. 14, pp. 2137-2150, May 2006.

[43] H. Kobayashi, "Hereditary breast and ovarian cancer susceptibility genes (Review)," Oncol. Rep., Jun. 2013.

[44] P. Kenemans, R. A. Verstraeten, and R. H. M. Verheijen, "Oncogenic pathways in hereditary and sporadic breast cancer," Maturitas, vol. 61, no. 1-2, pp. 141-150, Oct. 2008. 
[45] Z. Zhang, G. Jiang, F. Yang, and J. Wang, "Knockdown of mutant K-ras expression by adenovirus-mediated siRNA inhibits the in vitro and in vivo growth of lung cancer cells," Cancer Biol. Ther., vol. 5, no. 11, pp. 1481-1486, Nov. 2006.

[46] E. Sinn, W. Muller, P. Pattengale, I. Tepler, R. Wallace, and P. Leder, "Coexpression of MMTV/v-Ha-ras and MMTV/c-myc genes in transgenic mice: synergistic action of oncogenes in vivo," Cell, vol. 49, no. 4, pp. 465-475, May 1987.

[47] C. J. Quaife, C. A. Pinkert, D. M. Ornitz, R. D. Palmiter, and R. L. Brinster, "Pancreatic neoplasia induced by ras expression in acinar cells of transgenic mice," Cell, vol. 48, no. 6, pp. 1023-1034, Mar. 1987.

[48] T. J. Grob, U. Heilenkötter, S. Geist, P. Paluchowski, C. Wilke, F. Jaenicke, A. Quaas, W. Wilczak, M. Choschzick, G. Sauter, and A. Lebeau, "Rare oncogenic mutations of predictive markers for targeted therapy in triple-negative breast cancer," Breast Cancer Res. Treat., vol. 134, no. 2, pp. 561-567, Jul. 2012.

[49] E. Tilch, T. Seidens, S. Cocciardi, L. E. Reid, D. Byrne, P. T. Simpson, A. C. Vargas, M. C. Cummings, S. B. Fox, S. R. Lakhani, and G. Chenevix Trench, "Mutations in EGFR, BRAF and RAS are rare in triple-negative and basal-like breast cancers from Caucasian women," Breast Cancer Res. Treat., vol. 143, no. 2, pp. 385-392, Jan. 2014.

[50] A. Sánchez-Muñoz, E. Gallego, V. de Luque, L. G. Pérez-Rivas, L. Vicioso, N. Ribelles, J. Lozano, and E. Alba, "Lack of evidence for KRAS oncogenic mutations in triple-negative breast cancer," BMC Cancer, vol. 10, no. 1, p. 136, Apr. 2010.

[51] G. J. Clark and C. J. Der, "Aberrant function of the Ras signal transduction pathway in human breast cancer," Breast Cancer Res. Treat., vol. 35, no. 1, pp. 133-144, Jul. 1995.

[52] L. B. Eckert, G. A. Repasky, A. S. Ulkü, A. McFall, H. Zhou, C. I. Sartor, and C. J. Der, "Involvement of Ras activation in human breast cancer cell signaling, invasion, and anoikis," Cancer Res., vol. 64, no. 13, pp. 4585-4592, Jul. 2004.

[53] S. Sharif, A. Moran, S. M. Huson, R. Iddenden, A. Shenton, E. Howard, and D. G. R. Evans, "Women with neurofibromatosis 1 are at a moderately increased risk of developing breast cancer and should be considered for early screening," J. Med. Genet., vol. 44, no. 8, pp. 481-484, Aug. 2007.

[54] S. R. Morris and L. A. Carey, "Trastuzumab and beyond: New possibilities for the treatment of HER2-positive breast cancer," Oncol. Williston Park N, vol. 20, no. 14, pp. 1763-1771; discussion 1771-1772, 1774-1776, Dec. 2006.

[55] J. Carlsson, H. Nordgren, J. Sjöström, K. Wester, K. Villman, N. O. Bengtsson, B. Ostenstad, H. Lundqvist, and C. Blomqvist, "HER2 expression in breast cancer primary tumours and corresponding metastases. Original data and literature review," Br. J. Cancer, vol. 90, no. 12, pp. 2344-2348, Jun. 2004.

[56] J. S. Ross, J. A. Fletcher, G. P. Linette, J. Stec, E. Clark, M. Ayers, W. F. Symmans, L. Pusztai, and K. J. Bloom, "The Her-2/neu gene and protein in breast cancer 2003: biomarker and target of therapy," The Oncologist, vol. 8, no. 4, pp. 307-325, 2003.

[57] Z. Gabos, R. Sinha, J. Hanson, N. Chauhan, J. Hugh, J. R. Mackey, and B. Abdulkarim, "Prognostic significance of human epidermal growth factor receptor positivity for the development of brain metastasis after newly diagnosed breast 
cancer," J. Clin. Oncol. Off. J. Am. Soc. Clin. Oncol., vol. 24, no. 36, pp. 56585663, Dec. 2006.

[58] P. D. Angelini, M. F. Zacarias Fluck, K. Pedersen, J. L. Parra-Palau, M. Guiu, C. Bernadó Morales, R. Vicario, A. Luque-García, N. P. Navalpotro, J. Giralt, F. Canals, R. R. Gomis, J. Tabernero, J. Baselga, J. Villanueva, and J. Arribas, "Constitutive HER2 signaling promotes breast cancer metastasis through cellular senescence," Cancer Res., vol. 73, no. 1, pp. 450-458, Jan. 2013.

[59] T. M. Trost, E. U. Lausch, S. A. Fees, S. Schmitt, T. Enklaar, D. Reutzel, L. R. Brixel, P. Schmidtke, M. Maringer, I. B. Schiffer, C. K. Heimerdinger, J. G. Hengstler, G. Fritz, E. O. Bockamp, D. Prawitt, B. U. Zabel, and C. Spangenberg, "Premature senescence is a primary fail-safe mechanism of ERBB2-driven tumorigenesis in breast carcinoma cells," Cancer Res., vol. 65, no. 3, pp. 840-849, Feb. 2005.

[60] M. M. Moasser, "The oncogene HER2; Its signaling and transforming functions and its role in human cancer pathogenesis," Oncogene, vol. 26, no. 45, pp. 6469-6487, Oct. 2007.

[61] R. Cipriano, C. E. Kan, J. Graham, D. Danielpour, M. Stampfer, and M. W. Jackson, "TGF-beta signaling engages an ATM-CHK2-p53-independent RASinduced senescence and prevents malignant transformation in human mammary epithelial cells," Proc. Natl. Acad. Sci. U. S. A., vol. 108, no. 21, pp. 8668-8673, May 2011.

[62] M. Y. Sherman, L. Meng, M. Stampfer, V. L. Gabai, and J. A. Yaglom, "Oncogenes induce senescence with incomplete growth arrest and suppress the DNA damage response in immortalized cells," Aging Cell, vol. 10, no. 6, pp. 949-961, Dec. 2011.

[63] Y. L. Chai, J. Cui, N. Shao, E. Shyam, P. Reddy, and V. N. Rao, "The second BRCT domain of BRCA1 proteins interacts with $\mathrm{p} 53$ and stimulates transcription from the $\mathrm{p} 21 \mathrm{WAF} 1 / \mathrm{CIP} 1$ promoter," Oncogene, vol. 18, no. 1, pp. 263-268, Jan. 1999.

[64] Z. Tu, K. M. Aird, B. G. Bitler, J. P. Nicodemus, N. Beeharry, B. Xia, T. J. Yen, and R. Zhang, "Oncogenic Ras Regulates BRIP1 Expression to Induce Dissociation of BRCA1 from Chromatin, Inhibit DNA Repair, and Promote Senescence," Dev. Cell, vol. 21, no. 6, pp. 1077-1091, Dec. 2011.

[65] L. Hesson, A. Dallol, J. D. Minna, E. R. Maher, and F. Latif, "NORE1A, a homologue of RASSF1A tumour suppressor gene is inactivated in human cancers," Oncogene, vol. 22, no. 6, pp. 947-954, 2003.

[66] M. Esteller, J. M. Silva, G. Dominguez, F. Bonilla, X. Matias-Guiu, E. Lerma, E. Bussaglia, J. Prat, I. C. Harkes, E. A. Repasky, E. Gabrielson, M. Schutte, S. B. Baylin, and J. G. Herman, "Promoter hypermethylation and BRCA1 inactivation in sporadic breast and ovarian tumors," J. Natl. Cancer Inst., vol. 92, no. 7, pp. 564569, Apr. 2000.

[67] F. Magdinier, S. Ribieras, G. M. Lenoir, L. Frappart, and R. Dante, "Downregulation of BRCA1 in human sporadic breast cancer; analysis of DNA methylation patterns of the putative promoter region," Oncogene, vol. 17, no. 24, pp. 3169-3176, Dec. 1998.

[68] M. E. Thompson, R. A. Jensen, P. S. Obermiller, D. L. Page, and J. T. Holt, "Decreased expression of BRCA1 accelerates growth and is often present during 
sporadic breast cancer progression," Nat. Genet., vol. 9, no. 4, pp. 444-450, Apr. 1995.

[69] J. C. Rice, K. S. Massey-Brown, and B. W. Futscher, "Aberrant methylation of the BRCA1 CpG island promoter is associated with decreased BRCA1 mRNA in sporadic breast cancer cells," Oncogene, vol. 17, no. 14, pp. 1807-1812, Oct. 1998.

[70] D. Vavvas, X. Li, J. Avruch, and X.-F. Zhang, "Identification of Nore1 as a Potential Ras Effector," J. Biol. Chem., vol. 273, no. 10, pp. 5439-5442, Mar. 1998.

[71] G. Kumari, P. K. Singhal, M. R. K. S. Rao, and S. Mahalingam, "Nuclear transport of Ras-associated tumor suppressor proteins: different transport receptor binding specificities for arginine-rich nuclear targeting signals," J. Mol. Biol., vol. 367, no. 5, pp. 1294-1311, Apr. 2007.

[72] A. Moshnikova, S. Kuznetsov, and A. V. Khokhlatchev, "Interaction of the growth and tumour suppressor NORE1A with microtubules is not required for its growthsuppressive function," BMC Res. Notes, vol. 1, no. 1, p. 13, May 2008.

[73] G. Kumari, P. K. Singhal, R. Suryaraja, and S. Mahalingam, "Functional interaction of the Ras effector RASSF5 with the tyrosine kinase Lck: critical role in nucleocytoplasmic transport and cell cycle regulation," J. Mol. Biol., vol. 397, no. 1, pp. 89-109, Mar. 2010.

[74] S.-J. Park, D. Lee, C.-Y. Choi, and S.-Y. Ryu, "Induction of apoptosis by NORE1A in a manner dependent on its nuclear export," Biochem. Biophys. Res. Commun., vol. 368, no. 1, pp. 56-61, Mar. 2008.

[75] C. Bee, A. Moshnikova, C. D. Mellor, J. E. Molloy, Y. Koryakina, B. Stieglitz, A. Khokhlatchev, and C. Herrmann, "Growth and Tumor Suppressor NORE1A Is a Regulatory Node between Ras Signaling and Microtubule Nucleation," J. Biol. Chem., vol. 285, no. 21, pp. 16258-16266, May 2010.

[76] R. Suryaraja, M. Anitha, K. Anbarasu, G. Kumari, and S. Mahalingam, "The E3 ubiquitin ligase Itch regulates tumor suppressor protein RASSF5/NORE1 stability in an acetylation-dependent manner," Cell Death Dis., vol. 4, no. 3, p. e565, Mar. 2013.

[77] J. Geli, P. Kogner, F. Lanner, N. Natalishvili, C. Juhlin, N. Kiss, G. J. Clark, T. J. Ekström, F. Farnebo, and C. Larsson, "Assessment of NORE1A as a putative tumor suppressor in human neuroblastoma," Int. J. Cancer J. Int. Cancer, vol. 123, no. 2, pp. 389-394, Jul. 2008.

[78] H. Donninger, M. D. Vos, and G. J. Clark, "The RASSF1A tumor suppressor," $J$. Cell Sci., vol. 120, no. Pt 18, pp. 3163-3172, Sep. 2007.

[79] D. Pan, "Hippo signaling in organ size control," Genes Dev., vol. 21, no. 8, pp. 886897, Apr. 2007.

[80] A. Khokhlatchev, S. Rabizadeh, R. Xavier, M. Nedwidek, T. Chen, X. Zhang, B. Seed, and J. Avruch, "Identification of a novel Ras-regulated proapoptotic pathway," Curr. Biol. CB, vol. 12, no. 4, pp. 253-265, Feb. 2002.

[81] Y. Aoyama, J. Avruch, and X.-F. Zhang, "Nore1 inhibits tumor cell growth independent of Ras or the MST1/2 kinases," Oncogene, vol. 23, no. 19, pp. 34263433, Apr. 2004.

[82] M. D. Vos, A. Martinez, C. A. Ellis, T. Vallecorsa, and G. J. Clark, "The Proapoptotic Ras Effector Nore1 May Serve as a Ras-regulated Tumor Suppressor in the Lung," J. Biol. Chem., vol. 278, no. 24, pp. 21938-21943, Jun. 2003. 
[83] M. L. Schmidt, H. Donninger, and G. J. Clark, "Ras regulates $\mathrm{SCF}(\beta-\mathrm{TrCP})$ protein activity and specificity via its effector protein NORE1A," J. Biol. Chem., vol. 289, no. 45, pp. 31102-31110, Nov. 2014.

[84] G. Steiner, P. Cairns, T. J. Polascik, F. F. Marshall, J. I. Epstein, D. Sidransky, and M. Schoenberg, "High-density mapping of chromosomal arm 1q in renal collecting duct carcinoma: region of minimal deletion at 1q32.1-32.2," Cancer Res., vol. 56, no. 21, pp. 5044-5046, Nov. 1996.

[85] J. Chen, W.-O. Lui, M. D. Vos, G. J. Clark, M. Takahashi, J. Schoumans, S. K. Khoo, D. Petillo, T. Lavery, J. Sugimura, D. Astuti, C. Zhang, S. Kagawa, E. R. Maher, C. Larsson, A. S. Alberts, H. Kanayama, and B. T. Teh, "The $t(1 ; 3)$ breakpoint-spanning genes LSAMP and NORE1 are involved in clear cell renal cell carcinomas," Cancer Cell, vol. 4, no. 5, pp. 405-413, Nov. 2003.

[86] J. Park, S. I. Kang, S.-Y. Lee, X. F. Zhang, M. S. Kim, L. F. Beers, D.-S. Lim, J. Avruch, H.-S. Kim, and S. B. Lee, "Tumor suppressor ras association domain family 5 (RASSF5/NORE1) mediates death receptor ligand-induced apoptosis," $J$. Biol. Chem., vol. 285, no. 45, pp. 35029-35038, Nov. 2010.

[87] P. A. Futreal, Q. Liu, D. Shattuck-Eidens, C. Cochran, K. Harshman, S. Tavtigian, L. M. Bennett, A. Haugen-Strano, J. Swensen, Y. Miki, and A. Et, "BRCA1 mutations in primary breast and ovarian carcinomas," Science, vol. 266, no. 5182, pp. 120-122, Oct. 1994.

[88] V. Birgisdottir, O. A. Stefansson, S. K. Bodvarsdottir, H. Hilmarsdottir, J. G. Jonasson, and J. E. Eyfjord, "Epigenetic silencing and deletion of the BRCA1 gene in sporadic breast cancer," Breast Cancer Res., vol. 8, no. 4, p. R38, Jul. 2006.

[89] K. W. Caestecker and G. R. Van de Walle, "The role of BRCA1 in DNA doublestrand repair: Past and present," Exp. Cell Res., vol. 319, no. 5, pp. 575-587, Mar. 2013.

[90] W. Wu, A. Koike, T. Takeshita, and T. Ohta, "The ubiquitin E3 ligase activity of BRCA1 and its biological functions," Cell Div., vol. 3, no. 1, p. 1, Jan. 2008.

[91] S. L. Clark, A. M. Rodriguez, R. R. Snyder, G. D. V. Hankins, and D. Boehning, "Structure-Function Of The Tumor Suppressor BRCA1," Comput. Struct.

Biotechnol. J., vol. 1, Mar. 2012.

[92] D. E. Christensen, P. S. Brzovic, and R. E. Klevit, "E2-BRCA1 RING interactions dictate synthesis of mono- or specific polyubiquitin chain linkages," Nat. Struct. Mol. Biol., vol. 14, no. 10, pp. 941-948, Oct. 2007.

[93] X. Yu, S. Fu, M. Lai, R. Baer, and J. Chen, "BRCA1 ubiquitinates its phosphorylation-dependent binding partner CtIP," Genes Dev., vol. 20, no. 13, pp. 1721-1726, Jul. 2006.

[94] K. Sato, E. Sundaramoorthy, E. Rajendra, H. Hattori, A. D. Jeyasekharan, N. Ayoub, R. Schiess, R. Aebersold, H. Nishikawa, A. S. Sedukhina, H. Wada, T. Ohta, and A. R. Venkitaraman, "A DNA-Damage Selective Role for BRCA1 E3 Ligase in Claspin Ubiquitylation, CHK1 Activation, and DNA Repair," Curr. Biol., vol. 22, no. 18, pp. 1659-1666, Sep. 2012.

[95] C. M. Eakin, M. J. Maccoss, G. L. Finney, and R. E. Klevit, "Estrogen receptor alpha is a putative substrate for the BRCA1 ubiquitin ligase," Proc. Natl. Acad. Sci. U. S. A., vol. 104, no. 14, pp. 5794-5799, Apr. 2007. 
[96] R. Shakya, L. J. Reid, C. R. Reczek, F. Cole, D. Egli, C.-S. Lin, D. G. deRooij, S. Hirsch, K. Ravi, J. B. Hicks, M. Szabolcs, M. Jasin, R. Baer, and T. Ludwig, "BRCA1 tumor suppression depends on BRCT phosphoprotein binding, but not its E3 ligase activity," Science, vol. 334, no. 6055, pp. 525-528, Oct. 2011.

[97] R. Scully, J. Chen, A. Plug, Y. Xiao, D. Weaver, J. Feunteun, T. Ashley, and D. M. Livingston, "Association of BRCA1 with Rad51 in Mitotic and Meiotic Cells," Cell, vol. 88, no. 2, pp. 265-275, Jan. 1997.

[98] Q. Zhong, C.-F. Chen, S. Li, Y. Chen, C.-C. Wang, J. Xiao, P.-L. Chen, Z. D. Sharp, and W.-H. Lee, "Association of BRCA1 with the hRad50-hMre11-p95 Complex and the DNA Damage Response," Science, vol. 285, no. 5428, pp. 747750, Jul. 1999.

[99] Q. Wang, H. Zhang, K. Kajino, and M. I. Greene, "BRCA1 binds c-Myc and inhibits its transcriptional and transforming activity in cells," Oncogene, vol. 17, no. 15, pp. 1939-1948, Oct. 1998.

[100] O. N. Aprelikova, B. S. Fang, E. G. Meissner, S. Cotter, M. Campbell, A. Kuthiala, M. Bessho, R. A. Jensen, and E. T. Liu, "BRCA1-associated growth arrest is RB-dependent," Proc. Natl. Acad. Sci., vol. 96, no. 21, pp. 11866-11871, Oct. 1999.

[101] C. F. Chen, S. Li, Y. Chen, P. L. Chen, Z. D. Sharp, and W. H. Lee, "The nuclear localization sequences of the BRCA1 protein interact with the importin-alpha subunit of the nuclear transport signal receptor," J. Biol. Chem., vol. 271, no. 51, pp. 32863-32868, Dec. 1996.

[102] X. Yu, C. C. S. Chini, M. He, G. Mer, and J. Chen, "The BRCT Domain Is a Phospho-Protein Binding Domain," Science, vol. 302, no. 5645, pp. 639-642, Oct. 2003.

[103] M. Peng, R. Litman, Z. Jin, G. Fong, and S. B. Cantor, "BACH1 is a DNA repair protein supporting BRCA1 damage response," Oncogene, vol. 25, no. 15, pp. 22452253, Feb. 2006.

[104] E. Kumaraswamy and R. Shiekhattar, "Activation of BRCA1/BRCA2-Associated Helicase BACH1 Is Required for Timely Progression through S Phase," Mol. Cell. Biol., vol. 27, no. 19, pp. 6733-6741, Oct. 2007.

[105] S. A. Narod and W. D. Foulkes, "BRCA1 and BRCA2: 1994 and beyond," Nat. Rev. Cancer, vol. 4, no. 9, pp. 665-676, Sep. 2004.

[106] D. P. Silver and D. M. Livingston, "Mechanisms of BRCA1 Tumor Suppression," Cancer Discov., vol. 2, no. 8, pp. 679-684, Aug. 2012.

[107] E. R. Jang and J.-S. Lee, "DNA Damage Response Mediated through BRCA1," Cancer Res. Treat. Off. J. Korean Cancer Assoc., vol. 36, no. 4, pp. 214-221, Aug. 2004.

[108] P. A. Futreal, P. Söderkvist, J. R. Marks, J. D. Iglehart, C. Cochran, J. C. Barrett, and R. W. Wiseman, "Detection of frequent allelic loss on proximal chromosome $17 q$ in sporadic breast carcinoma using microsatellite length polymorphisms," Cancer Res., vol. 52, no. 9, pp. 2624-2627, May 1992.

[109] R. Di Micco, M. Fumagalli, A. Cicalese, S. Piccinin, P. Gasparini, C. Luise, C. Schurra, M. Garre', P. G. Nuciforo, A. Bensimon, R. Maestro, P. G. Pelicci, and F. d'Adda di Fagagna, "Oncogene-induced senescence is a DNA damage response 
triggered by DNA hyper-replication," Nature, vol. 444, no. 7119, pp. 638-642, Nov. 2006.

[110] N. Turner, A. Tutt, and A. Ashworth, "Hallmarks of 'BRCAness' in sporadic cancers," Nat. Rev. Cancer, vol. 4, no. 10, pp. 814-819, Oct. 2004.

[111] J. A. Yaglom, C. McFarland, L. Mirny, and M. Y. Sherman, "Oncogene-triggered suppression of DNA repair leads to DNA instability in cancer," Oncotarget, vol. 5, no. 18, pp. 8367-8378, Jul. 2014.

[112] S. A. J. Vaziri, L. M. Krumroy, P. Elson, G. T. Budd, G. Darlington, J. Myles, R. R. Tubbs, and G. Casey, "Breast Tumor Immunophenotype of BRCA1-Mutation Carriers Is Influenced by Age at Diagnosis," Clin. Cancer Res., vol. 7, no. 7, pp. 1937-1945, Jul. 2001.

[113] M. Robson, P. Rajan, P. P. Rosen, T. Gilewski, Y. Hirschaut, P. Pressman, B. Haas, L. Norton, and K. Offit, "BRCA-associated Breast Cancer: Absence of a Characteristic Immunophenotype," Cancer Res., vol. 58, no. 9, pp. 1839-1842, May 1998.

[114] L. A. Quenneville, K.-A. Phillips, H. Ozcelik, R. K. Parkes, J. A. Knight, P. J. Goodwin, I. L. Andrulis, and F. P. O'Malley, "HER-2/neu status and tumor morphology of invasive breast carcinomas in Ashkenazi women with known BRCA1 mutation status in the Ontario Familial Breast Cancer Registry," Cancer, vol. 95, no. 10, pp. 2068-2075, Nov. 2002.

[115] W. Reed, B. Sandstad, R. Holm, and J. M. Nesland, "The prognostic impact of hormone receptors and c-erbB-2 in pregnancy-associated breast cancer and their correlation with BRCA1 and cell cycle modulators," Int. J. Surg. Pathol., vol. 11, no. 2, pp. 65-74, Apr. 2003.

[116] Y. Ansquer, L. Mandelbrot, T. Lehy, L. Salomon, C. Dhainaut, P. Madelenat, G. Feldmann, and F. Walker, "Expression of BRCA1, HER-1 (EGFR) and HER-2 in sporadic breast cancer and relationships to other clinicopathological prognostic features," Anticancer Res., vol. 25, no. 6C, pp. 4535-4541, Dec. 2005.

[117] Y. M. Li, Y. Pan, Y. Wei, X. Cheng, B. P. Zhou, M. Tan, X. Zhou, W. Xia, G. N. Hortobagyi, D. Yu, and M.-C. Hung, "Upregulation of CXCR4 is essential for HER2-mediated tumor metastasis," Cancer Cell, vol. 6, no. 5, pp. 459-469, Nov. 2004.

[118] S. Cantor, R. Drapkin, F. Zhang, Y. Lin, J. Han, S. Pamidi, and D. M. Livingston, "The BRCA1-associated protein BACH1 is a DNA helicase targeted by clinically relevant inactivating mutations," Proc. Natl. Acad. Sci. U. S. A., vol. 101, no. 8, pp. 2357-2362, Feb. 2004.

[119] A. Malek, Experimental Metastasis: Modeling and Analysis. Springer Science \& Business Media, 2013.

[120] S. M. Frisch and H. Francis, "Disruption of epithelial cell-matrix interactions induces apoptosis," J. Cell Biol., vol. 124, no. 4, pp. 619-626, Feb. 1994.

[121] D.-E. Pefani, R. Latusek, I. Pires, A. M. Grawenda, K. S. Yee, G. Hamilton, L. van der Weyden, F. Esashi, E. M. Hammond, and E. O'Neill, "RASSF1A-LATS1 signalling stabilizes replication forks by restricting CDK2-mediated phosphorylation of BRCA2," Nat. Cell Biol., vol. 16, no. 10, pp. 962-971, Oct. 2014. 
[122] B. M. Gyori, G. Venkatachalam, P. S. Thiagarajan, D. Hsu, and M.-V. Clement, "OpenComet: An automated tool for comet assay image analysis," Redox Biol., vol. 2, pp. 457-465, 2014.

[123] A. Fernández-Medarde and E. Santos, "Ras in Cancer and Developmental Diseases," Genes Cancer, vol. 2, no. 3, pp. 344-358, Mar. 2011.

[124] T. Satoh, M. Endo, M. Nakafuku, T. Akiyama, T. Yamamoto, and Y. Kaziro, "Accumulation of p21ras.GTP in response to stimulation with epidermal growth factor and oncogene products with tyrosine kinase activity.," Proc. Natl. Acad. Sci., vol. 87, no. 20, pp. 7926-7929, Oct. 1990.

[125] C. K. Galang, J. J. García-Ramírez, P. A. Solski, J. K. Westwick, C. J. Der, N. N. Neznanov, R. G. Oshima, and C. A. Hauser, "Oncogenic Neu/ErbB-2 Increases Ets, AP-1, and NF-B-dependent Gene Expression, and Inhibiting Ets Activation Blocks Neu-mediated Cellular Transformation," J. Biol. Chem., vol. 271, no. 14, pp. 79927998, Apr. 1996.

[126] J. Bartkova, N. Rezaei, M. Liontos, P. Karakaidos, D. Kletsas, N. Issaeva, L.-V. F. Vassiliou, E. Kolettas, K. Niforou, V. C. Zoumpourlis, M. Takaoka, H.

Nakagawa, F. Tort, K. Fugger, F. Johansson, M. Sehested, C. L. Andersen, L. Dyrskjot, T. Ørntoft, J. Lukas, C. Kittas, T. Helleday, T. D. Halazonetis, J. Bartek, and V. G. Gorgoulis, "Oncogene-induced senescence is part of the tumorigenesis barrier imposed by DNA damage checkpoints," Nature, vol. 444, no. 7119, pp. 633637, Nov. 2006.

[127] S. Courtois-Cox, S. L. Jones, and K. Cichowski, "Many roads lead to oncogeneinduced senescence," Oncogene, vol. 27, no. 20, pp. 2801-2809, Jan. 2008.

[128] J. Wu, L.-Y. Lu, and X. Yu, "The role of BRCA1 in DNA damage response," Protein Cell, vol. 1, no. 2, pp. 117-123, Feb. 2010.

[129] Z. Tu, K. M. Aird, and R. Zhang, "RAS, cellular senescence and transformation: the BRCA1 DNA repair pathway at the crossroads," Small GTPases, vol. 3, no. 3, pp. 163-167, Sep. 2012.

[130] Y. QIN, J. XU, K. AYSOLA, N. BEGUM, V. REDDY, Y. CHAI, W. E. GRIZZLE, E. E. PARTRIDGE, E. S. P. REDDY, and V. N. RAO, "Ubc9 Mediates Nuclear Localization and Growth Suppression of BRCA1 and BRCA1a Proteins," $J$. Cell. Physiol., vol. 226, no. 12, pp. 3355-3367, Dec. 2011.

[131] Y. Chen, C. F. Chen, D. J. Riley, D. C. Allred, P. L. Chen, D. Von Hoff, C. K. Osborne, and W. H. Lee, "Aberrant subcellular localization of BRCA1 in breast cancer," Science, vol. 270, no. 5237, pp. 789-791, Nov. 1995.

[132] T. D. Halazonetis, V. G. Gorgoulis, and J. Bartek, "An oncogene-induced DNA damage model for cancer development," Science, vol. 319, no. 5868, pp. 13521355, Mar. 2008.

[133] S. Mannava, K. C. Moparthy, L. J. Wheeler, V. Natarajan, S. N. Zucker, E. E. Fink, M. Im, S. Flanagan, W. C. Burhans, N. C. Zeitouni, D. S. Shewach, C. K. Mathews, and M. A. Nikiforov, "Depletion of Deoxyribonucleotide Pools Is an Endogenous Source of DNA Damage in Cells Undergoing Oncogene-Induced Senescence," Am. J. Pathol., vol. 182, no. 1, pp. 142-151, Jan. 2013.

[134] S. Pathania, J. Nguyen, S. J. Hill, R. Scully, J. Feunteun, and D. M. Livingston, "BRCA1 is Required for Post-replication Repair After UV-induced DNA Damage," Mol. Cell, vol. 44, no. 2, pp. 235-251, Oct. 2011. 
[135] E. Petermann, M. L. Orta, N. Issaeva, N. Schultz, and T. Helleday, "Hydroxyurea-Stalled Replication Forks Become Progressively Inactivated and Require Two Different RAD51-Mediated Pathways for Restart and Repair," Mol. Cell, vol. 37, no. 4, pp. 492-502, Feb. 2010.

[136] N. Blom, S. Gammeltoft, and S. Brunak, "Sequence and structure-based prediction of eukaryotic protein phosphorylation sites," J. Mol. Biol., vol. 294, no. 5, pp. 1351-1362, Dec. 1999.

[137] B. R. Henderson, "The BRCA1 Breast Cancer Suppressor: Regulation of Transport, Dynamics, and Function at Multiple Subcellular Locations," Scientifica, vol. 2012, p. e796808, Nov. 2012.

[138] T. Foukakis, A. Y. M. Au, G. Wallin, J. Geli, L. Forsberg, R. Clifton-Bligh, B. G. Robinson, W.-O. Lui, J. Zedenius, and C. Larsson, "The Ras Effector NORE1A Is Suppressed in Follicular Thyroid Carcinomas with a $P A X 8-P P A R \gamma$ Fusion," J. Clin. Endocrinol. Metab., vol. 91, no. 3, pp. 1143-1149, Mar. 2006.

[139] S. Kuznetsov and A. V. Khokhlatchev, "The Growth and Tumor Suppressors NORE1A and RASSF1A Are Targets for Calpain-Mediated Proteolysis," PLoS ONE, vol. 3, no. 12, p. e3997, Dec. 2008.

[140] M. Serrano, "Senescence helps regeneration," Dev. Cell, vol. 31, no. 6, pp. 671672, Dec. 2014.

[141] K. M. Imbalzano, I. Tatarkova, A. N. Imbalzano, and J. A. Nickerson, "Increasingly transformed MCF-10A cells have a progressively tumor-like phenotype in three-dimensional basement membrane culture," Cancer Cell Int., vol. 9, no. 1, p. 7, Mar. 2009.

[142] S. de Carné Trécesson, Y. Guillemin, A. Bélanger, A.-C. Bernard, L. Preisser, E. Ravon, E. Gamelin, P. Juin, B. Barré, and O. Coqueret, "Escape from p21-mediated oncogene-induced senescence leads to cell dedifferentiation and dependence on anti-apoptotic Bcl-xL and MCL1 proteins," J. Biol. Chem., vol. 286, no. 15, pp. 12825-12838, Apr. 2011.

[143] W. S. el-Deiry, T. Tokino, V. E. Velculescu, D. B. Levy, R. Parsons, J. M. Trent, D. Lin, W. E. Mercer, K. W. Kinzler, and B. Vogelstein, "WAF1, a potential mediator of p53 tumor suppression," Cell, vol. 75, no. 4, pp. 817-825, Nov. 1993.

[144] K. H. Vousden and C. Prives, "Blinded by the Light: The Growing Complexity of p53," Cell, vol. 137, no. 3, pp. 413-431, May 2009.

[145] C. L. Brooks and W. Gu, "New insights into p53 activation," Cell Res., vol. 20, no. 6, pp. 614-621, Jun. 2010.

[146] Q. Li, R. A. Feldman, V. M. Radhakrishnan, S. Carey, and J. D. Martinez, "Hsf1 Is Required for the Nuclear Translocation of p53 Tumor Suppressor," Neoplasia N. Y. N, vol. 10, no. 10, pp. 1138-1145, Oct. 2008.

[147] Y.-H. Lee, M. T. Bedford, and M. R. Stallcup, "Regulated recruitment of tumor suppressor BRCA1 to the p21 gene by coactivator methylation," Genes Dev., vol. 25, no. 2, pp. 176-188, Jan. 2011.

[148] M. Sedic, A. Skibinski, N. Brown, M. Gallardo, P. Mulligan, P. Martinez, P. J. Keller, E. Glover, A. L. Richardson, J. Cowan, A. E. Toland, K. Ravichandran, H. Riethman, S. P. Naber, A. M. Näär, M. A. Blasco, P. W. Hinds, and C.

Kuperwasser, "Haploinsufficiency for BRCA1 leads to cell-type-specific genomic instability and premature senescence," Nat. Commun., vol. 6, p. 7505, Jun. 2015. 
[149] Z. Tu, X. Zhuang, Y.-G. Yao, and R. Zhang, "BRG1 Is Required for Formation of Senescence-Associated Heterochromatin Foci Induced by Oncogenic RAS or BRCA1 Loss," Mol. Cell. Biol., vol. 33, no. 9, pp. 1819-1829, May 2013.

[150] J. Debnath and J. S. Brugge, "Modelling glandular epithelial cancers in threedimensional cultures," Nat. Rev. Cancer, vol. 5, no. 9, pp. 675-688, Sep. 2005.

[151] A. P. Gilmore, "Anoikis," Cell Death Differ., vol. 12, no. S2, pp. 1473-1477, 2005.

[152] S. M. Frisch and E. Ruoslahti, "Integrins and anoikis," Curr. Opin. Cell Biol., vol. 9, no. 5, pp. 701-706, Oct. 1997.

[153] A. P. Young, S. Schlisio, Y. A. Minamishima, Q. Zhang, L. Li, C. Grisanzio, S. Signoretti, and W. G. Kaelin, "VHL loss actuates a HIF-independent senescence programme mediated by Rb and p400," Nat. Cell Biol., vol. 10, no. 3, pp. 361-369, Mar. 2008.

[154] S. C. Gupta, J. H. Kim, S. Prasad, and B. B. Aggarwal, "Regulation of survival, proliferation, invasion, angiogenesis, and metastasis of tumor cells through modulation of inflammatory pathways by nutraceuticals," Cancer Metastasis Rev., vol. 29, no. 3, pp. 405-434, Sep. 2010.

[155] A. G. Knudson, "Mutation and Cancer: Statistical Study of Retinoblastoma," Proc. Natl. Acad. Sci. U. S. A., vol. 68, no. 4, pp. 820-823, Apr. 1971.

[156] M. Rytömaa, L. M. Martins, and J. Downward, "Involvement of FADD and caspase-8 signalling in detachment-induced apoptosis," Curr. Biol. CB, vol. 9, no. 18, pp. 1043-1046, Sep. 1999.

[157] M. J. Reginato, K. R. Mills, J. K. Paulus, D. K. Lynch, D. C. Sgroi, J. Debnath, S. K. Muthuswamy, and J. S. Brugge, "Integrins and EGFR coordinately regulate the pro-apoptotic protein Bim to prevent anoikis," Nat. Cell Biol., vol. 5, no. 8, pp. 733740, Aug. 2003.

[158] A. Schulze, K. Lehmann, H. B. Jefferies, M. McMahon, and J. Downward, "Analysis of the transcriptional program induced by Raf in epithelial cells," Genes Dev., vol. 15, no. 8, pp. 981-994, Apr. 2001.

[159] D. Hanahan and R. A. Weinberg, "The hallmarks of cancer," Cell, vol. 100, no. 1, pp. 57-70, Jan. 2000.

[160] Y. Shiloh, "ATM and related protein kinases: safeguarding genome integrity," Nat. Rev. Cancer, vol. 3, no. 3, pp. 155-168, Mar. 2003.

[161] M. S. Y. Huen, S. M. H. Sy, and J. Chen, "BRCA1 and its toolbox for the maintenance of genome integrity," Nat. Rev. Mol. Cell Biol., vol. 11, no. 2, pp. 138148, Feb. 2010.

[162] B. Wang, S. Matsuoka, B. A. Ballif, D. Zhang, A. Smogorzewska, S. P. Gygi, and S. J. Elledge, "Abraxas and RAP80 form a BRCA1 protein complex required for the DNA damage response," Science, vol. 316, no. 5828, pp. 1194-1198, May 2007.

[163] A. K. Varma, R. S. Brown, G. Birrane, and J. A. A. Ladias, "Structural basis for cell cycle checkpoint control by the BRCA1-CtIP complex," Biochemistry (Mosc.), vol. 44, no. 33, pp. 10941-10946, Aug. 2005.

[164] X. Yu and J. Chen, "DNA damage-induced cell cycle checkpoint control requires CtIP, a phosphorylation-dependent binding partner of BRCA1 C-terminal domains," Mol. Cell. Biol., vol. 24, no. 21, pp. 9478-9486, Nov. 2004. 
[165] F. Zhang, J. Ma, J. Wu, L. Ye, H. Cai, B. Xia, and X. Yu, "PALB2 links BRCA1 and BRCA2 in the DNA-damage response," Curr. Biol. CB, vol. 19, no. 6, pp. 524 529, Mar. 2009.

[166] Y. Dong, M.-A. Hakimi, X. Chen, E. Kumaraswamy, N. S. Cooch, A. K. Godwin, and R. Shiekhattar, "Regulation of BRCC, a holoenzyme complex containing BRCA1 and BRCA2, by a signalosome-like subunit and its role in DNA repair," Mol. Cell, vol. 12, no. 5, pp. 1087-1099, Nov. 2003.

[167] R. A. Greenberg, B. Sobhian, S. Pathania, S. B. Cantor, Y. Nakatani, and D. M. Livingston, "Multifactorial contributions to an acute DNA damage response by BRCA1/BARD1-containing complexes," Genes Dev., vol. 20, no. 1, pp. 34-46, Jan. 2006.

[168] S. B. Cantor, D. W. Bell, S. Ganesan, E. M. Kass, R. Drapkin, S. Grossman, D. C. Wahrer, D. C. Sgroi, W. S. Lane, D. A. Haber, and D. M. Livingston, "BACH1, a novel helicase-like protein, interacts directly with BRCA1 and contributes to its DNA repair function," Cell, vol. 105, no. 1, pp. 149-160, Apr. 2001.

[169] D. Branzei and M. Foiani, "The DNA damage response during DNA replication," Curr. Opin. Cell Biol., vol. 17, no. 6, pp. 568-575, Dec. 2005.

[170] C. Lucca, F. Vanoli, C. Cotta-Ramusino, A. Pellicioli, G. Liberi, J. Haber, and M. Foiani, "Checkpoint-mediated control of replisome-fork association and signalling in response to replication pausing," Oncogene, vol. 23, no. 6, pp. 1206-1213, Dec. 2003.

[171] E. Petermann and T. Helleday, "Pathways of mammalian replication fork restart," Nat. Rev. Mol. Cell Biol., vol. 11, no. 10, pp. 683-687, Oct. 2010.

[172] K. Schlacher, H. Wu, and M. Jasin, "A distinct replication fork protection pathway connects Fanconi anemia tumor suppressors to RAD51-BRCA1/2," Cancer Cell, vol. 22, no. 1, pp. 106-116, Jul. 2012.

[173] J. Zhang, "The role of BRCA1 in homologous recombination repair in response to replication stress: significance in tumorigenesis and cancer therapy," Cell Biosci., vol. 3, p. 11, Feb. 2013.

[174] A. De Nicolo, M. Tancredi, G. Lombardi, C. C. Flemma, S. Barbuti, C. Di Cristofano, B. Sobhian, G. Bevilacqua, R. Drapkin, and M. A. Caligo, "A novel breast cancer-associated BRIP1 (FANCJ/BACH1) germ-line mutation impairs protein stability and function," Clin. Cancer Res. Off. J. Am. Assoc. Cancer Res., vol. 14, no. 14, pp. 4672-4680, Jul. 2008.

[175] A.-Y. Cao, J. Huang, Z. Hu, W.-F. Li, Z.-L. Ma, L.-L. Tang, B. Zhang, F.-X. Su, J. Zhou, G.-H. Di, K.-W. Shen, J. Wu, J.-S. Lu, J.-M. Luo, W.-T. Yuan, Z.-Z. Shen, W. Huang, and Z.-M. Shao, "Mutation analysis of BRIP1/BACH1 in BRCA1/BRCA2 negative Chinese women with early onset breast cancer or affected relatives," Breast Cancer Res. Treat., vol. 115, no. 1, pp. 51-55, May 2009.

[176] T. Walsh and M.-C. King, "Ten genes for inherited breast cancer," Cancer Cell, vol. 11, no. 2, pp. 103-105, Feb. 2007.

[177] S. B. Cantor and S. Guillemette, "Hereditary breast cancer and the BRCA1associated FANCJ/BACH1/BRIP1," Future Oncol. Lond. Engl., vol. 7, no. 2, pp. 253-261, Feb. 2011.

[178] H. Gaillard, T. García-Muse, and A. Aguilera, "Replication stress and cancer," Nat. Rev. Cancer, vol. 15, no. 5, pp. 276-289, May 2015. 
[179] A. Aguilera and T. García-Muse, "Causes of genome instability," Annu. Rev. Genet., vol. 47, pp. 1-32, 2013.

[180] G. Minotti, P. Menna, E. Salvatorelli, G. Cairo, and L. Gianni, “Anthracyclines: Molecular Advances and Pharmacologic Developments in Antitumor Activity and Cardiotoxicity," Pharmacol. Rev., vol. 56, no. 2, pp. 185-229, Jun. 2004.

[181] R. Litman, M. Peng, Z. Jin, F. Zhang, J. Zhang, S. Powell, P. R. Andreassen, and S. B. Cantor, "BACH1 is critical for homologous recombination and appears to be the Fanconi anemia gene product FANCJ," Cancer Cell, vol. 8, no. 3, pp. 255-265, Sep. 2005.

[182] H. Farmer, N. McCabe, C. J. Lord, A. N. J. Tutt, D. A. Johnson, T. B. Richardson, M. Santarosa, K. J. Dillon, I. Hickson, C. Knights, N. M. B. Martin, S. P. Jackson, G. C. M. Smith, and A. Ashworth, "Targeting the DNA repair defect in BRCA mutant cells as a therapeutic strategy," Nature, vol. 434, no. 7035, pp. 917921, Apr. 2005.

[183] S. Vinayak and J. M. Ford, "PARP Inhibitors for the Treatment and Prevention of Breast Cancer," Curr. Breast Cancer Rep., vol. 2, no. 4, pp. 190-197, Dec. 2010.

[184] S. Banerjee, S. B. Kaye, and A. Ashworth, "Making the best of PARP inhibitors in ovarian cancer," Nat. Rev. Clin. Oncol., vol. 7, no. 9, pp. 508-519, Sep. 2010.

[185] M. A. Burgess and S. L. Puhalla, "BRCA 1/2-mutation related and sporadic breast and ovarian cancers: more alike than different," Cancer Mol. Targets Ther., vol. 4, p. 19, 2014.

[186] P. Bouwman, A. Aly, J. M. Escandell, M. Pieterse, J. Bartkova, H. van der Gulden, S. Hiddingh, M. Thanasoula, A. Kulkarni, Q. Yang, B. G. Haffty, J. Tommiska, C. Blomqvist, R. Drapkin, D. J. Adams, H. Nevanlinna, J. Bartek, M. Tarsounas, S. Ganesan, and J. Jonkers, "53BP1 loss rescues BRCA1 deficiency and is associated with triple-negative and BRCA-mutated breast cancers," Nat. Struct. Mol. Biol., vol. 17, no. 6, pp. 688-695, Jun. 2010.

[187] N. McCabe, N. C. Turner, C. J. Lord, K. Kluzek, A. Bialkowska, S. Swift, S. Giavara, M. J. O’Connor, A. N. Tutt, M. Z. Zdzienicka, G. C. M. Smith, and A. Ashworth, "Deficiency in the repair of DNA damage by homologous recombination and sensitivity to poly(ADP-ribose) polymerase inhibition," Cancer Res., vol. 66, no. 16, pp. 8109-8115, Aug. 2006.

[188] S. L. Puhalla, L. J. Appleman, J. H. Beumer, H. Tawbi, R. G. Stoller, T. K. Owonikoko, S. S. Ramalingam, C. P. Belani, A. M. Brufsky, J. Abraham, S. P. Shepherd, V. Giranda, A. P. Chen, and E. Chu, "Abstract PD09-06: Two phase I trials exploring different dosing schedules of carboplatin $(\mathrm{C})$, paclitaxel $(\mathrm{P})$, and the poly-ADP-ribose polymerase (PARP) inhibitor, veliparib (ABT-888) (V) with activity in triple negative breast cancer (TNBC)," Cancer Res., vol. 72, no. 24 Supplement, pp. PD09-06-PD09-06, Dec. 2012.

[189] R. Baer and T. Ludwig, "The BRCA1/BARD1 heterodimer, a tumor suppressor complex with ubiquitin E3 ligase activity," Curr. Opin. Genet. Dev., vol. 12, no. 1, pp. 86-91, Feb. 2002.

[190] L. M. Starita, Y. Machida, S. Sankaran, J. E. Elias, K. Griffin, B. P. Schlegel, S. P. Gygi, and J. D. Parvin, "BRCA1-Dependent Ubiquitination of $\gamma$-Tubulin Regulates Centrosome Number," Mol. Cell. Biol., vol. 24, no. 19, pp. 8457-8466, Oct. 2004. 
[191] M. Fan, A. Park, and K. P. Nephew, "CHIP (carboxyl terminus of Hsc70interacting protein) promotes basal and geldanamycin-induced degradation of estrogen receptor-alpha," Mol. Endocrinol. Baltim. Md, vol. 19, no. 12, pp. 29012914, Dec. 2005.

[192] A. Brekman, K. E. Singh, A. Polotskaia, N. Kundu, and J. Bargonetti, "A p53independent role of Mdm2 in estrogen-mediated activation of breast cancer cell proliferation," Breast Cancer Res. BCR, vol. 13, no. 1, p. R3, 2011.

[193] A. Peschiaroli, N. V. Dorrello, D. Guardavaccaro, M. Venere, T. Halazonetis, N. E. Sherman, and M. Pagano, "SCFbetaTrCP-mediated degradation of Claspin regulates recovery from the DNA replication checkpoint response," Mol. Cell, vol. 23, no. 3, pp. 319-329, Aug. 2006. 


\title{
CURRICULUM VITAE
}

\author{
Nicholas C. Nelson
}

Louisville, KY 40206

M: 601-620-9077• E: nicholas.nelson@louisville.edu

\section{Education}

Ph.D. Biochemistry and Molecular Genetics, University of Louisville, Louisville, KY, 2015

M.S. Biochemistry and Molecular Biology, University of Louisville, Louisville, KY, 2013

B.S. Biomedical Sciences, Auburn University, Auburn, AL, 2010

\section{Selected Publications}

Nicholas Nelson and GJ Clark. "Rheb complexes with RASSF1A to coordinate Hippo and TOR signaling".

H Donninger, J Clark, F Rinaldo, Nicholas Nelson, T Barnoud, L Schmidt, K Hobbing, M Vos, B Sils, GJ Clark. "The RASSF1A tumor suppressor regulates XPA-mediated DNA repair". Molecular and Cellular Biology. Oct 2014.

H Donninger, T Barnoud, Nicholas Nelson, S Kassler, J Clark, T Cummins, DW Powell, S Nyante, R Millikan, GJ Clark. "RASSF1A and the rs2073498 Cancer Associated SNP". Frontiers in Oncology. Dec 2011.

R Munigunti, Nicholas Nelson, V Mulabagal, MP Gupta, R Brun, AI Calderon. "Identification of Oleamide in Guatteria recurvisepala by LC/MS-Based Plasmodium falciparum Thioredoxin Reductase Ligand Binding Method”. Planta Medica. May 2011.

\section{Research Experience}

Graduate Researcher, Geoffrey J. Clark Lab, University of Louisville, School of Medicine, Louisville, KY, 2010-2015

Elucidating the role of the RASSF5/BRCA1 tumor suppressor complex in human breast cancer pathogenesis using advanced biochemical and molecular biological techniques.

Undergraduate Researcher, Angela I. Calderon Lab, Auburn University, Harrison School of Pharmacy, Auburn, AL, 2009

Proteomic analysis and identification of anti-tuberculosis and anti-malarial properties of Panamanian plant extracts using High-performance Liquid Chromatography-Mass Spectrometry (HPLC-MS). 


\section{Professional Organizations}

World Affairs Council of Kentucky \& Southern Indiana, Member, Louisville, KY, 2014present

Science Policy \& Outreach Organization, Member, University of Louisville, 2014-present

Faculty Forum, Representative, University of Louisville, School of Medicine, 2011-2014

Graduate Student Council, Representative, University of Louisville, School of Medicine, 20102011 